\author{
UNIVERSIDADE DE SÃO PAULO \\ FACULDADE DE MEDICINA DE RIBEIRÃO PRETO \\ DEPARTAMENTO DE GENÉTICA
}

\title{
MECANISMOS ENVOLVIDOS COM A INIBIÇÃO DE AURORA- QUINASES EM CARCINOMA DE ADRENAL
}

\section{Kleiton Silva Borges}

\begin{abstract}
Tese de Doutorado apresentada ao Departamento de Genética da Faculdade de Medicina de Ribeirão Preto da Universidade de São Paulo para obtenção do Título de Doutor em Ciências, área de concentração Genética.
\end{abstract}

Orientador: Prof. Dr. Luiz Gonzaga Tone

\section{Ribeirão Preto}


AUTORIZO A REPRODUÇÃO E DIVULGAÇÃO TOTAL OU PARCIAL DESTE

TRABALHO, POR QUALQUER MEIO CONVENCIONAL OU ELETRÔNICO, PARA

FINS DE ESTUDO E PESQUISA, DESDE QUE CITADA A FONTE.

\section{FICHA CATALOGRÁFICA}

Borges, Kleiton Silva

Mecanismos envolvidos com a inibição de aurora-quinases em carcinoma de adrenal. Ribeirão Preto, 2014.

95p. : il. ; $30 \mathrm{~cm}$

Tese de Doutorado apresentada ao Departamento de Genética da Faculdade de Medicina de Ribeirão Preto da Universidade de São Paulo para obtenção do Título de Doutor em Ciências, área de concentração Genética.

Orientador: Tone, Luiz Gonzaga.

1. Tumor adrenocortical. 2. Aurora quinases. 3. AMG900. 4. H295A 


\section{Apoio e Suporte Fincanceiro}

Este trabalho foi realizado com o apoio financeiro das seguintes instituições:

$\checkmark$ Fundação de Amparo à Pesquisa do Estado de São Paulo - FAPESP (Processos $n^{\circ}$ 10/08699-5 e 10/07020-9).

$\checkmark$ Fundação de Apoio ao Ensino, Pesquisa e Assistência do Hospital das Clínicas de Ribeirão Preto/USP - FAEPA

$\checkmark$ Faculdade de Medicina de Ribeirão Preto

$\checkmark$ Hospital das Clínicas da Faculdade de Medicinade Ribeirão Preto - USP 


\section{FOLHA DE APROVAÇÃO}

Nome: Kleiton Silva Borges

Título: Mecanismos envolvidos com a inibição de aurora-quinases em carcinoma de adrenal

Tese de Doutorado apresentada ao Departamento de Genética da Faculdade de Medicina de Ribeirão Preto da Universidade de São Paulo para obtenção do Título de Doutor em Ciências, área de concentração Genética.

Aprovado em:

Banca Examinadora

Prof. Dr.

Instituição:

Assinatura:

Prof. Dr.

Instituição:

Assinatura:

Prof. Dr.

Instituição:

Assinatura:

Prof. Dr.

Instituição:

Assinatura:

Prof. Dr.

Instituição:

Assinatura: 
À minha mãe, Maria Anita, pelo amor incondicional, incentivo constante e pelo exemplo de mulher guerreira. Às minhas irmãs, Lana e Diana, pelo amor e incentivo durante toda a minha trajetória. 
À minha querida esposa Vanessa, pelo amor e companheirismo, fundamentais para a conclusão desta etapa. Me sinto realizado por tê-la ao meu lado sempre, fazendo a minha vida muito mais feliz. 


\section{Agradecimentos}

Ao Prof. Dr. Luiz Gonzaga Tone, meu orientador, por ter aberto as portas do laboratório para mim e ter me dado todo o apoio necessário para a realização deste trabalho. Além disso, sou muito grato pela liberdade que sempre me foi concedida para experimentar novos desafios científicos e profissionais durante esta jornada. Isso tudo foi muito importante para meu crescimento. Sinto-me muito feliz por tê-lo como exemplo de ser humano, profissional e líder.

Ao Prof. Dr. Carlos Alberto Scrideli pelo apoio desde a minha chegada ao laboratório e pela ajuda dispensada sempre que necessário. Sempre foi, mesmo que extra-oficialmente, um ótimo co-orientador. Sua boa vontade e alegria em discutir os dados sempre me animaram muito para fazer bem o meu trabalho.

Ao Dr. Eric Vilain pela oportunidade de estagiar no seu laboratório na UCLA. Esse período foi importantíssimo para meu crescimento profissional e pessoal.

Ao Coordenador do curso de pós-graduação do Departamento de Genética, prof. Dr. Ademilson Espencer Egea Soares pela atenção e auxílio durante a pós-graduação.

À Dra. Rosane Gomes de Paula Queiroz e à Veridiana Kill Suazo, que sempre contribuíram com uma boa vontade imensa para todas as minhas atividades no laboratório. Além disso, sempre esteveram dispostas a ensinar e ajudar com o que fosse necessário para a concretização dessa caminhada.

Aos amigos Angel Maurício Castro Gamero e Augusto Faria Andrade pelas intensas discussões sobre a biologia do câncer durante esta jornada, por me permitir fazer parte da trajetória científica de vocês e pelos excelentes momentos compartilhados no decorrer deste tempo.

Aos amigos Ciro Silveira, Daniel Antunes Moreno e Gustavo Alencastro pelos momentos de descontração, pelas palavras de incentivo em todos os momentos e acima de tudo pela grande amizade durante todo este trajeto. 
Aos amigos do laboratório Gabriela, Julia, Lenisa, Luiz Guilherme, Dra. Maria Sol, Pamela, Paola, Régia, Carol e Mirela. Obrigado pela torcida e pelo apoio em todos os momentos durante a realização deste trabalho.

Ao meu sogro José Teruel e à minha sogra Maria Amélia pelo apoio durante os vários momentos de transição e pelo constante incentivo durante esta jornada.

Às técnicas do laboratório de Citogenética do Departamento de Puericultura e Pediatria Aide Barbosa, Sônia Scandusi, Maria Luisa Machado e Lucimar Fernandes pelo apoio e agradável convivência.

Às secretárias do Departamento de Genética Susie Adriana Penha Nalon, Maria Aparecida Oliveira Silva Elias e Silvia Sant'anna Consiglieri e à secretária do Laboratório de Puericultura e Pediatria Evelice Visconte, pela atenção e apoio prestados durante o mestrado.

À Fundação de Amparo à Pesquisa do Estado de São Paulo (FAPESP) pela concessão da bolsa de mestrado.

À Fundação de Apoio ao Ensino, Pesquisa e Assistência do Hospital das Clínicas da Faculdade de Medicina de Ribeirão Preto da Universidade de São Paulo (FAEPA) pelo auxílio financeiro. 
"As idéias vieram a mim, como vêm a todos nós. A diferença é que eu levei essas idéias a sério. Não fiquei desencorajado pelo fato das outras pessoas não verem o que eu via. Eu tinha confiança na minha percepção, e não nos dogmas ou nas opiniões dos outros. Eu não deixei ninguém me desencorajar -- e olhe que muitos tentaram. Mas a vida não é um concurso de popularidade."

Jonas Salk

Inventor da vacina contra a poliomielite 


\section{RESUMO}

Borges, KS. Mecanismos envolvidos com a inibição de aurora-quinases em carcinoma de adrenal. 2014, 95 f. Tese de Doutorado - Faculdade de Medicina de Ribeirão Preto, Universidade de São Paulo, Ribeirão Preto, Brasil.

Introdução: Tumores adrenocorticais (TAC) são raros, correspondendo somente a $0,2 \%$ de todas as neoplasias pediátricas, sendo que a maioria dos casos são diagnosticados no Brasil e estão associados com a mutação TP53 p.R337H. A cirurgia é o único tratamento efetivo conhecido para os TAC, sendo os tumores em estadios avançados frequentemente fatais. A família das Aurora-quinases é formada por três membros (Aurora-A, -B e -C) os quais atuam em diversas fases do ciclo celular, como alinhamento dos cromossomos, formação do fuso mitótico e citocinese. Diferentes trabalhos mostraram a expressão alterada de membros desta família em vários tipos de tumores e a inibição da atividade destas proteínas tem sido considerada uma potencial abordagem para o tratamento do câncer. Objetivo: A partir da análise da expressão dos genes Aurora- $A$ e Aurora-B em amostras de TAC pediátrico, foram investigados os efeitos do AMG 900, um pan-inibidor de aurora quinases, na proliferação, apoptose, síntese hormonal e perfil transcricional da linhagem H295A. Além disso, foram avaliados os efeitos do AMG 900 combinado com diferentes quimioterápicos. Metodologia: Os níveis de expressão dos genes Aurora-A e Aurora-B foram analisados em 60 crianças com TAC através das técnicas de RT-qPCR e imuno-histoquímica. A proliferação celular foi avaliada por coloração com Giemsa e a apoptose foi realizada por citometria de fluxo. A análise de combinação de drogas foi feita com base no método de Chou-Talalay e o ensaio de microarray foi realizado utilizando a plataforma da Agilent. Resultados: A expressão dos genes Aurora-A e Aurora-B foi associada com estadios avançados da doença e a expressão do Aurora- $A$ foi associada com a presença da mutação TP53 p.R337H. O tratamento com o AMG900 causou a inibição da proliferação, aumento da apoptose e sensibilizou as células para os inibidores de topoisomerase II (doxorrubicina e etoposídeo). Adicionalmente, o AMG 900 levou à redução da síntese de hormônios bem como modulou a expressão de genes envolvidos com esta atividade. A inibição das aurora-quinases alterou a expressão de genes associados com a regulação da fase G1 do ciclo celular e afetou a expressão de genes da via de sinalização Notch. Conclusão: A inibição das aurora-quinases pelo AMG 900 pode ser uma alternativa para o tratamento dos tumores adrenocorticais.

Palavras-chave: Tumor adrenocortical, aurora quinases, AMG 900, H295A 


\begin{abstract}
Borges, KS. Mechanisms involved in the inhibition of aurora kinases in adrenal carcinoma. 2014, 95 f. Doctoral Thesis - Ribeirão Preto Medical School, University of São Paulo, Ribeirão Preto, Brazil.

Introduction: Pediatric adrenocortical tumors (ACT) are rare malignancies representing only $0.2 \%$ of all pediatric cancers. Most cases are diagnosed in Brazil and are associated with TP53 p.R337H mutation. Surgery is the only effective treatment known for the ACT however this approach has a small impact on survival in advanced disease. The Aurora kinase family is comprised of three members (Aurora-A, -B and -C) which act at different phases of the cell cycle, such as chromosomes alignment, mitotic spindle formation and cytokinesis. Several studies have demonstrated altered expression of members of this family in various types of tumors and the functional inhibition of the aurora kinases have been considered as a potential approach to cancer treatment. Aim: On the basis of analysis of Aurora-A and Aurora-B gene expression in the samples from pediatric ACT, we investigated the effects of AMG 900, a pan-aurora kinase inhibitor, on proliferation, apoptosis rate, hormone synthesis and transcriptional profile of H295A cell line. Furthermore, we evaluated the effects of AMG 900 combined with different chemotherapeutic agents. Methods: The mRNA expression levels of Aurora-A and Aurora-B genes were analyzed in 60 children with ACT by RT-qPCR and immunohistochemistry. Cell proliferation was assessed by Giemsa staining and apoptosis was performed by flow cytometry. Drug combination analysis was made on the basis of ChouTalalay method. Microarray experiments were carried out using the Agilent human microarray. Results: Aurora-A and Aurora-B overexpression was associated with advanced disease. Patients carrying the TP53 p.R337H mutation presented significantly higher expression values of Aurora-A. Treatment with AMG900 caused inhibition of proliferation, increased apoptosis and sensitized the cells to topoisomerase II inhibitors (doxorubicin and etoposide). Additionally, the AMG 900 led to decreased synthesis of hormones and modulated the expression of genes involved in this activity. Finally, Aurora kinases inhibition altered the expression of genes associated with G1 cell cycle phase regulation and affected the Notch signaling pathway target genes. Conclusion: These data suggest that Aurora kinase inhibition by AMG900 may be a new therapeutic approach to adrenocortical carcinoma treatment.
\end{abstract}

Key words: Adrenocortical tumor, aurora kinases, AMG 900, H295A 


\section{LISTA DE FIGURAS}

Figura 1 - Representação do córtex adrenal adulto. Em destaque a divisão das três zonas: glomerulosa, fasciculada e reticulada. Modificado de Wang \& Rainey 2012.

Figura 2 - Vias de biossíntese de esteroides. Aqui está ilustrado os três principais produtos do cóstex supra-renal humano: aldosterona, cortisol e os andrógenos adrenais DHEA, DHEA-S, bem como as enzimas que sintetizam estes esteroides. DHEA: dehidroepiandrosterona, DHEA-S: Sulfato de dehidroepiandrosterona. Modificado de Wang \& Rainey 2012.

Figura 3 - Atividade da Aurora-A e da Aurora-B durante a progressão do ciclo celular. Aurora-A localiza-se no principalmente no centrossomo e está envolvida na separação e maturação destas organelas, bem como na montagem e estabilidade do fuso mitótico. A Aurora-B está associada ao cinetocoro do cromossomo durante a passagem da prófase para a metáfase, apresentando níveis elevados também na zona equatorial da célula em anáfase, e no anel contrátil da membrana celular durante a telófase Modificado de Marumoto et al., (2005).

Figura 4 - Representação dos diferentes tipos de conexão das fibras do fuso mitótico com o cinetocoro dos cromossomos. (I) Merotélica. (II) Monotélica. (III) Sintélica e (IV) Anfitélica. Modificado de Andrews (2005).

Figura 5 - Estrutura química do AMG 900. (Payton et al, 2006)

Figura 6 - Perfil da expressão gênica do Aurora-A e do Aurora-B em amostras de tumores adrenocorticais e tecido adrenal não neoplásico pediátricos. (A) $\mathrm{AURKA}=$ Aurora-A (B) $\mathrm{AURKB}=$ Aurora-B. As linhas correspondem à mediana dos valores de expressão. Resultados apresentados como $\log 10$ e como fold change. Significância obtida através do teste de Mann-Whitney.

Figura 7 - Perfil da expressão gênica nas amostras de TAC de acordo com o escore de Weiss, Aurora-A (A) e Aurora-B (B); de acordo com evento, Aurora-A (C) e Aurora-B (D); de acordo com a presença da mutação TP53 R337H, Aurora-A (E) e de acordo com sobrevida Aurora-A (F). AURKA=Aurora-A e AURKB=Aurora-B. As linhas correspondem à mediana dos valores de expressão. Resultados apresentados como $\log 10 \mathrm{e}$ como fold change. Significância obtida através do teste de Mann-Whitney.

Figura 8 - Sobrevida Livre de Eventos (SLE) de acordo com a expressão relativa de duas vezes acima ou abaixo da mediana de expressão no tecido não-neoplásico. Sobrevida Geral: Aurora-A (A) e Aurora-B (B) e sobrevida no grupo de pacientes com TAC com Weiss $\geq 3$ : Aurora-A (C) e Aurora-B (D). AURKA=Aurora-A e $\mathrm{AURKB}=$ Aurora-B. Testes realizados através da análise de Kaplan-Meyer.

Figura 9 - Microfotografias representativas da técnica de imuno-histoquímica para a Aurora-A e para a Aurora-B nos tumores adrenocorticais pediátricos. Células tumorais apresentando marcação citoplasmática e nuclear positiva para a Aurora-A (A e B) e Aurora-B (C e D). (400x). 
Figura 10 - Efeito do inibidor de AMG900 na proliferação da linhagem H295A. ${ }^{*} \mathrm{p}<0.05$. Teste One-way ANOVA com pós-teste de Bonferroni

Figura 11 - Efeito de diferentes quimioterápicos na proliferação da linhagem H295A. (A) Etoposideo. (B) Doxorrubicina. (C) Cisplatina. ${ }^{*} p<0.05$. Teste One-way ANOVA com pós-teste de Bonferroni.

Figura 12 - Representação gráfica da combinação do AMG900 com os quimioterápicos. Etoposídeo (A), Cisplatina (B) e Doxorrubicina (D). Cada x representa um ponto de combinação. Pontos $(\mathrm{x})$ acima da linha pontilhada, que representao número 1 , indicam antagonismo $(\mathrm{CI}>1$ =antagonismo) e pontos abaixo desta linha são considerados sinérgicos $(\mathrm{CI}<1=$ sinergismo $)$.

Figura 13 - Efeitos do AMG900 isolado (A) ou combinado com etoposídeo (B), cisplatina (C) ou doxorrubicina (D) na indução de apoptose. $\mathrm{SAL}=$ salina. ${ }^{*} \mathrm{p}<0,05$. Teste One-way ANOVA com pós-teste de Bonferroni.

Figura 14 - Efeitos do AMG900 na síntese de hormônios sintetizados pala H295A. (A) Sulfato de dehidroepiandrosterona (DHEA-S), (B) 4-androstenediona (D4), (C) testosterona (D) cortisol. T1: $48 \mathrm{~h}$ de exposição. T2: $48 \mathrm{~h}$ de exposição mais $48 \mathrm{~h}$ de incubação com meio de cultura livre de droga.

Figura 15 - Expressão relativa dos genes TP53 (A), GDF15 (B) e p21 (C) na linhagem H295A após o tratamento com o AMG-900. Tempo 1: 48h de exposição. Tempo 2: 48h de exposição mais $48 \mathrm{~h}$ de incubação com meio de cultura livre de droga.

Figura 16 - Possível efeito do AMG 900 no ciclo celular da linhagem H295A. (A) Ciclo celular normal. Uma célula normal origina duas células filhas com o mesmo número de cromossomos da célula inicial. (B) Célula tratada com o AMG 900. Uma célula com os mecanismos de checagem do fuso mitótico inibidos progride pelo ciclo através de uma mitose defeituosa, completando-o sem executar a citocinese. Adaptado de Gizatullin et al., 2006

Figura 17 - Representação esquemática da via de síntese hormonal. Em destaque os genes modulados ( $\uparrow=$ induzido $\downarrow=$ reprimido) pelo tratamento com o inibidor de aurora quinases AMG 900. Adaptado de Zhu \& Conney 1998; Tsuchiya et al., 2004; Wang \& Rainey. 2012; Doherty et al., 2014 


\section{LISTA DE TABELAS}

Tabela 1 - Estadiamento proposto para tumores adrenocorticais em crianças (Modificado por Sandrini et al., 1997)

Tabela 2 - Esquema de combinação de drogas ............................................................... 45

Tabela 3 - Lista de processos biológicos selecionados e seus genes correspondentes............ 52 


\section{LISTA DE ABREVIATURAS E SIGLAS}

$\mathrm{CO}_{2}$

Dióxido de carbono

DAVID

Database for Annotation, Visualization and Integrated Discovery

DMSO

dimetilsulfóxido

DNA

ácido desoxirribonucléico

MDM2

transformed mouse 3 T3 cell double minute 2

$\mathrm{mM}$

milimolar

mRNA

Ácido ribonucléico mensageiro

PBS

Tampão salina fosfato

PCR

Reação em cadeia da polimerase

qRT-PCR

Real Time quantitative reverse transcription PCR

RNA

Ácido ribonucléico

SAM

Significance analysis of microarrays

SBF

Soro fetal bovino

SPSS

Statistical Package for the Social Sciences

$\mu \mathrm{g}$

micrograma

$\mu \mathrm{M}$

micromolar 


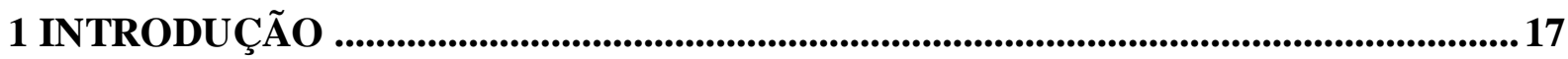

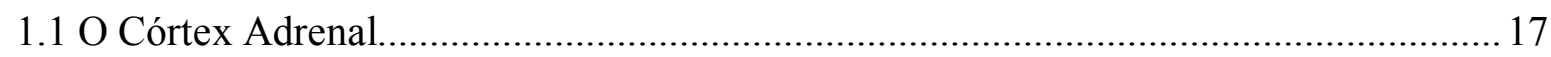

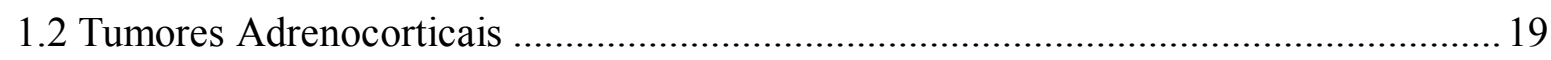

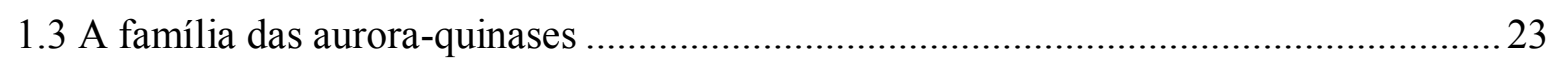

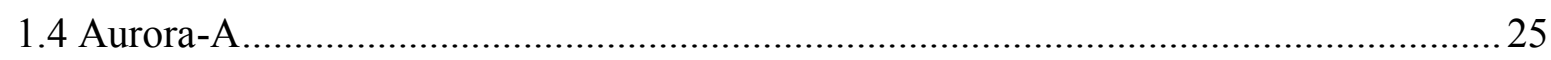

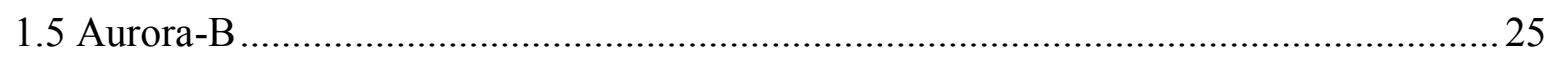

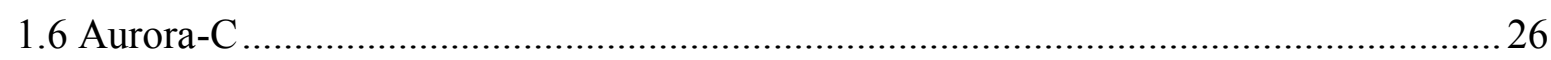

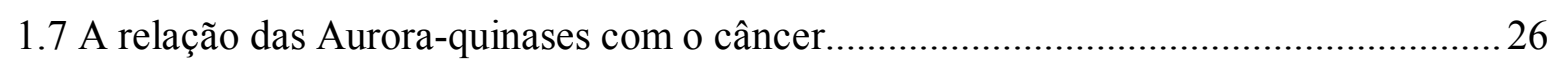

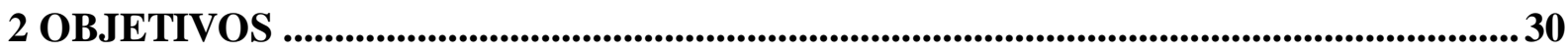

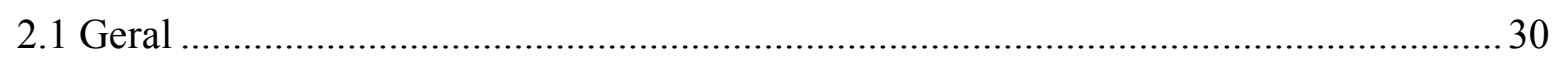

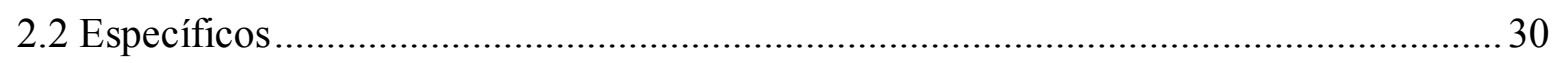

3 MATERIAL E MÉTODOS ............................................................................................. 31

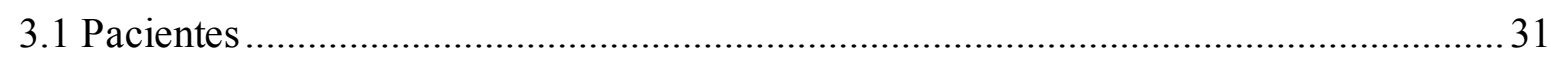

3.2 Coleta de amostras e Microdisseç̧ão ........................................................................ 31

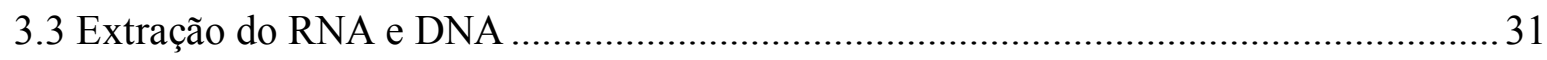

3.4 Quantificação por PCR em Tempo Real (qRT-PCR).................................................. 32

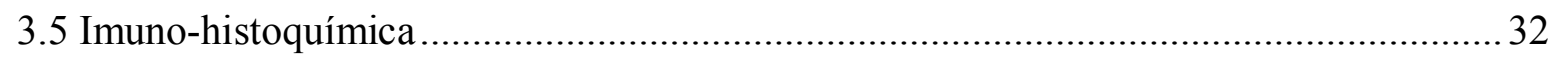

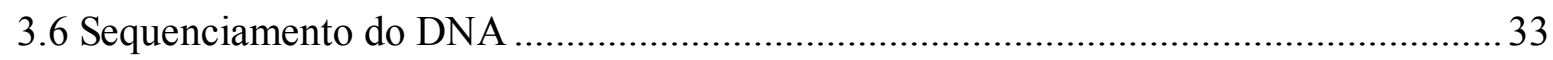

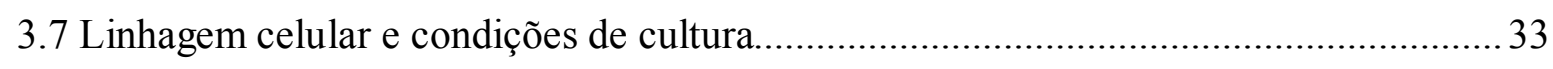

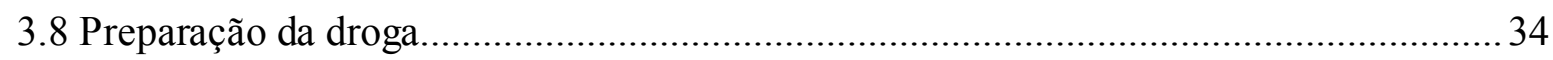

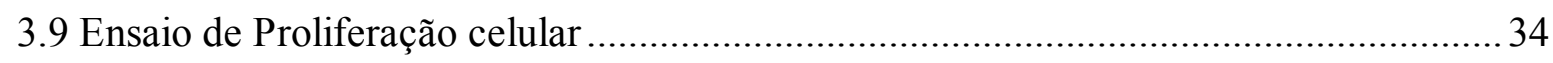

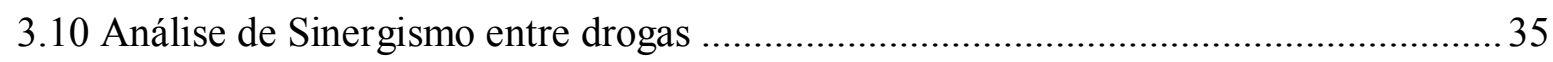

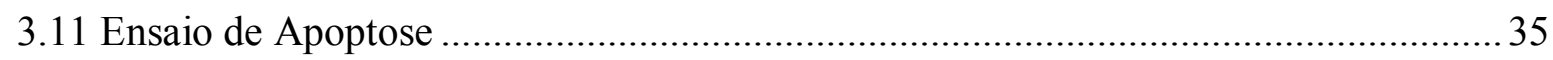

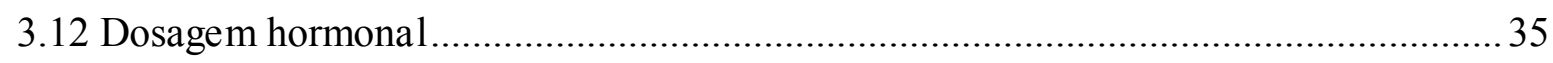

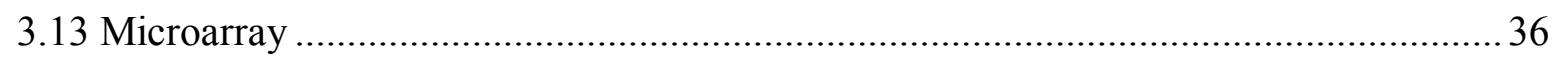

3.14 Categorização dos genes diferencialmente expressos ....................................................36

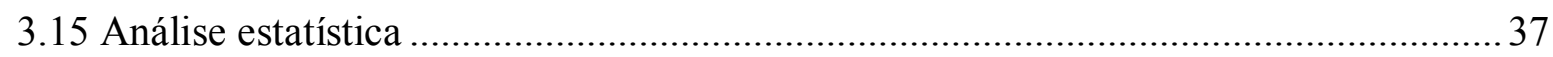

4 RESULTADOS ........................................................................................................ 38

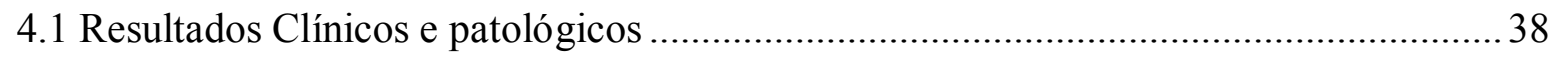


4.2 Expressão dos genes Aurora-A e Aurora-B e características clínicas e biológicas.........38

4.3 A expressão proteica da Aurora-A e da Aurora-B no tecido adrenal tumoral.

4.4 Efeitos do AMG 900 isolado ou combinado com quimioterápicos na proliferação celular

4.5 Efeitos do AMG 900 isolado ou combinado com quimioterápicos na indução de apoptose.

4.6 Efeito do AMG 900 na síntese de hormônios sintetizados pela linhagem H295A ........ 47

4.7 Efeitos do AMG 900 na expressão dos genes TP53, p21 e GDF15 ............................. 49

4.8 Perfis de expressão gênica por microarranjos de cDNA ............................................. 50

\section{DISCUSSÃO}

5.1 A expressão dos genes Aurora-A e Aurora-B está associada com características

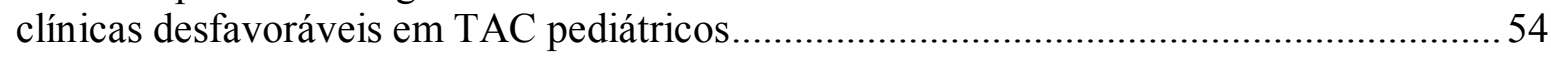

5.2 Efeitos do inibidor de aurora quinases AMG 900 na linhagem H295A........................56

5.3 Efeitos do AMG 900 combinado com diferentes quimioterápicos na linhagem

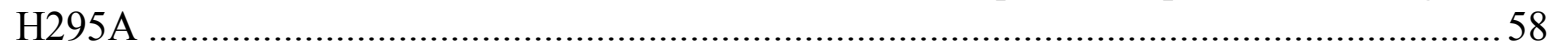

5.4 Efeitos do AMG 900 na síntese de hormônios da linhagem H295A............................. 60

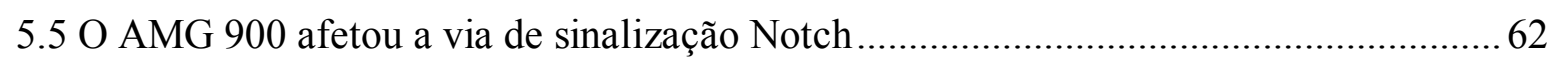

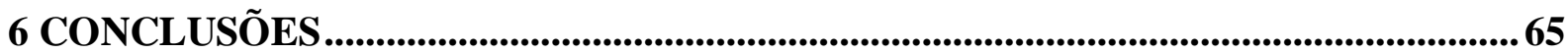

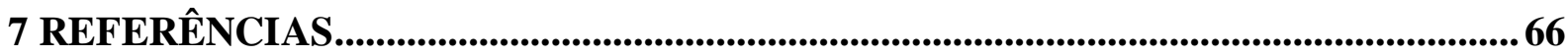

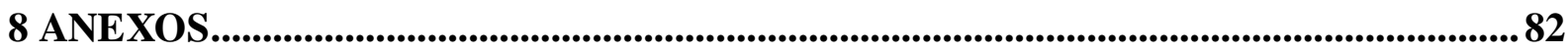

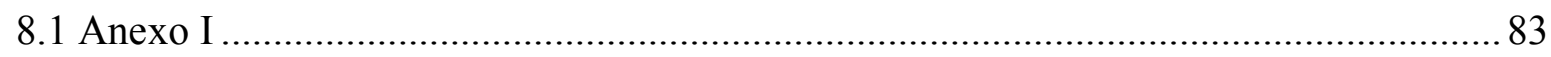

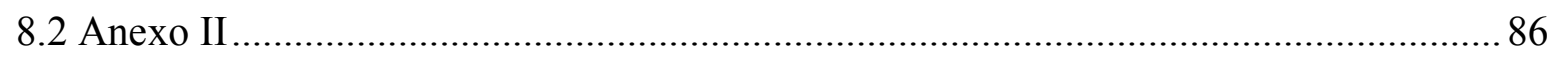

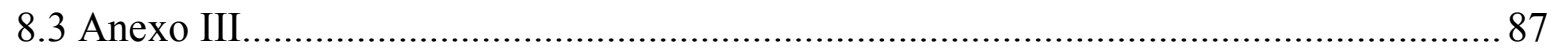

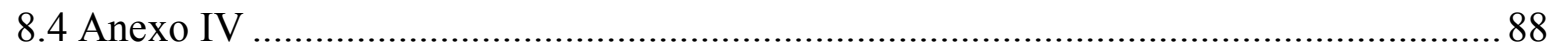




\section{INTRODUÇÃO}

\subsection{O Córtex Adrenal}

As glândulas supra-renais ou adrenais são órgãos endócrinos e localizam-se entre a face superior-medial dos rins e o diafragma. Cada glândula é composta por duas partes histologicamente e funcionalmente distintas: o córtex e a medula (Fig. 1) (Kempná \& Flück 2008; Wang \& Rainey 2011). O córtex é constituído por três zonas histológicas denominadas de acordo com a disposição das células secretoras: zona glomerulosa (ZG), responsável pela produção de mineralocorticoides (aldosterona), zona fasciculada (ZF), onde é sintetizado os hormônios glicorticóides (cortisol e corticosterona) e a zona reticular (ZR), responsável pela síntese de andrógenos (DHEA e DHEA-S). O DHEA e o DHEA-S não são andrógenos bioativos, mas agem como precursores para a síntese de andrógenos mais potentes, como a testosterona e estrogênio, em tecidos periféricos. A medula supra-renal é responsável pela síntese de epinefrina e noraepinerina (Kempná \& Flück 2008; Wang \& Rainey 2011).

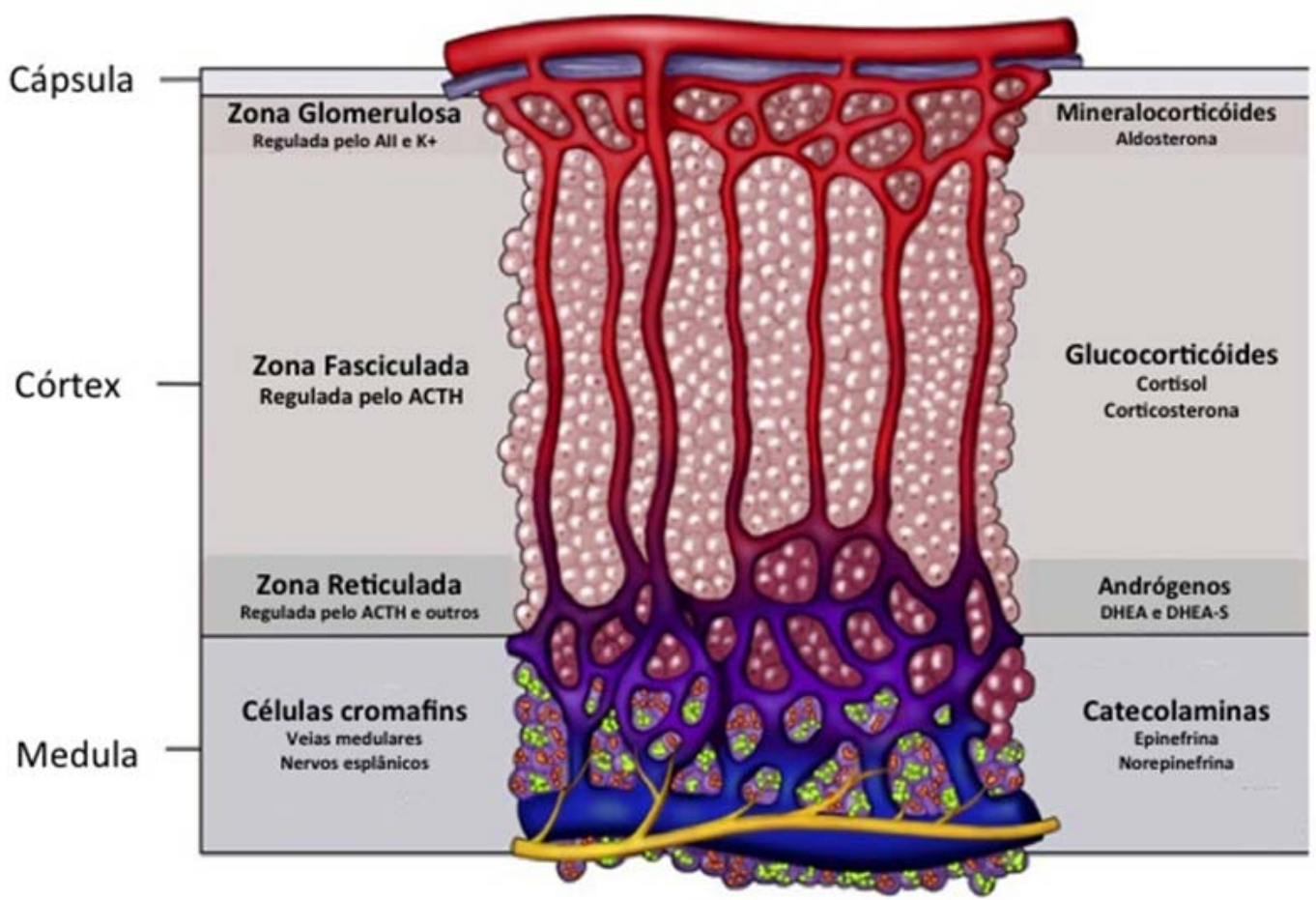

Figura 1 - Representação do córtex adrenal adulto. Em destaque a divisão das três zonas: glomerulosa, fasciculada e reticulada. Modificado de Wang \& Rainey 2012. 
Já foi estabelecido que cada zona do córtex adrenal possui um padrão de expressão gênica específico que governa o metabolismo da síntese dos hormônios (Fig. 2). Entretanto, os mecanismos que regulam essa expressão zona-específica ainda não estão totalmente elucidados (Kempná \& Flück 2008; Wood et al., 2013).

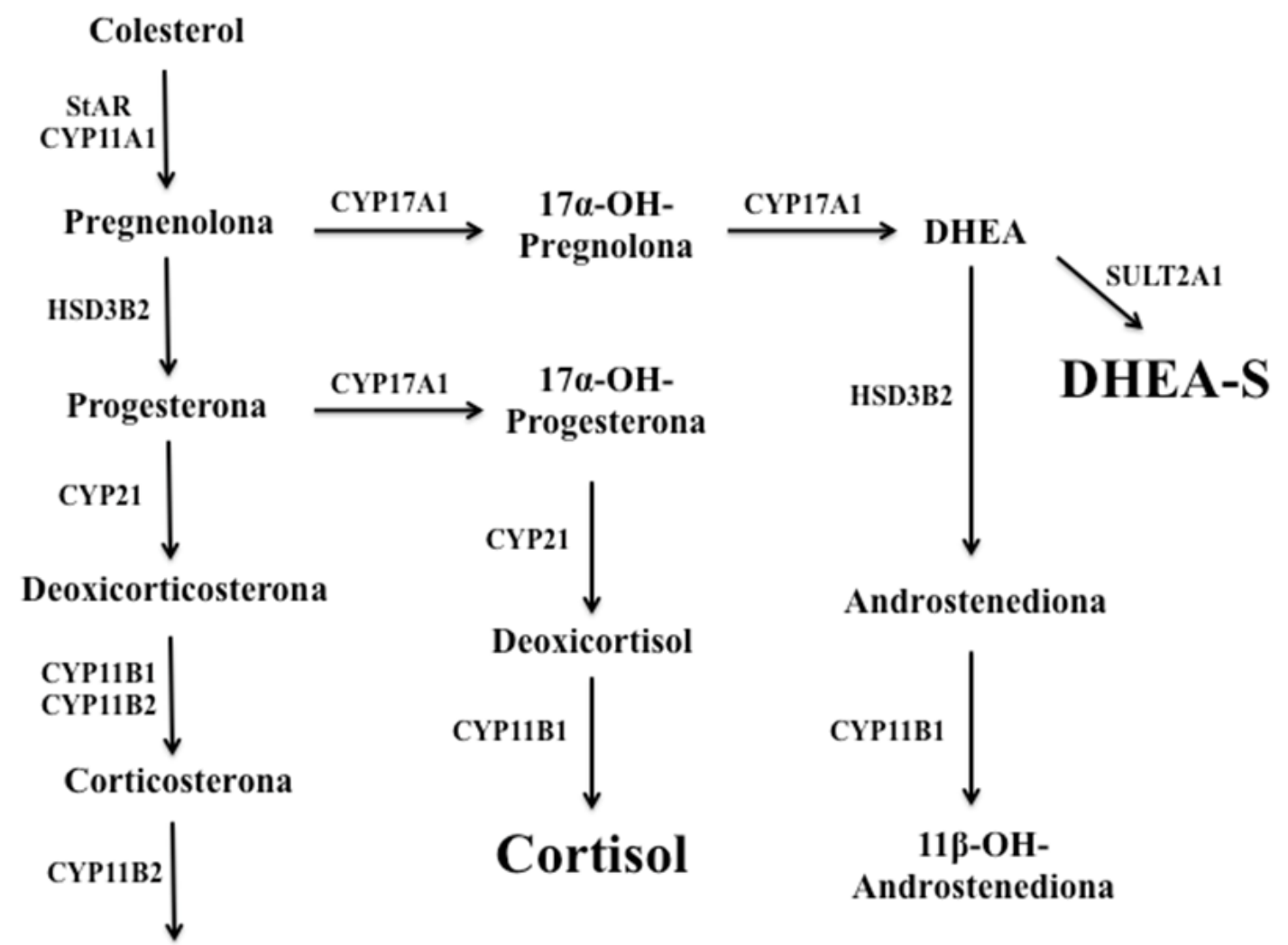

\section{Aldosterona}

Figura 2 - Vias de biossíntese de esteroides. Aqui está ilustrado os três principais produtos do cóstex supra-renal humano: aldosterona, cortisol e os andrógenos adrenais DHEA, DHEA-S, bem como as enzimas que sintetizam estes esteroides. DHEA: dehidroepiandrosterona, DHEA-S: Sulfato de dehidroepiandrosterona. Modificado de Wang \& Rainey 2012.

O córtex adrenal tem origem embrionária semelhante à das gônadas, a partir do mesoderma, e a medula em comum com os gânglios do sistema nervoso simpático, a partir da crista neural. O córtex supra-renal começa a se desenvolver a partir da condensação do epitélio celômico no embrião. Nos seres humanos essa condensação pode ser observada a partir da terceira semana de gestação. Células epiteliais celômicas proliferam e migram no período compreendido entre as 4 e $6^{\text {a }}$ semanas de gestação ao passo que a diferenciação morfológica da adrenal fetal em duas zonas distintas (a zona definitiva exterior e uma zona fetal interior) evidencia-se por volta da $8^{\text {a }}$ semana de gestação (Kempná \& Flück 2008; Ishimoto H \& Jaffe RB 2011) 
Por volta do final da gestação, uma terceira camada (zona de transição) é evidente entre as zonas definitivas e fetais, com características intermediárias. Durante os primeiros meses após o nascimento, a supra-renal passa por um processo de remodelagem intensa, induzida pelo desaparecimento da zona fetal por apoptose e uma progressiva proliferação e diferenciação de células da zona definitiva, culminando na formação da supra-renal adulta (Kempná \& Flück 2008; Ishimoto \& Jaffe 2011).

\subsection{Tumores Adrenocorticais}

Os tumores adrenocorticais (TAC) são neoplasias raras e em estadios avançados são frequentemente fatais. Sua incidência em criança é extremamente baixa: $0,2 \%$ de todos os cânceres pediátricos. Por esta razão os dados sobre sua malignidade são escassos e diversas informações são obtidas a partir de estudos realizados em pacientes adultos (RodriguezGalindo et al., 2005; Sbragia et al., 2005; Sutter e Grimberg, 2006).

Os TAC podem ocorrer em qualquer idade. Uma distribuição bimodal tem sido relatada, ocorrendo um primeiro pico antes dos 5 anos de idade e um segundo entre a $4^{\mathrm{a}}$ e $5^{\mathrm{a}}$ décadas de vida. O TCA é raro na infância. Nos Estados Unidos, a incidência anual estimada é de 0,3 casos/1.000.000 em indivíduos abaixo de 15 anos de idade. Por outro lado, nas regiões sul e sudeste do Brasil, em especial nos estados do Paraná e São Paulo, esta incidência está aumentada em 10 a 15 vezes, chegando a 4,2 casos/ 1.000.000 (Ribeiro et al., 2004; Allolio \& Fassanacht 2006; Libè et al., 2007).

Tradicionalmente, os tumores adrenocorticais (ACT) em adultos são divididos em adenomas e carcinomas. Embora a presença de metástases constitue a evidência absoluta de malignidade, a classifição de tumores localizados como benigno ou maligno pode ser um desafio tanto para o patologista como para o médico responsável pelo tratamento. Identificar a presença de malignidade é de vital importância para o prognóstico dos pacientes e sobrevida global. Em 1984, Weiss propôs escores de malignidade baseados em critérios histopatológicos, os quais incluem alto índice mitótico, presença de necrose confluente, peso e tamanho da massa e invasão venosa e capsular. Recentemente foi sugerida a modificação deste escore onde seriam mantidos somente os seguintes critérios: índice mitótico (>5/50 campos de grande aumento, claridade do citoplasma (<25\%), mitoses anormais, necrose e invasão capsular (Aubert et al. 2002).

Uma limitação importante dos escores de Weiss (1984) é a não aplicabilidade aos tumores adrenocorticais pediátricos. Diferentemente dos adultos, os tumores adrenocorticais pediátricos com prognóstico desfavorável baseado somente em critérios histopatológicos 
apresentam frequentemente evolução clínica favorável (Mendonça et al., 1995; Wajchenberg et al., 2000; Wieneke et al., 2003).

Nos casos pediátricos, a classificação por estadiamento continua sendo o fator que mais determina o prognóstico (Tucci et al., 2005). Sandrini e colaboradores (1997) propuseram um estadiamento que é baseado na extensão da doença, tamanho e peso do tumor (Tabela 1). Os dados de sobrevida do International Pediatric Adrenocortical Tumor Registry (IPACTR), baseados nesta classificação, estimam que mais de $90 \%$ dos pacientes com estadio I tratados somente com cirurgia sejam sobreviventes em longo prazo, mas somente $10 \%$ dos pacientes com estadio IV, mesmo submetendo-os a tratamentos quimioterápicos intensos (Michalkiewcz et al., 2004).

Tabela 1 - Estadiamento proposto para tumores adrenocorticais em crianças (Modificado por Sandrini et al., 1997).

\begin{tabular}{l|l}
\hline Estadio & \multicolumn{1}{|c}{ Definição } \\
\hline I & $\begin{array}{l}\text { Tumores pequenos }\left(<200 \mathrm{~cm}^{3} \text { ou }<100 \mathrm{~g}\right), \\
\text { completamente ressecáveis e concentrações } \\
\text { hormonais normais após a cirurgia }\end{array}$ \\
II & $\begin{array}{l}\text { Tumores grandes }\left(\geq 200 \mathrm{~cm}^{3} \text { ou } \geq 100 \mathrm{~g}\right) \text { e } \\
\text { disseminação do tumor durante a cirurgia } \\
\text { ou persistência de concentrações hormonais } \\
\text { elevadas após a cirurgia } \\
\text { Tumor inoperável ou doença residual após } \\
\text { a cirurgia ou persistência de níveis } \\
\text { hormonais anormais após a cirurgia }\end{array}$ \\
\hline III & \begin{tabular}{l} 
Doença Metastática \\
\hline
\end{tabular}
\end{tabular}

O estadiamento é útil na definição do prognóstico e da terapêutica. Somente pacientes com estadiamento I e II são curáveis com cirurgia. Apesar da ressecção cirúrgica completa, aproximadamente $90 \%$ dos pacientes com estadiamento III têm recorrência e doença metastática dentro dos primeiros 5 anos após a cirurgia (Allolio et al., 2006; Michalkiewicz et al., 2004; Fassnacht et al., 2009). 
As manifestações clínicas mais freqüentes dos TCA estão relacionadas ao aumento da secreção de hormônios pelo córtex adrenal e, eventualmente, à presença de uma massa abdominal palpável. A virilização, a síndrome de Cushing e a hipertensão são as formas de apresentação clínica. Crianças e adolescentes apresentam-se, tipicamente, com sinais e sintomas de produção excessiva de andrógenos, com quadro de virilização, sendo este o distúrbio hormonal mais comum, ou de excesso de cortisol, com quadro de síndrome de Cushing, ou ainda com ambos, sendo considerados tumores mistos. Em adultos, a síndrome mais comumente associada é a síndrome de Cushing. Em pacientes mais idosos, a maioria dos TAC tende a ser não funcionante (1,2,6). (Antonini et al., 2011; Ribeiro et al., 2012; Else et al., 2013). A virilização é secundária à secreção aumentada de andrógenos, incluindo sulfato de dehidroepiandrosterona (S-DHEA); $\Delta 5$-androstenediol e $\Delta 4$-androstenediona, os quais são convertidos para testosterona e $5 \alpha$-di-hidrotestosterona. Também são encontradas alterações nos níveis de testosterona, 17-hidroxiprogesterona e androstenediona. O padrão de secreção hormonal pode predizer o potencial maligno da lesão, como altas concentrações de S-DHEA ou estradiol elevado em homens. Raramente os TAC apresentam secreção de estrógeno ou aldosterona (Antonini et al., 2011; Ribeiro et al., 2012).

Os TAC são geralmente associados com sídromes genéticas constitucionais, entre estas estão as síndromes de Li-Fraumeni, de Beckwith-Wiedemann, de múltiplas neoplasias endócrinas 1 , a de complexo de Carney e a da hiperplasia adrenal congênita. Diversos genes envolvidos nestas síndromes estão também associados com a tumorigênese de tumores esporádicos (Opocher et al., 2009; Else et al., 2013; Lerario et al., 2013). Entre estes pode-se destacar as mutações do gene TP53, a via do hormônio adrenocorticotrópico-cAMP-proteína quinase A, a via do gene Wnt e as alterações na expressão dos genes $H 19$, IGF2 e $p 57^{k i p}$ (Lerario et al., 2013; Opocher et al., 2009). Vale ressaltar que dados recentes provenientes de pacientes brasileiros sugerem o envolvimento das vias IGF, WNT e de apoptose nos TAC pediátricos (Almeida et al., 2008; Leal et al., 2011; Lorea et al., 2012)

Mutações no gene TP53 estão associadas com TAC tanto nos pacientes infantojuvenis norte-americanos como nos brasileiros. No entanto no Brasil, região de maior incidência, foi observado que existe uma única mutação no exon 10 do gene TP53 (c.1010G $>A$ ), mais precisamente no códon 337, trocando o aminoácido arginina pela histidina (TP53 p.R337H), enquanto nos pacientes norte-americanos a mutação ocorre primariamente nos éxons 2 ao 8 (Ribeiro et al., 2001). Acredita-se que nas regiões Sul e Sudeste do Brasil, em torno de $75 \%$ a $90 \%$ das crianças e $20 \%$ a $30 \%$ dos adultos com TAC apresentam a mutação germinativa TP53 p.R337H em heterozigose (Latronico et al., 2001; Ribeiro et al., 
2001; Sandrini et al., 2005; Figueiredo et al., 2006). A penetrância desta mutação é baixa (somente 10-15\% dos portadores desenvolvem TCA) (Rodriguez-Galindo et al., 2005; Figueiredo et al., 2006), e tem sido associada com tumores como carcinoma de mama, de plexo coróide e osteossarcoma (Assumpção et al., 2008; Palmero et al., 2008; Custodio et al., 2011; Seidinger et al., 2011).

A análise de haplótipos deste mutante demonstrou um possível efeito fundador (Pinto et al., 2004) e estudos recentes demonstraram que as famílias brasileiras que carreaiam esse alelo mutante habitam locais ao longo da principal rota utilizada pelos comerciantes portugueses nos séculos XVIII e XIX (Garritano et al, 2010), sugerindo que esse gene mutante pode ter sido de origem portuguesa. Em crianças, onde a mutação TP53 p.R337H foi mais frequente, não houve associação direta entre a presença dessa mutação com o grau de malignidade ou o prognóstico desses pacientes (Latronico et al., 2001; Ribeiro et al., 2001; Sandrini et al., 2005). Em adultos, no entanto, essa e outras mutações do gene TP53 parecem associar-se a prognóstico mais desfavorável (Latronico et al., 2001; Ragazzon et al., 2010).

A mutação p.R337H se localiza no domínio de tetramerização da p53 (resíduos 324355) e em pH 8,0 a proteína é desestabilizada alterando sua conformação (DiGiammarino et al., 2002). Baseado nestas informações foi desenvolvida uma teoria que explicaria a alta incidência de TAC em indivíduos carreando esta mutação. Segundo esta teoria, durante o desenvolvimento da glândula adrenal, pode ocorrer a elevação do $\mathrm{pH}$ intracelular como resultado da intensa remodelagem tecidual (apoptose) e esteroidogênese. Tal fato poderia desestabilizar a proteína p53 mutante, levando à perda da sua função de supressora tumoral (DiGiammarino et al., 2002).

A terapia atual para o TAC pediátrico baseia-se fundamentalmente na ressecção cirúrgica do tumor, único tratamento efetivo conhecido, principalmente se a doença for detectada em estágios iniciais (I e II). Embora mitotane acompanhado ou não com quimioterápicos tem sido usada com pouco sucesso, diversos efeitos adversos estão relacionados ao tratamento com este quimioterápico. O mitotane é um composto adrenolítico com o mecanismo de ação desconhecido. A monitorização da concentração desta droga é necessária para obtenção de tratamento efetivo. (Michalkiewicz et al., 2004; Else et al., 2013). Como o tratamento do carcinoma adrenocortical metastático é ineficaz, protocolos de quimioterapia de compostos isolados e/ou combinados têm sido usados, contudo os resultados são limitados (Zancanella et al., 2006; Fassnacht et al., 2012). Portanto, novas alternativas terapêuticas são necessárias para o tratamento deste tumor. 


\subsection{A família das aurora-quinases}

Para garantir que as duas células filhas recebam cópias idênticas do genoma, a progressão através do ciclo celular é rigorosamente regulada e controlada por uma seqüência de eventos de síntese, ativação e degradação de proteínas, as quais às vezes requerem uma série de modificações pós-traducionais. A fosforilação e a desfosforilação de proteínas desempenham uma importante função no controle dos eventos mitóticos (Lopes et al., 2003; Schmidt et al., 2007).

Entre as proteínas quinases envolvidas na divisão celular, as mais bem conhecidas estão a CDK1 (ciclina dependente de quinase 1), a proteínas da família PLK (polo-like quinase), a Bub1 (budding uninhibited by benzimidazole 1), a Nek 2 e as aurora-quinases (Schmidt \& Bastians 2007).

A família das aurora-quinases compreende quinases de serina/treonina que atuam em diversos processos do ciclo celular, tais como duplicação e separação do centrossomo, interação dos microtúbulos com o cinetocoro das cromátides irmãs, e montagem do fuso mitótico. Além disso, desempenham funções importantes na condensação dos cromossomos, estabelecimento do fuso mitótico, orientação dos cromossomos, sendo necessárias também para a própria efetivação da citocinese (Fig. 3). Elas são responsáveis pela checagem do fuso mitótico durante a divisão celular. Caso ocorra algum erro na montagem do fuso ou no pareamento dos cromossomos elas bloqueiam o ciclo para que as devidas correções sejam realizadas. Falhas nestes mecanismos de checagem causam alterações cromossômicas (Carmena \& Earnshaw 2003; Montembault et al., 2005; Gautschi et al., 2008; Mountzios et al., 2008).

O primeiro homólogo da família das aurora-quinases foi identificado após estudo genético para encontrar mutações que induziam aumento de ploidia em células de leveduras (increase-in-ploidy phenotype - Ipl1) (Chan \& Botstein 1993). Um homólogo foi encontrado em Drosófila em 1995, após a observação de mutações no gene chamado aurora. Esta mutação bloqueou o ciclo celular quando os cromossomos condensados foram recrutados para apenas um pólo do fuso mitótico (Glover et al., 1995). Este nome foi escolhido devido à semelhança entre a morfologia do fuso mitótico defeituoso com o fenômeno luminoso observado nas regiões polares do planeta Terra (Mountzios et al., 2008). 


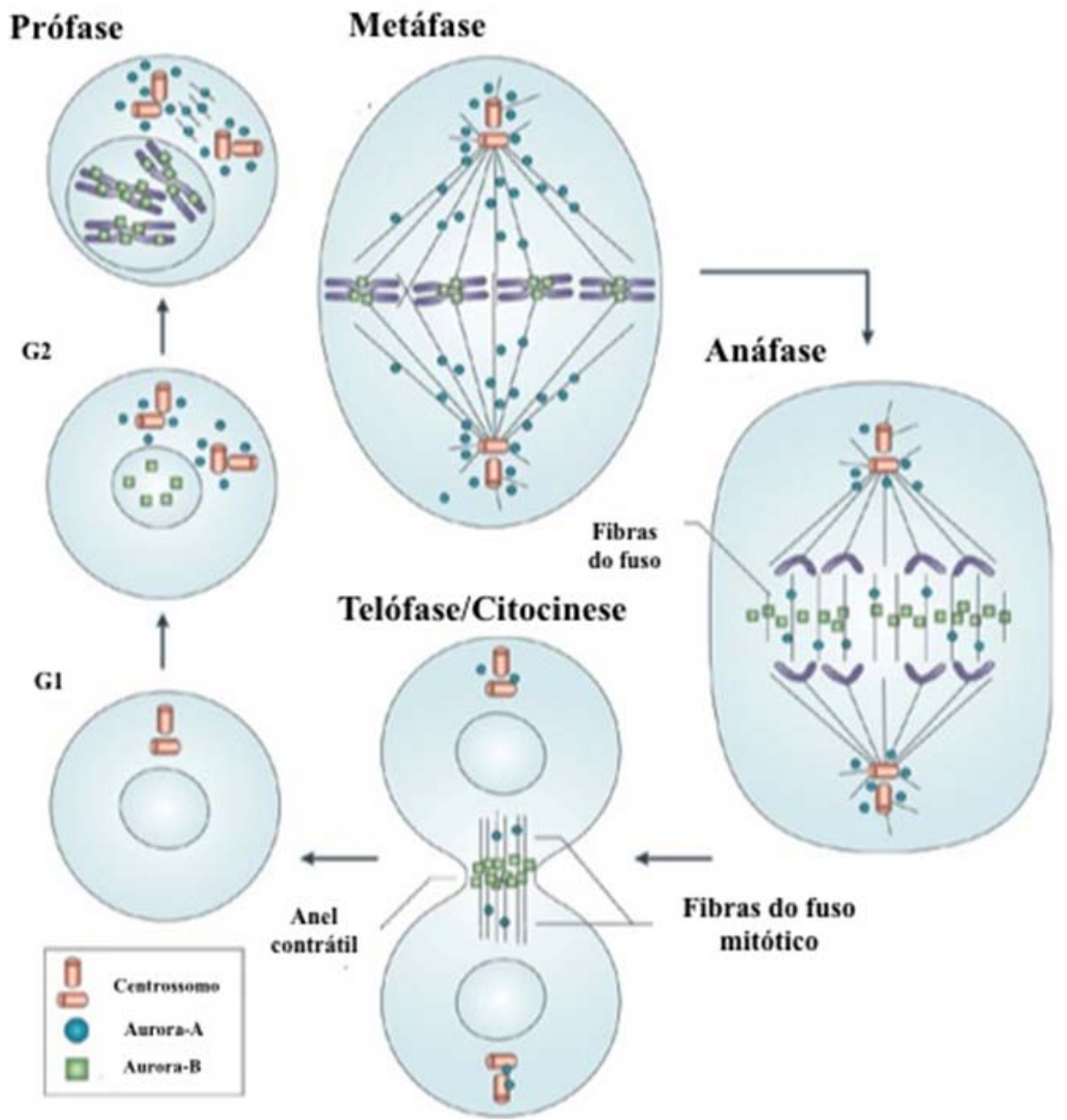

Figura 3 - Atividade da Aurora-A e da Aurora-B durante a progressão do ciclo celular. Aurora-A localizase no principalmente no centrossomo e está envolvida na separação e maturação destas organelas, bem como na montagem e estabilidade do fuso mitótico. A Aurora-B está associada ao cinetocoro do cromossomo durante a passagem da prófase para a metáfase, apresentando níveis elevados também na zona equatorial da célula em anáfase, e no anel contrátil da membrana celular durante a telófase Modificado de Marumoto et al., (2005).

Em 1998, três homólogos de aurora-quinase foram identificados em humanos, AuroraA (AURKA, Aurora-2/BTAK, STK15, STK16, ARK1, AIK), Aurora-B (AURKB, Aurora-1, Ipl1, STK12, AIM-1, ARK2) e Aurora-C (AURKC, Aurora 3, STK13, AIK, AIE-2), localizados nas regiões cromossômicas 20q13.2-q13.3, 17p13.1 e 19q13.43, respectivamente (Carmena \& Earnshaw 2003; Montembault et al., 2005). Estes genes apresentam grande homologia nas seqüências de nucleotídeos, ocupam locais distintos na célula, são ciclo-dependentes e desempenham diferentes funções no ciclo celular (Adams et al., 2001).

A atividade das aurora-quinase no ciclo celular aumenta gradualmente na fase $\mathrm{S}$ e o pico é alcançado na fase M. Subsequentemente, as quinases são degradadas pelo proteossoma após a saída da mitose. A hiperexpressão de algumas das aurora-quinases leva ao aumento da ploidia, principalmente devido à amplificação do centrossomo e/ou desregulação dos pontos 
de checagem da divisão mitótica (Fu et al, 2007; Gautschi et al., 2008; Mountzios et al., 2008).

\subsection{Aurora-A}

A Aurora-A localiza-se no centrossomo, sendo encontrada também associada aos microtúbulos no pólo metafásico durante a mitose (Kimura et al., 1997) (Fig. 3). A atividade de fosforilação está envolvida na separação e maturação do centrossomo, bem como na montagem e estabilidade do fuso mitótico (Glover et al., 1995). A hiperexpressão ou inibição da expressão do aurora- $A$ causa diversas anormalidades no fuso celular. Foi relatado que a expressão ectópica do gene Aurora-A em linhagens celulares NIH/373 imortalizadas é suficiente para provocar a transformação destas células, definindo o Aurora-A como um oncogene (Bischoff et al., 1998; Zhou et al., 1998). Entretanto, a atividade oncogênica do deste gene foi questionada por outro estudo mostrando a não transformação celular quando o gene estava com a expressão aumentada (Zhang et al., 2004). Desta forma, verifica-se que possivelmente há necessidade da presença de outras alterações genéticas para que a hiperexpressão do gene em questão cause transformação celular. (Anand et al., 2003).

\subsection{Aurora-B}

A proteína Aurora-B faz parte do Complexo de Proteínas Passageiras (CPP), que se movem do centrômero para o fuso mitótico durante a divisão celular, monitorando a separação equitativa dos cromossomos (Adams et al., 2001). Além disso, esta proteína está associada ao cinetocoro do cromossomo durante a passagem da prófase para a metáfase, apresentando níveis elevados também na zona equatorial da célula em anáfase, e no anel contrátil da membrana celular durante a telófase (Fig. 3) (Carmena et al., 2003).

Dentre outras funções, a Aurora-B regula a interação do cinetocoro com os microtúbulos durante a metáfase, garantindo que a célula prossiga pela metáfase somente quando todos os cromossomos tenham adquirido uma conexão bipolar com os microtúbulos que procedem de cada centrossomo (conexão anfitélica) (Fig. 4). De fato, a Aurora-B pode prevenir conexões sintélicas ou monotélicas. A primeira é caracterizada pela interação de ambos os cinetocoros com o mesmo pólo do fuso mitótico, enquanto a monotélica se caracteriza pela ligação de um cinetocoro com ambos os pólos metafásicos. Portanto, caso seja identificado uma conexão incorreta (sintélica ou monotélica), os mecanismos de correção 
são ativados para garantir a montagem adequada do fuso celular (Ducat \& Zheng 2004; Meraldi et al., 2004).

Embora a Aurora-B não induza a transformação celular, células com a expressão elevada do gene Aurora-B promoveram a formação de tumores agressivos quando implantadas em camundongos imunodeficientes (Ota et al., 2002).

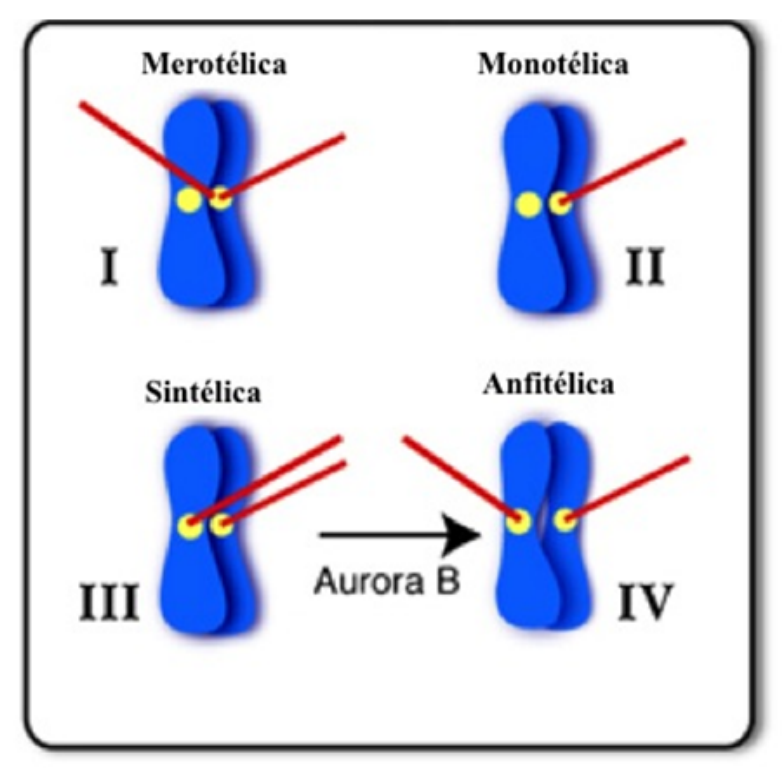

Figura 4 - Representação dos diferentes tipos de conexão das fibras do fuso mitótico com o cinetocoro dos cromossomos. (I) Merotélica. (II) Monotélica. (III) Sintélica e (IV) Anfitélica. Modificado de Andrews (2005).

\subsection{Aurora-C}

Este último membro da família das Aurora-quinases não está muito bem caracterizado. Embora tenha sido encontrada hiperexpressa em algumas células tumorais, provavelmente está envolvida apenas na espermatogênese (Kimura et al., 1999). Inicialmente relatado como uma proteína centrossômica somente da anáfase para a citocinese (Kimura et al., 1997), a Aurora-C foi descrita recentemente como uma proteína que faz parte do Complexo de Proteínas Passageiras (CPP) (Li et al., 2004; Sasai et al., 2004).

\subsection{A relação das Aurora-quinases com o câncer}

A aneuploidia é a alteração genômica mais prevalente nos tumores sólidos humanos (Jallepalli \& Lengauer 2001). Problemas nos centrossomos (quantidade, organização e comportamento) têm sido encontrados em diversos tipos de câncer afetando a segregação 
normal dos cromossomos e consequentemente produzindo células aneuplóides (Sato et al., 2001; Saunders et al., 2001). Alterações na maturação do centrossomo têm sido descritos em carcinomas de mama, cervical e de próstata. Além disso, tumores colorretais, de cabeça e pescoço e diferentes tipos de linfoma exibem defeitos na segregação cromossômica associadas com amplificação do centrossomos, o que parece se correlacionar com o grau de malignidade destas neoplasia (Lengauer et al., 1997; Gisselsson et al., 2002; Duesing et al., 2003; Kramer et al., 2003; Pihan et al., 2003). Todos estas alterações contribuem para a aquisição de uma instabilidade genética tipicamente observada em células neoplásicas, como predito por Boveri, que já no começo do século passado citava que tumores podem tornar-se malignos devido ao número cromossômico anormal (Boveri et al., 1914).

Aneuploidia e anormalidades do centrossomo são também detectadas após a hiperexpressão ou inibição dos genes da família aurora-quinase, caracterizando estas como moléculas que possivelmente possuem uma importante função no surgimento e na progressão do câncer (Fu et al., 2007; Gautschi et al., 2008). A expressão aumentada das aurora-quinase tem sido observada em muitos cânceres e estudos de diferentes tecidos têm mostrado que anormalidades cromossômicas são freqüentes em regiões contendo estes genes. Por exemplo, a amplificação na região cromossômica 20q13, onde está presente o Aurora-A, foi primeiro descrita nos cânceres de mama, colorretal, bexiga e ovário, através da técnica de hibridação genômica comparativa (Courjal et al., 1996; Reznikoff et al., 1996; Tanner et al., 1995), e o homólogo humano do Aurora-B foi inicialmente identificado em estudo de quinases que se apresentavam expressas em tumores (Bischoff et al., 1998).

A amplificação gênica e a hiperexpressão das proteínas aurora-quinase têm sido bem caracterizadas em vários tumores, incluindo carcinomas colorretais (Bischoff, 1998; Tatsuka et al., 1998; Ota et al., 2002), de mama (Tanaka et al., 1999), ovário (Tanner et al., 2000), hepatocarcinomas (Jeng et al., 2004), meduloblastomas (Neben et al., 2004) e gliomas (Scrideli et al., 2008).

Modificações na expressão ou na atividade das aurora-quinases estão associadas a alterações na expressão do TP53. A Aurora-A fosforila a TP53 na serina 315, levando à ubiquitinação através do Mdm2 e subsequentemente degradação da TP53 (Katayama et al., 2004). A inibição da Aurora-B causa aumento na expressão do p53, através da ativação da via ATM/ATR, desencadeada após danos causados ao DNA (Dreier et al., 2009; Kaestner et al. 2009). Estas duas relações podem estar associadas com a resistência ou não ao tratamento com o inibidor, bem como podem explicar algumas das repostas apresentadas pelas células ao tratamento com inibidores de aurora-quinases (Gizatullin et al., 2006). 
Diversos trabalhos mostraram os efeitos da inibição farmacológica ou por RNAi dos dois principais membros da família das aurora-quinases (A e B), e resultados interessantes foram alcançados em diversas neoplasias, inclusive diferentes inibidores estão em ensaio clínico (Boss et al., 2009; Perez Fidalgo et al., 2009). É interessante destacar que atualmente existem diversos inibidores de aurora quinases, entre estes há os pan-inibidores, que atuam em ambas Aurora-A e B, e os inibidores específicos, que agem em apenas um dos membros da família (Gautschi et al., 2008; Mountzions et al., 2008; Montembault et al., 2007; Matthews et al., 2006).

Recentemente, um novo potente e seletivo pan-inibidor de aurora quinases foi descrito, o AMG 900 (Fig. 5). Esta droga apresentou atividade em linhagens celulares tumorais resistentes a taxanos (paclitaxel) e a outros inibidores de aurora-quinases (AZD1152, MK-0457 e PHA-739358). Este composto também causou efeitos significativos em linhagens HCT116 carreando uma mutação na Aurora B (W221L) e resistentes ao AZD1152 (outra droga que inibe a Aurora B), enquanto que fibroblastos humanos foram relativamente insensíveis para esta droga. Adicionalmente, o AMG-900 induziu morte celular em células mononucleares humanas provenientes da medula óssea, mostrando seus efeitos em células com uma alta taxa de proliferação (Payton et al., 2006). Tratamento de camundongos com o AMG-900 resultou em até $75 \%$ de inibição de crescimento do tumor. Além disso, este composto causou inibição de crescimento do tumor em modelos in vivo de linhagens resistentes a multidrogas. Entre as toxicidades relatadas estão perda de peso moderada e mielossupressão. Entretanto, de forma geral, o AMG 900 mostrou uma famacocinética e farmacodinâmica favoráveis com uma toxicidade mínima (Payton et al., 2006).

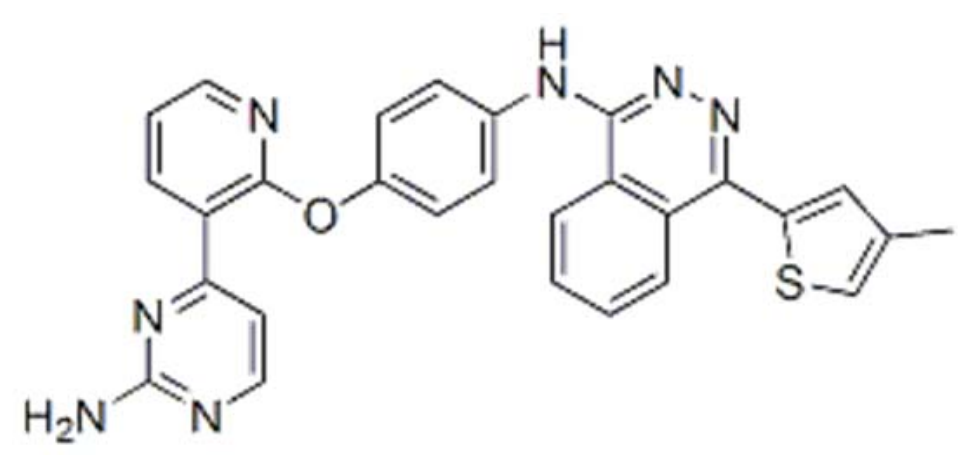

Figura 5 - Estrutura química do AMG 900. (Payton et al, 2006)

Como o Aurora-A e o Aurora-B foram encontrados com a expressão elevada em diversas neoplasias em comparação com os respectivos tecidos não-neoplásicos, vários 
trabalhos buscaram investigar estes genes como marcadores de prognóstico/diagnóstico e/ou como potenciais alvos terapêuticos. Desta forma, verifica-se na literatura inúmeros relatos da associação da expressão destes genes com um prognóstico desfavorável ou com o aumento do grau do tumor (Boss et al., 2009; Lok et al., 2010). No caso do carcinoma de adrenal, não foram encontrados relatos da expressão dos genes da família aurora-quinases em casos pediátricos, somente em amostras de pacientes adultos (Giordano et al. 2003; Reyniès et al., 2009). Como novas alternativas terapêuticas são necessárias para o tratamento dos TAC, o estudo da expressão dos genes Aurora-A e Aurora-B e a investigação dos efeitos in vitro das inibição da atividade destas proteínas poderá trazer novas perpesctivas para o tratamento dos TAC e fornecer informações importantes sobre a biologia deste tumor. 


\section{OBJETIVOS}

\subsection{Geral}

- Avaliar os mecanismos envolvidos com a inibição de aurora-quinases em carcinoma de adrenal

\subsection{Específicos}

- Avaliar a expressão dos genes Aurora-A e Aurora-B em amostras pediátricas de tumores adrenocorticais pediátricos e investigar a associação desta expressão com as características clinicas e biológicas dos pacientes;

- Investigar os efeitos in vitro da inibição das aurora-quinases, usando o AMG 900, nos processos de proliferação celular, síntese hormonal e apoptose da linhagem de carcinoma de adrenal H295A;

- Estudar o efeito da combinação do inibidor de aurora quinases AMG 900 com os quimioterápicos doxorrubicina, etoposídeo e cisplatina;

- Avaliar os efeitos in vitro da inibição das aurora-quinases no perfil transcricional da linhagem H295A. 


\section{MATERIAL E MÉTODOS}

\subsection{Pacientes}

Foram analisados 60 pacientes pediátricos consecutivos diagnosticados com tumores adrenocorticais entre outubro de 1991 e julho de 2009 no Hospital das Clínicas da Faculdade de Medicina de Ribeirão Preto, Universidade de São Paulo e no Centro Infantil Boldrini - CIB, Campinas. Todos os pacientes foram submetidos a investigações clínicas e hormonais. Além dos testes bioquímicos, foi realizada também a tomografia computadorizada abdominal (TCA) e/ou a ressonância magnética. A tomografia computadorizada de tórax e a cintilografia foram realizadas para a identificação de metástases. A classificação de Sandrini (Sandrini et al., 1997) foi utilizada para o estadiamento da doença e o diagnóstico histológico foi baseado no critério de Weiss. Onze amostras de córtex adrenal obtidas de crianças com nefrectomia de tumor de Wilms sem invasão de adrenal foram analisadas como tecido controle. Este estudo foi aprovado pelo Comitê de Ética em pesquisa local (número de protocolo: 8380/2010) e foram obtidos termos de consentimento livre e esclarecido dos pacientes ou responsáveis (Anexo III)

\subsection{Coleta de amostras e Microdissecção}

As amostras de adrenal foram coletadas em criotubo durante a ressecção cirúrgica, sendo imediatamente colocadas em nitrogênio líquido e estocadas. Antes do processamento da amostra, foi realizada a microdissecção no laboratório do prof. Dr. Luciano Neder, do Departamento de Patologia da FMRP-USP para retirada de tecido normal e necrótico garantindo a qualidade da amostra.

\subsection{Extração do RNA e DNA}

Previamente ao início do processo de extração, as amostras foram pesadas e aliquotadas entre 5 e $20 \mathrm{mg}$ de tecido adrenal. A extração foi realizada por meio de colunas utilizando o $R N A / D N A /$ Protein Purification Kit ${ }^{\circledR}$ (Cat. \#23500; Norgen, Canda) conforme orientação do fabricante. O DNA e RNA de cada amostra foram quantificados em espectrofotômetro. Para a verificação da integridade do RNA obtido, cada amostra foi submentida à eletroforese em gel de agarose 1\%. E do DNA foi submetido à eletroforese em gel de agarose $2 \%$. A síntese de cDNA à partir do mRNA foi realizado utilizando o kit High Capacity (Applied Biosystems), de acordo com as instruções do fabricante. 


\subsection{Quantificação por PCR em Tempo Real (qRT-PCR)}

A análise da expressão gênica foi realizada através da técnica de PCR em tempo real (qRT-PCR) em equipamento ABI PRISMTM 7500 Sequence Detection Systems (PE Applied Biosystems), utilizando-se sondas Taqman específicas para cada um dos genes de estudo (AURKA: Hs00269212_ml, AURKB: Hs00177782_ml e GAPDH: 4326317-E 0905031), que foram adquiridas by demand da Applied Biosystems.

A concentração final dos primers foi de $900 \mathrm{nM}$ e a concentração para as sondas Taqman foi de $300 \mathrm{nM}$. O volume final para cada PCR foi de $20 \mu \mathrm{L}$, incluindo $9 \mu \mathrm{L}$ de amostra investigada diluída (1/10), $10 \mu \mathrm{L}$ Universal PCR Master Mix (Applied Biosystems) e $1 \mu \mathrm{L}$ de sonda. Foi utilizado como controle endógeno o gene $G A P D H$. A quantificação relativa da expressão gênica foi determinada utilizando a equação 2- $\Delta \Delta C$ T (Livak \& Schmittgen 2001).

Para a determinação do nível de expressão dos genes alvo CDKN2A, TP53 e GDF15 e de referência endógena ( $G A P D H$ e $A C T B)$ na linhagem H295A após o tratamento com o inibidor de aurora-quinases também foi utilizada a técnica de PCR em tempo real (RQ-PCR). Entretanto, neste experimento foi utilizada o kit SYBR Green PCR Master Mix (Life Bioscience) contendo SYBR Green dye, AmpliTaq Gold DNA Polimerase, dNTPs (com dUTP), referência passiva e tampão otimizado.

O preparo das reações foi realizado segundo as instruções do fabricante e para cada reação foram utilizadas amostras de cDNA em diluições de 1:10. Utilizou-se para o preparo de todas as reações, placas de polipropileno para 96 reações. Os parâmetros do aparelho foram ajustados para pré-aquecimento inicial a $50^{\circ} \mathrm{C}$ por 2 minutos, desnaturação a $95^{\circ} \mathrm{C}$ por 10 minutos e 50 ciclos de amplificação e quantificação $\left(15\right.$ segundos a $95^{\circ} \mathrm{C}$ e 60 segundos a $60^{\circ} \mathrm{C}$ ), seguidos de um período de dissociação de 60 segundos a $95^{\circ} \mathrm{C}$. Todas as amostras e seus respectivos controles foram avaliados em duplicadas experimentais e biológicas. A especificidade dos produtos amplificados foi determinada pela avaliação de curvas de dissociação. Os tempos de exposição e as doses testadas foram baseadas no trabalho de Payton et al., (2010).

\subsection{Imuno-histoquímica}

A reação de imuno-histoquímica foi realizada em um conjunto de 48 amostras de tecido de tumor a partir de 60 pacientes. As secções foram incubadas com um anticorpo primário monoclonal específico para a Aurora-A e para a Aurora-B (Millipore, Temecula, 
CA, diluição 1:100) de acordo com as instruções do fabricante, seguindo-se a detecção de sinal com o método complexo avidina-biotina (Kit Vectastain Elite ABC, Universal; Vector Laboratories, Inc., Burlingame, CA). A imunomarcação foi analisada de acordo com a intensidade e a quantidade de células com marcação citoplasmática, de membrana ou nuclear. A intensidade de coloração foi classificada de 0 (negativo), 1 (fraca), 2 (moderado) e 3 (forte). Foi utilizado um sistema de pontuação onde foram atribuídos pontos para intensidade de marcação: 0 pontos (negativa), 2 pontos (moderada), 3 pontos (intensa); e para porcentagem de células positivas: 0 pontos $(0 \%), 1$ ponto $(1 \%-10 \%), 2$ pontos $(11 \%-25 \%), 3$ pontos $(26 \%-50 \%)$ e 4 pontos ( $>51 \%)$. A pontuação de ambos os parâmetros foram então somadas e a imunomarcação das amostras foi classificada com: negativa (total $=0$ pontos), fraca (total $=$ 1 a 2 pontos), moderada (total $=3$ a 4 pontos) ou intensa (total $=5$ a 7 pontos)

\subsection{Sequenciamento do DNA}

De acordo com as instruções do fabricante, as amostras foram purificadas com o kit Wizard PCR preps DNA Purification System ${ }^{\circledR}$ (Promega, Madison, WI) e seqüenciadas por PCR assimétrico usando o ABI-Prism ${ }^{\circledR}$ BigDye ${ }^{\mathrm{TM}}$ Terminator Cycle Sequencing Ready Reaction kit em um sequenciador ABI Prism 377 DNA sequencer Apparatus (Perkin-Elmer Corporation). Foram usados os primers 5'- CTG AGG CAC AAG AAT CAC-3' (sense) e 5' - TCC TAT GGC TTT CCA ACC-3' (antisense) (Sandrini et al., 2005). Os cromatogramas e seqüências foram analisados com os softwares ABI sequence Analysis v.3.3 e Chromas v.2.33 (Technelysium Pty Ltd /www.technelysium.com.au, Queensland, Austrália), respectivamente.

\subsection{Linhagem celular e condições de cultura}

A linhagem celular H295A foi gentilmente cedida pelo Prof. Dr. Sonir Antonini do Departamento de Endocrinologia da Faculdade de Medicina de Ribeirão Preto. Esta linhagem foi derivada da linhagem de carcinoma de adrenal NCI-H295 (Gazdar et al., 1990). Esta seleção foi realizada por meio da remoção de células não aderidas, através da remoção do meio de cultivo, para selecionar uma população de células que crescessem aderidas à superfície do frasco de cultura. Esta linhagem manteve as características de produção de hormônios observadas na NCI-H295 (Rodriguez et al., 1997). 
As células foram mantidas em meio RPMI (Gibco BRL, Life Technologies ${ }^{\circledR}$, Carlsbad, CA, USA) suplementado com 2\% de SBF, 1\% ITS (BD Biosciences, Bedford, MA, USA), $100 \mathrm{U} / \mathrm{mL}$ penicilina e $100 \mu \mathrm{g} / \mathrm{mL}$ estreptomicina, em atmosfera úmida contendo $5 \%$ de $\mathrm{CO}_{2}$ a $37^{\circ} \mathrm{C}$. Na realização dos experimentos, a contagem e o teste de viabilidade celular foram determinados utilizando o teste de exclusão do azul de Trypan.

\subsection{Preparação da droga}

Uma solução estoque de $1 \mathrm{mM}$ do inibidor de Aurora-quinase AMG900 (Selleckchem ${ }^{\circledR}$, USA) foi preparada em DMSO e estocada em alíquotas a $-80^{\circ} \mathrm{C}$. A cisplatina $\left(\right.$ Sigma $\left.{ }^{\circledR}\right)$ foi dissolvida em solução salina a $1,66 \mathrm{mmol} / 1$, e sonicada durante $1 \mathrm{~h}$ (Fischer et al., 2008). A Doxorrubicina (Sigma $\left.{ }^{\circledR}\right)$ e o Etoposídeo (Sigma ${ }^{\circledR}$ ) foram preparadas nas concentrações de com $40 \mathrm{mM}$ e $20 \mathrm{mM}$ em DMSO. Após a preparação, todas as soluções de estoque foram mantidas a $-20^{\circ} \mathrm{C}$. Todas as drogas foram adicionadas em meio de cultura completo imediatamente antes de serem aplicadas nas células. Todas as doses utilizadas estavam com a mesma quantidade de DMSO, 0,1\%, exceto para as células tratadas com cisplatina, a qual não possui efeitos citotóxicos.

\subsection{Ensaio de Proliferação celular}

O ensaio de proliferação celular foi realizado com através da técnica de coloração com o Giemsa, conforme publicação do nosso grupo (Castro-Gamero et al., 2012). Os efeitos do AMG-900 foram avaliados conforme Payton et al., 2010. As linhagens semeadas em placas de 96 poços $\left(6 \times 10^{3}\right)$ e após $48 \mathrm{~h}$ as células foram tratadas om o inibidor de Aurora-quinases AMG 900 (2,5-500nM). Após 48h de tratamento, as células foram lavadas com PBS e meio sem droga foi adicionado à cultura. A partir deste ponto, considerado o tempo 0, a proliferação celular foi avaliada nos tempos de 24, 48 e $72 \mathrm{~h}$. Para mensurar a proliferação celular, o meio de cultura foi removido, as células lavadas com PBS, fixadas com metanol absoluto e coradas com Giemsa a 1\%. Após a coloração, as células foram lavadas com água corrente e o corante dissolvido com metanol absoluto. A leitura da absorbância de $655 \mathrm{~nm}$ foi realizada utilizando o aparelho iMark Microplate Absorbance reader (BioRad Laboratories, Inc, CA, EUA). Os experimentos foram realizados em triplicata em três momentos diferentes. 


\subsection{Análise de Sinergismo entre drogas}

Para a análise do efeito da combinação das drogas utilizadas nos experimentos utilizouse o software CalcuSyn (Biosoft, Cambridge, U.K.). O efeito dessas combinações pode ser expresso como índice de combinação (CI). O CI é um método usado para quantificar o sinergismo causado pelos efeitos citotóxicos da combinação de diferentes drogas. Este método é baseado na lei da ação das massas e no principio do efeito-médio derivado de modelos de cinética enzimática desenvolvido por Chou e Talalay (Chou, 2006), sendo amplamente utilizado para a análise de interações de drogas, principalmente as antineoplásicas. Com o uso do CI, sinergismo é definido como um efeito aditivo mais que o esperado, enquanto que antagonismo é definido como um efeito aditivo menos que o esperado. Sendo assim, por meio desse método, um CI igual a 1 indica um efeito aditivo, um CI maior que 1 indica antagonismo, enquanto que um CI menor que 1 indica sinergismo (Chou, 2006).

\subsection{Ensaio de Apoptose}

O ensaio para detecção de morte celular foi realizado através da marcação de células apoptóticas com Anexina V - Isotiocianato de fluoresceína (FITC) (BD Biosciences Pharmigen, USA) e células necróticas com iodeto de propídio. Anexina V é uma molécula que apresenta alta afinidade pela fosfatidilserina, se ligando a esta especificamente. A fosfatidilserina é um fosfolipídio presente na face interna da membrana das células. Sua externalização ocorre durante o processo de apoptose e serve como um sinal para as células serem removidas. A marcação positiva com iodeto de propídio indica que as células perderam a integridade da membrana. Após o tratamento, $1 \times 10^{5}$ células foram tripsinizadas e centrifugadas a $1000 \mathrm{rpm}$ por $5 \mathrm{~min}$ a $4^{\circ} \mathrm{C}$, lavadas com PBS gelado e depois ressuspendidas em 300uL de tampão de ligação 1X (BD Biosciences Pharmigen, USA). As células foram então coradas com $5 \mu \mathrm{L}$ de anexina e $50 \mu \mathrm{L}$ de uma solução de iodeto de propídio (PI) e incubadas protegidas da luz em temperatura ambiente. As células foram analisadas com um citômetro de fluxo BD FACSCalibur ${ }^{\mathrm{TM}}$ (BD Biosciences, San Jose, CA, USA).

\subsection{Dosagem hormonal}

As dosagens dos hormônios D4, DHEA, DHEA-S e cortisol foram realizadas no Laboratório de Endocrinologia e Metabologia da Faculdade de Medicina de Ribeirão Preto da 
Universidade de São Paulo. Os procedimentos realizados foram os mesmos para a análise de amostras clínicas.

\subsection{Microarray}

Para análise do transcriptoma da linhagem H295A tratada ou não com o AMG 900 foram utilizadas lâminas de microarrays Whole Human Gene Expression microarrays kit (4x44 K) (Agilent Technologies, Santa Clara, CA, USA). Foi utilizada a metodologia monocolor Cy3 (cianina 3). Para a amplificação, marcação e hibridação dos mRNAs das amostras com os microarrays foi utilizada o Kit Agilent Quik Amp Labeling (Agilent Technologies, Santa Clara, CA, USA), seguindo as recomendações do fabricante. As etapas do procedimento de microarrays foram realizadas no Laboratório de Hematologia no Hospital das Clínicas da Faculdade de Medicina de Ribeirão Preto, Universidade de São Paulo (USP), Brasil.

Utilizou-se $1,65 \mu \mathrm{g}$ de cRNA para a reação de hibridação, o qual foi incubado por 30 minutos a $60^{\circ} \mathrm{C}$ juntamente com 10X Blocking Agent, 25X Fragmentation Buffer e água livre de RNAse/DNase para obtenção de cRNA fragmentado. Este foi em seguida hibridado às lâminas, as quais foram em seguida incubadas em estufa a $65^{\circ} \mathrm{C}$ e submetidas a 10 rotações por minuto por 17 horas Após a lavagem e a secagem das lâminas, estas foram escaneada utilizando o software GenePix Pro 6.0 e um scanner GenePix 4000B (Axon Instruments, Foster City, CA, USA), seguindo recomendações do fabricante das lâminas.

Os valores de intensidade de sinal, referentes às hibridações das amostras de RNA com as sondas de cDNA presentes nas lâminas de microarranjos, foram processados pelo software do fabricante e o produto final dos cálculos de normalização para cada sonda ( "gProcessedSignal") foram utilizados nas análises subseqüentes de expressão diferencial. O método SAM (Significance Analysis of Microarrays) (Tusher et al., 2001, PMID: 11309499) pareado com permutações (100) foi aplicado para a identificação dos genes diferencialmente expressos. Foram atribuídos limites mínimo de 2 FC (Fold Change) e máximo de 1\% FDR (False Discovery Rate) com o intuito de obter resultados mais acurados e significativos.

\subsection{Categorização dos genes diferencialmente expressos}

Os genes diferencialmente expressos identificados na análise prévia foram categorizados com base nos processos biológicos aos quais fazem parte através do programa 
David Bioinformatic (Huang et a., 2009). Os genes sem nome foram excluídos dessa categorização bem como os grupos onde apresentaram menos de cinco genes. Finalmente, foram selecionados os grupos com EASE (valor de p de Fisher exato modificado) de 0,05 ou menos.

\subsection{Análise estatística}

A análise estatística foi realizada com o auxílio dos softwares (Graph Prism 5.0 (GraphPad Software, San Diego, CA, USA) e SPSS 15.0 (SPSS Inc. Chicago, USA). A associação entre as variáveis analisas (idade ( $<$ versus $\geq 4$ years), tamanho $<$ versus $\geq 200 \mathrm{~cm}^{3}$ e peso do tumor (< versus $\geq 100 \mathrm{~g}$ ), mutação do gene TP53 p.R337H (positive versus negative), estadiamento e evolução clínica ( $<3$ versus critério de Weiss $\geq 3$ ) e os níveis de expressão gênica foi avaliada utilizando-se o teste de Mann-Whitney. Sobrevida global, considerada da data do diagnóstico até a data do óbito ou do último retorno, foi analisada pelas curvas de Kaplan-Meier e comparadas pelo teste long-rank para as diferentes variáveis analisadas. A correlação entre os genes estudados foi analisada pelo teste de correlação de Spearman. Valoes de $\mathrm{p} \leq 0.05$ foram considerados como significantes. Para os ensaios com cultura células foi realizada One Way ANOVA seguido pelo teste de Bonferroni. 


\section{RESULTADOS}

\subsection{Resultados Clínicos e patológicos}

Foram avaliados 46 pacientes do sexo feminino e 14 do sexo masculino, com média de idade ao diagnóstico de 40.5 meses (variação de 5-187 meses). Cinquenta e sete pacientes apresentaram secreção de hormônios: 37 tumores secretores de andrógenos, 18 tumores mistos secretores de cortisol e andrógenos, 2 tumores secretores de cortisol, 2 tumores não secretavam hormônios e um não tinha dados disponíveis. Trinta e cinco pacientes foram classificados como estadio I, 10 como estadio II, 8 como estadio III e 7 como estadio IV. A mutação do TP53 p.R337H foi encontrada em 52/60 (86.6\%) dos pacientes com TAC. Quarenta e seis pacientes (76,6\%) apresentaram escore de classificação de Weiss $\geq 3,13$ escores $<3$ e 1 apresentou escore indeterminado. O tempo de seguimento variou de 8 a 168 meses com mediana de 68.3 meses. Foi perdido o seguimento de três pacientes (Anexo I).

\subsection{Expressão dos genes Aurora-A e Aurora-B e características clínicas e biológicas}

A comparação da expressão dos genes Aurora-A e Aurora-B dos tecidos adrenais nãoneoplásicos com os tecidos neoplásicos não evidenciou nenhuma diferença estatística (Aurora- $A$ $(\mathrm{p}=0.09)$ e Aurora- $B(\mathrm{p}=0.437)$ (Figura 6A e B). Uma correlação positiva foi observada entre a expressão dos genes Aurora-A e Aurora-B (coeficiente de correlação 0.496, p<0.001).
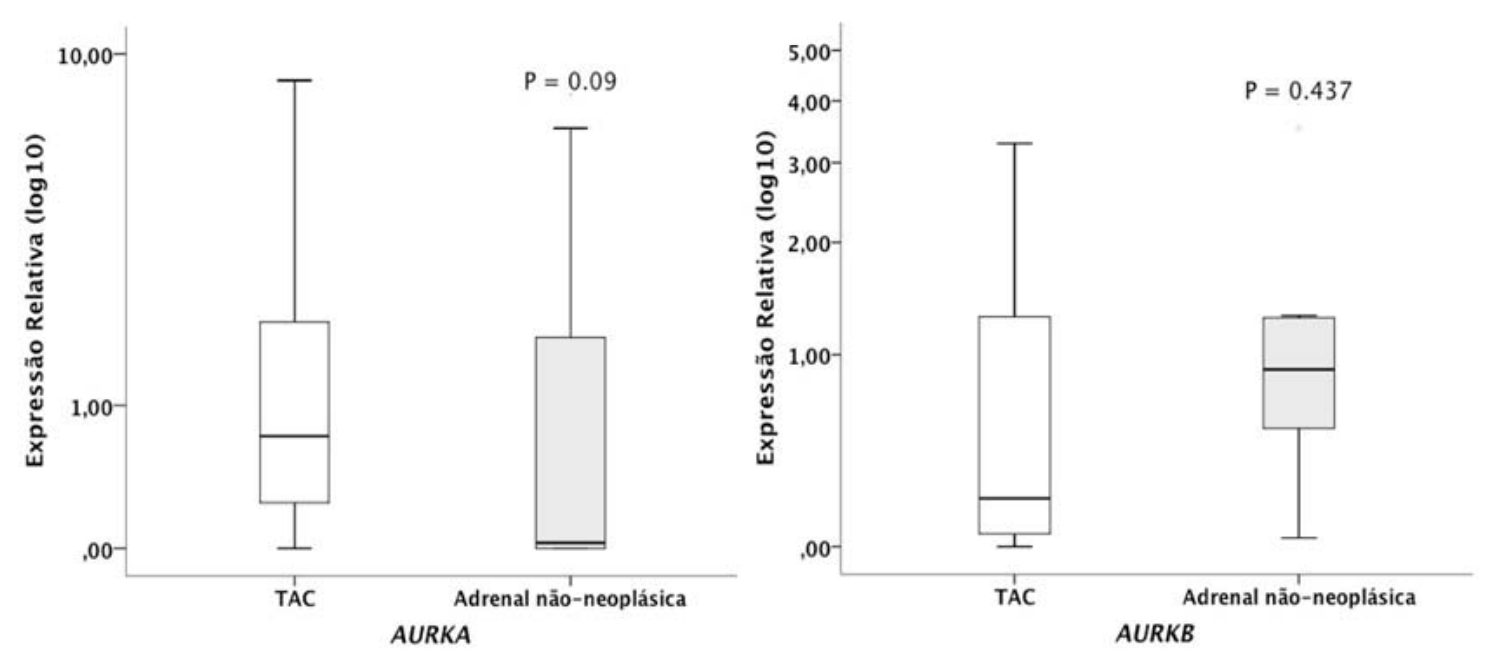

Figura 6 - Perfil da expressão gênica do Aurora-A e do Aurora-B em amostras de tumores adrenocorticais e tecido adrenal não neoplásico pediátricos. (A) AURKA=Aurora-A (B) AURKB=Aurora-B. As linhas correspondem à mediana dos valores de expressão. Resultados apresentados como $\log 10$ e como fold change. Significância obtida através do teste de Mann-Whitney. 
Uma elevada expressão dos genes Aurora- $A$ ( 2 vezes, $\mathrm{p}=0.01$ ) e Aurora- $B$ ( 7 vezes, $\mathrm{p}=0.01$ ) foi observada em TAC com escore histopatológico de Weiss $\geq 3$ (Figura 7A e B). Pacientes que apresentaram evento desfavorável (recaída e/ou óbito) apresentaram níveis elevados de expressão dos genes Aurora- $A$ ( 6 vezes, $\mathrm{p}=0.034$ ) e Aurora- $B$ ( 7 vezes, $\mathrm{p}=0.02$ ) (Figura 7C e D). Pacientes com a mutação do TP53 p.R337H apresentaram um elevada expressão do gene Aurora- $A$ (8,5 vezes, $\mathrm{p}=0.014)$ e níveis elevados de expressão do Aurora- $A$ (4,8 vezes, $\mathrm{p}=0.04)$ foram associados com óbito (Figura $7 \mathbf{E}$ e $\mathbf{F})$.
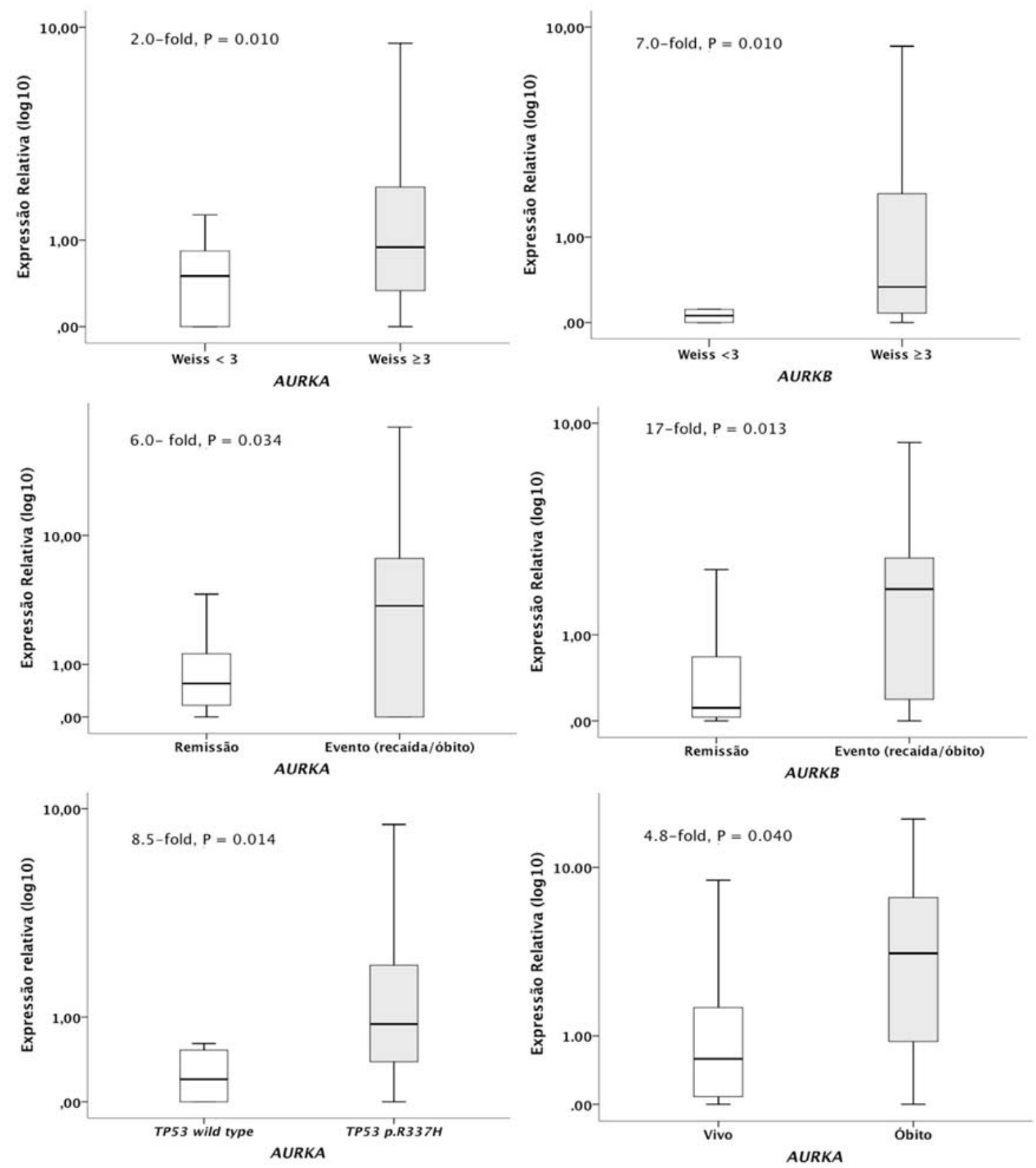

Figura 7 - Perfil da expressão gênica nas amostras de TAC de acordo com o escore de Weiss, Aurora-A (A) e Aurora-B (B); de acordo com evento, Aurora-A (C) e Aurora-B (D); de acordo com a presença da mutação TP53 R337H, Aurora-A (E) e de acordo com sobrevida Aurora-A (F). AURKA=Aurora-A e AURKB=Aurora-B. As linhas correspondem à mediana dos valores de expressão. Resultados apresentados como $\log 10$ e como fold change. Significância obtida através do teste de Mann-Whitney. 
Com o objetivo de analisar a possível relação entre os níveis de expressão destes genes com a sobrevida livre de eventos em 5 anos, os pacientes foram divididos em dois grupos. Pacientes que expressaram o gene duas vezes mais que a mediana de expressão do tecido nãoneoplásico foram considerados com expressão elevada ao passo que os que expressaram duas vezes menos que a mediana foram considerados com expressão reduzida. Valores de expressão acima da mediana para o gene Aurora- $A$ foram associados com baixa sobrevida livre de eventos em 5 anos (34.3. $\pm 13.1 \%$ vs. 82.6 $\pm 6.6, p=0.0001)$ (Figura 8A), com um alto risco de um evento desfavorável (HR: 6.822, 95\% CI: 2.400-19.394, p<0.0001). Valores de expressão acima da mediana para o gene Aurora-B também foram associados com baixa sobrevida livre de eventos em 5 anos $(40.0 \% \pm 15.5 \%$ vs. $77.5 \% \pm 6.8 \%, \mathrm{P}=0.006)$ (Figura 8B), com um alto risco de um evento desfavorável (HR: 2.799, 95\% CI: 1.350-10.687, $\mathrm{p}=0.01)$.

A análise multivariável mostrou que a elevada expressão do Aurora-A foi um fator independente de prognóstico desfavorável $(\mathrm{p}=0.02)$ quando analisado em combinação com estadio IV, idade $>4$ anos, tamanho do tumor $\geq 200 \mathrm{~cm}^{3}$. Excluindo o Aurora- $A$ do modelo, o Aurora-B também foi um fator prognóstico ( $\mathrm{p}=0.026$; HR: 3.624, 95\% CI: 1.160-11.382) quando analisado em combinação com peso do tumor $\geq 100 \mathrm{~g} \mathrm{p}=0.030$, HR: $6.211,95 \% \mathrm{CI}$ : 1.195-32.280), idade $>4$ anos $(p=0.574)$, estadio IV $(p=0.294)$ e tamanho do tumor $\geq 200 \mathrm{~cm}^{3}(\mathrm{p}=0.898)$.

Quando somente pacientes com escore de Weiss $\geq 3$ foram analisados, a elevada expressão do Aurora-A (5.3 vezes, $\mathrm{p}=0.044)$ and Aurora-B $(9.3$ vezes, $\mathrm{p}=0.016)$ foram observados em pacientes com evento desfavorável. Neste grupo, elevada expressão do Aurora- $A$ foi associada com uma baixa SLE em 5 anos $(34.3 \pm 13.1 \%$ vs. $73.4 \pm 9.6 \%$, p = 0.002) (Figura 8C) e um alto risco de um evento desfavorável (HR: 4.476, 95\% CI: 1.58012.678, $\mathrm{p}=0.005$ ). A elevada expressão do Aurora-B foi também associada com uma baixa SLE em 5 anos $(33.3 \pm 15.7 \%$ vs. $68.8 \pm 9.0 \%, \mathrm{p}=0.020)$ (Figura 8D) e um alto risco de um evento desfavorável (HR: 3.184, 95\% CI: 1.132-8.958, $\mathrm{p}=0.028)$. A análise multivariável mostrou que a elevada expressão do Aurora- $A$ foi um fator independente de prognóstico desfavorável ( $\mathrm{p}=0.004$, HR: 5.454, 95\% CI: $1.734-17.152)$ e o Aurora-B também $(\mathrm{P}=$ 0.036; HR: 3.338, 95\% CI: 1.080-10.276) quando analisado em combinação com idade, estádio IV, peso do tumor $\geq 100$ g e tamanho do tumor $\geq 200$. 
A
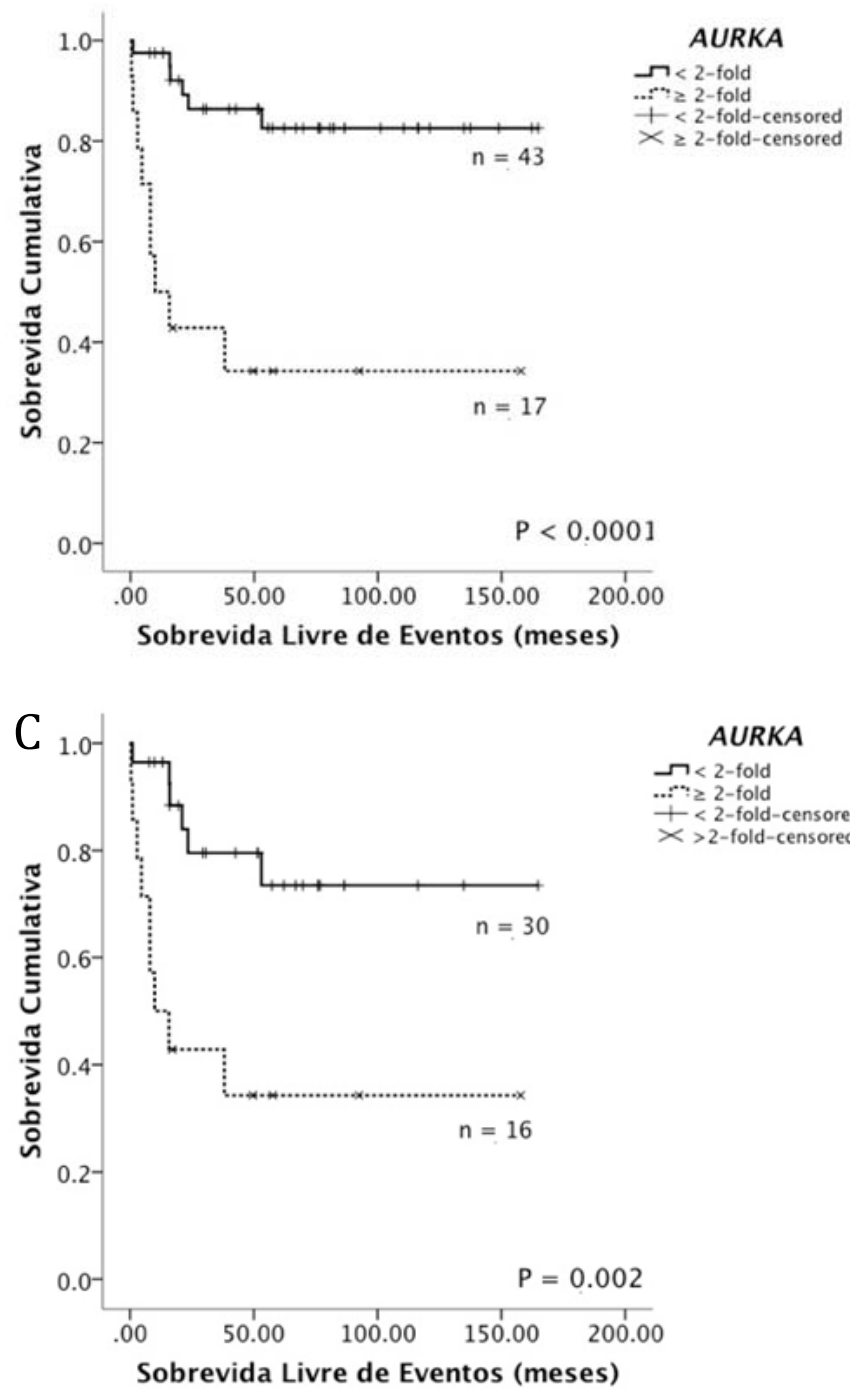

B

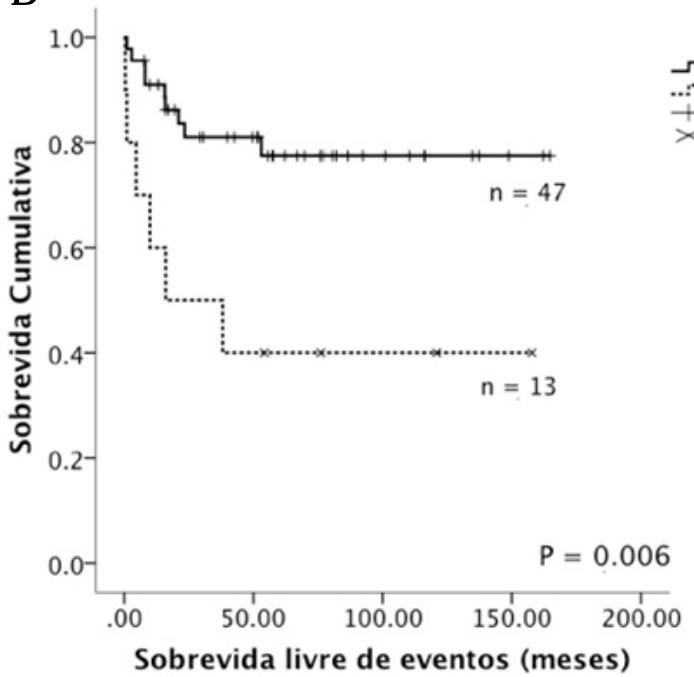

$\mathrm{D}$

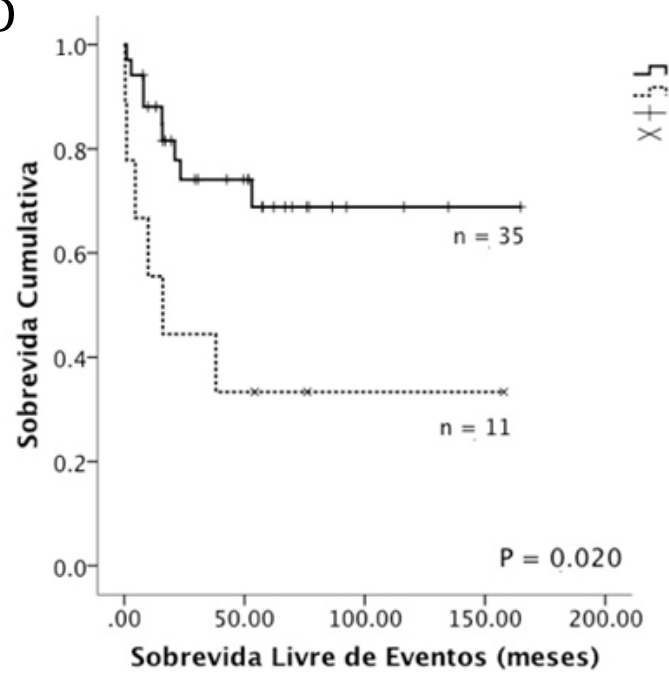

Figura 8 - Sobrevida Livre de Eventos (SLE) de acordo com a expressão relativa de duas vezes acima ou abaixo da me diana de expressão no tecido não-neoplásico. Sobrevida Geral: Aurora-A (A) e Aurora-B (B) e sobrevida no grupo de pacientes com TAC com Weiss $\geq 3$ : Aurora-A (C) e Aurora-B (D). AURKA=Aurora-A e $\mathrm{AURKB}=$ Aurora-B. Testes realizados através da análise de Kaplan-Meyer.

\subsection{A expressão proteica da Aurora-A e da Aurora-B no tecido adrenal tumoral}

A expressão da Aurora-A e da Aurora-B foi avaliada por imuno-histoquímica e os resultados foram semelhantes aos observados quando se utilizou RQ-PCR . Quarenta e oito amostras $(85,4 \%)$ de TAC foram analisadas e apresentaram imunomarcação para a Aurora-A. Em 12 casos (25\%) a imunomarcação foi classificada como forte, em 17 casos $(35,4 \%)$ como moderada, em 12 (25\%) como fraco e em 7 (14,6 \%) foi negativa. Quanto à Aurora-B, a imunomarcação foi positiva em 37 das 48 (77,8\%) amostras do TAC. Seis (12,5\%) tumores apresentaram imunomarcação classificada como forte, $16(35,5 \%)$ como moderada, 15 
$(31,2 \%)$ como fraco e $8(16,6 \%)$ apresentaram imunomarcação negativa ou fraca, em três casos $(6,2 \%)$ o resultado foi inconclusivo devido a uma intensa coloração de fundo e foram excluídos da análise . Os casos foram interpretados como Aurora-A e Aurora-B positivo se as células neoplásicas apresentaram marcação moderada ou forte. No grupo com positividade para a proteína Aurora-A a mediana da expressão relativa do RNAm foi de 1,17 (média: 2,71, intervalo: 0,00-16,94 ) e no grupo com fraca/negativa expressão da proteína Aurora-A a mediana da expressão relativa foi de 0,50 (média: 0,97, intervalo: 0,00-8,67 ) $(\mathrm{p}=0,040)$. No grupo com positividade para a proteína Aurora-B a mediana da expressão relativa do mRNA detectado por RQ-PCR foi de 0,24 (média: 2,44, intervalo: 0,00-25,75 ) e no grupo com fraca expressão/negativo a mediana foi de 0,06 (média: 0,67, intervalo: 0,00-8,41 ) $(\mathrm{P}=0,010)$. Uma figura representativa da marcação da Aurora-A e da Aurora-B através da imunohistoquímica é mostrado na Figura 8.

A SLE em 5 anos foi menor nos pacientes com imunomarcação forte/moderada para a Aurora-A $(55,2 \pm 10,5 \%$ vs $94,4 \pm 5,4 \%, p=0,012)$, com um maior risco de um evento desfavorável (HR: 8,717, IC 95\%: 1.123 -67,692, P = 0,038). Pacientes com imunomarcação forte/moderada para a Aurora-B tiveram uma menor SLE em 5 anos (53,2 $\pm 11,9 \%$ vs 84,8 \pm $8,1 \%, p=0,045$ ) e um maior risco de um evento desfavorável (HR: 3,487, IC 95\%:,94212,909, p = 0,061) (Anexo II).
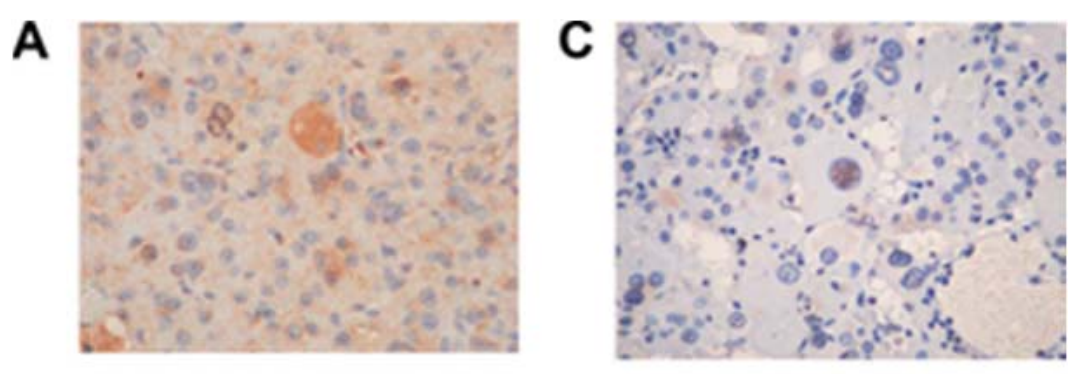

B
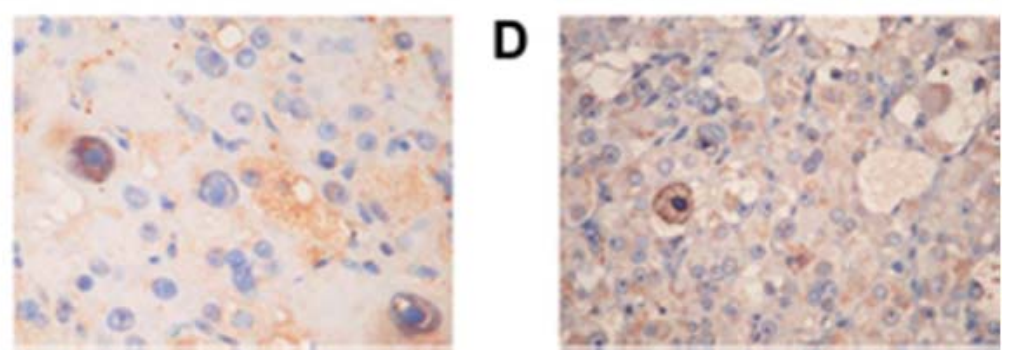

Figura 9 - Microfotografias representativas da técnica de imuno-histoquímica para a Aurora-A e para a Aurora-B nos tumores adrenocorticais pediátricos. Células tumorais apresentando marcação citoplasmática e nuclear positiva para a Aurora-A (A e B) e Aurora-B (C e D). (400x). 


\subsection{Efeitos do AMG 900 isolado ou combinado com quimioterápicos na proliferação celular}

A Figura 10 mostra o efeito do AMG-900 na proliferação da linhagem de carcinoma de adrenal H295A. A linhagem foi tratada com as doses de 2,5-500nM nos tempos de 24, 48 e 72h. A linhagem foi sensível à ação da droga, sofrendo inibição na proliferação. A partir da dose de $5 \mathrm{nM}$ todas as doses apresentaram efeito significativo na proliferação celular em todos os tempos avaliados $(\mathrm{p}<0,05)$. Não foi observado um efeito tempo dependente significativo e o efeito máximo de inibição da proliferação observado foi de $40 \%$.

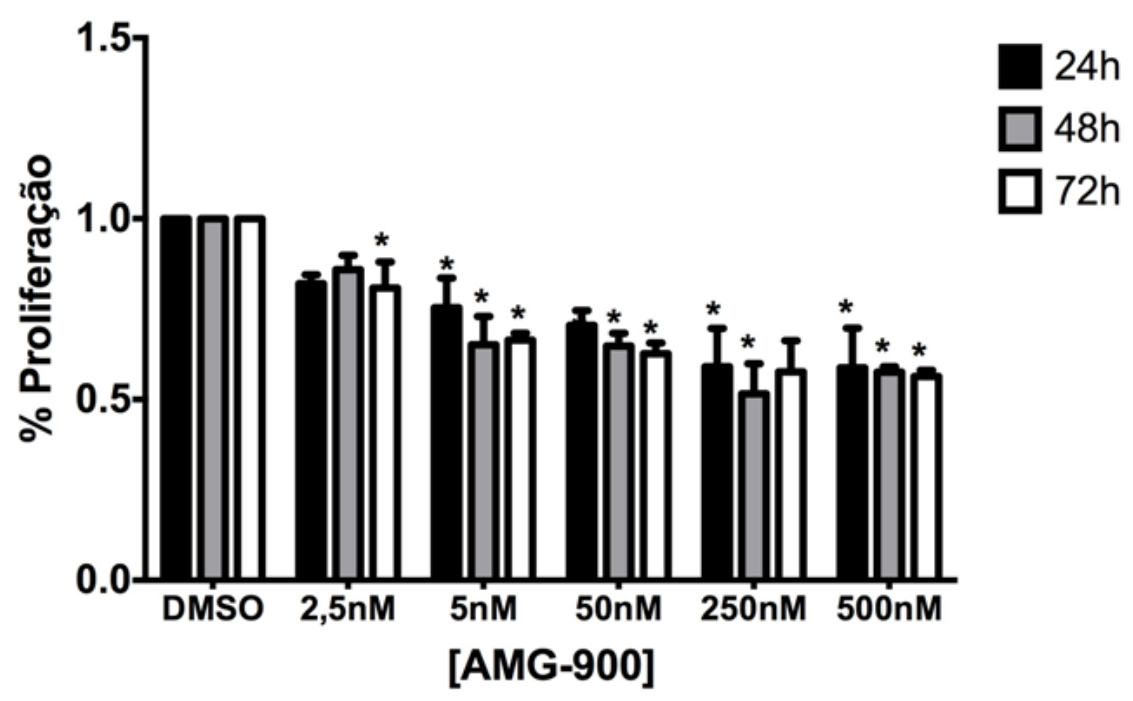

Figura 10 - Efeito do inibidor de AMG900 na proliferação da linhagem NCI-H295A. *p<0.05. Teste Oneway ANOVA com pós-teste de Bonferroni

Com o intuito de investigar a capacidade do AMG 900 de sensibilizar as células para a ação de outros quimioterápicos, testes de proliferação celular foram realizados com os quimioterápicos etoposídeo (ETO), doxorrubicina (DX) e cisplatina (CIS) após 48h de incubação, para assim definir as doses para a combinação de drogas.

O etoposídeo causou um pequeno efeito na proliferação da linhagem H295A, com a maior dose inibindo apenas 20\% (Figura 11A). Por outro lado, a doxorrubicina afetou a proliferação da linhagem desde a dose de $25 \mu \mathrm{M}$, chegando a uma inibição da proliferação de $35 \%$ na dose de $100 \mu \mathrm{M}$ (Figura 11B). A cisplatina também afetou a proliferação da linhagem H295A, principalmente nas doses de 7,5 e $10 \mu \mathrm{M}$, alcançando um efeito máximo de $40 \%$ de inibição da proliferação (Figura 11C). 

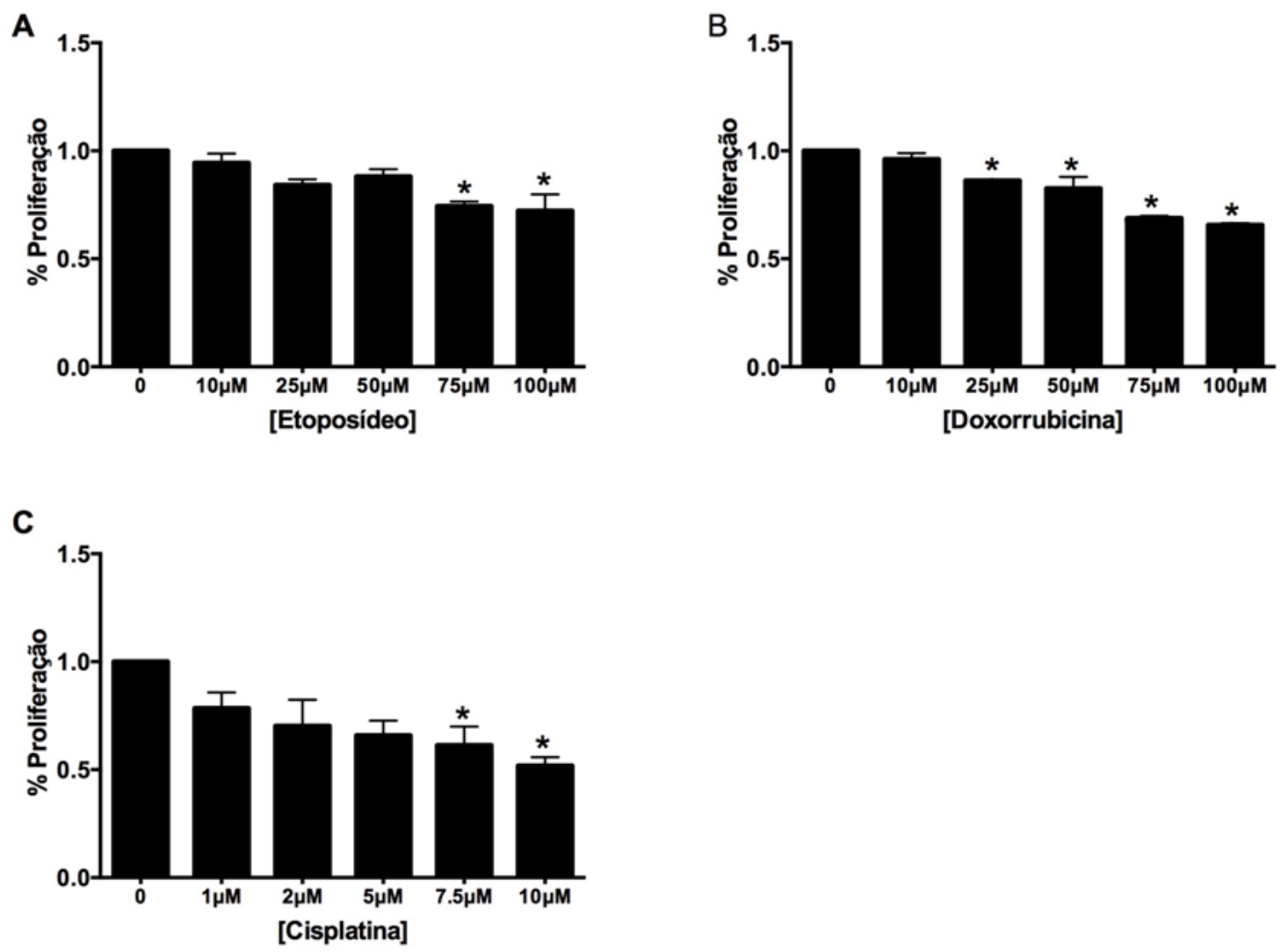

Figura 11 - Efeito de diferentes quimioterápicos na proliferação da linhagem NCI-H295A. (A) Etoposideo. (B) Doxorrubicina. (C) Cisplatina. * $<0.05$. Teste One-way ANOVA com pós-teste de Bonferroni.

Para a combinação, uma dose do AMG 900 foi selecionada pare ser combinada com três diferentes doses de cada quimioterápico, originando assim três pontos de combinação (Tabela II). Uma vez que não houve um efeito dose-dependente da droga AMG 900 e devido à inexistência de uma atividade de inibição de $50 \%$ da proliferação desta droga, a dose de 50nM foi estabelecida por ser uma dose intermediária na curva de proliferação. Além disso, trabalhos anteriores já mostraram que esta dose é efetiva na inibição da atividade das auroraquinases (Payton et al., 2010). No caso dos quimioterápicos, como também não foi observado um efeito que alcançasse valores de IC50, três doses da curva de proliferação de cada agente foi selecionada: a menor dose, a intermediária e a maior dose.

Baseado nessas doses, um esquema de combinação sequencial foi seguido. A linhagem de carcinoma de adrenal foi tratada por 48h com o AMG900, em seguida o meio de cultura foi substituído por meio contendo os quimioterápicos por mais $48 \mathrm{~h}$. Por fim, a proliferação foi avaliada e os dados analisados através do programa Calcusyn. 
Tabela 2 - Esquema de combinação de drogas*

\begin{tabular}{|c|c|c|}
\hline \multirow{4}{*}{ 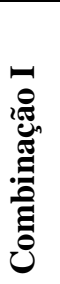 } & AMG900 & Etoposídeo (ETO) \\
\hline & $50 \mathrm{nM}$ & $25 \mu \mathrm{M}$ \\
\hline & $50 \mathrm{nM}$ & $50 \mu \mathrm{M}$ \\
\hline & $50 \mathrm{nM}$ & $100 \mu \mathrm{M}$ \\
\hline \multirow{4}{*}{ 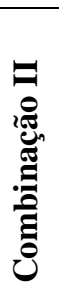 } & AMG900 & Doxorrubicina (DX) \\
\hline & $50 \mathrm{nM}$ & $10 \mu \mathrm{M}$ \\
\hline & $50 \mathrm{nM}$ & $50 \mu \mathrm{M}$ \\
\hline & $50 \mathrm{nM}$ & $100 \mu \mathrm{M}$ \\
\hline \multirow{4}{*}{ 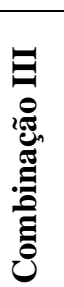 } & AMG900 & Cisplatina (CIS) \\
\hline & 50nM & $25 \mu \mathrm{M}$ \\
\hline & $50 \mathrm{nM}$ & $50 \mu \mathrm{M}$ \\
\hline & $50 \mathrm{nM}$ & $100 \mu \mathrm{M}$ \\
\hline
\end{tabular}

Fig. 12.

Como é possível observar na Figura 12A e B, a combinação do AMG 900 com os quimioterápicos ETO e CIS não mostrou nenhum efeito sinérgico e os três pontos de combinação se apresentaram com CI $>1$, indicando efeito antagônico. Observa-se que as maiores doses (pontos número 3) apresentaram-se mais próximas do valor de 1, ou seja, doses maiores das drogas exibiram valores mais próximos do sinergismo.

Na combinação do AMG 900 com a DX, houve sinergismo uma vez que os pontos de combinação exibiram valores de $\mathrm{CI}<1$. Tal efeito foi independente das doses utilizadas, ou seja, mesmo a menor dose foi sinérgica ao ser combinada com o AMG 900. 

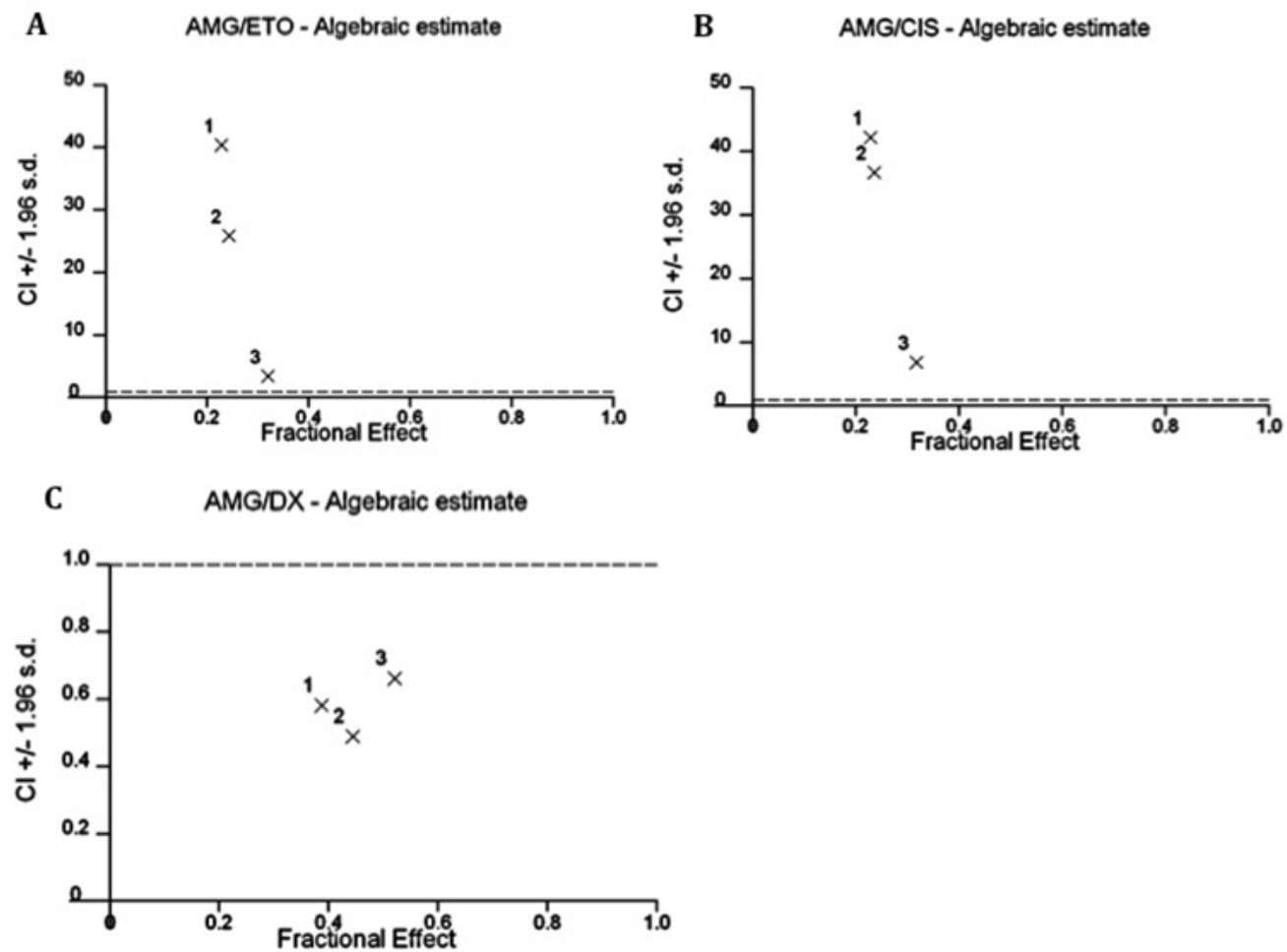

Figura 12 - Representação gráfica da combinação do AMG900 com os quimioterápicos. Etoposídeo (A), Cisplatina (B) e Doxorrubicina (D). Cada x representa um ponto de combinação. Pontos (x) acima da linha pontilhada, que representao número 1 , indicam antagonismo $(\mathrm{CI}>1=$ antagonismo) e pontos abaixo desta linha são considerados sinérgicos $(\mathrm{CI}<1=$ sinergismo $)$.

\subsection{Efeitos do AMG 900 isolado ou combinado com quimioterápicos na indução de apoptose}

Para avaliar se os efeitos citotóxicos encontrados não representavam somente diminuição da proliferação celular, foi avaliada a porcentagem de células apoptóticas após tratamento com o inibidor de aurora-quinases. As células foram tratadas com as diferentes doses de AMG 900 (5-500nM) por 48h. Foi observada uma indução significativa de apoptose a partir da dose de $5 \mathrm{nM}$ e essa indução alcançou um efeito máximo de $30 \%$ nas doses de 50 e $500 \mathrm{nM}(\mathrm{p}<0.05)$ (Figura 13A).

Após constatar a capacidade de indução de apoptose do inibidor de aurora-quinases, foi avaliada se a combinação do AMG 900 com os quimioterápicos ETO, DX e CIS alteraria o padrão de morte celular antes encontrada. A dose utilizada para o AMG 900 nesta combinação foi a mesma utilizada na combinação realizada com o ensaio de proliferação. Para os quimioterápicos foram selecionadas doses que apresentaram efeitos significativos na proliferação, 100, 50 e $10 \mu \mathrm{M}$ para o ETO, DX e CIS, respectivamente. 
É possível observar na Figura 13C que como na proliferação, a combinação do AMG 900 com a CIS não causou uma intensificação dos efeitos observados quando as drogas foram administradas isoladamente. Resultados coincidentes com a proliferação também foram observados na combinação do AMG900 com a DX (Figura 13D), uma vez que a porcentagem de células apoptóticas foi significativamente maior nas drogas combinadas do que nas drogas de forma isolada $(\mathrm{p}<0.05)$. Entretanto, um resultado foi discordante do obtido na proliferação, na combinação do AMG900 com o ETO observou-se uma indução maior de apoptose do que o causado pelas drogas separadamente (Figura 13B).
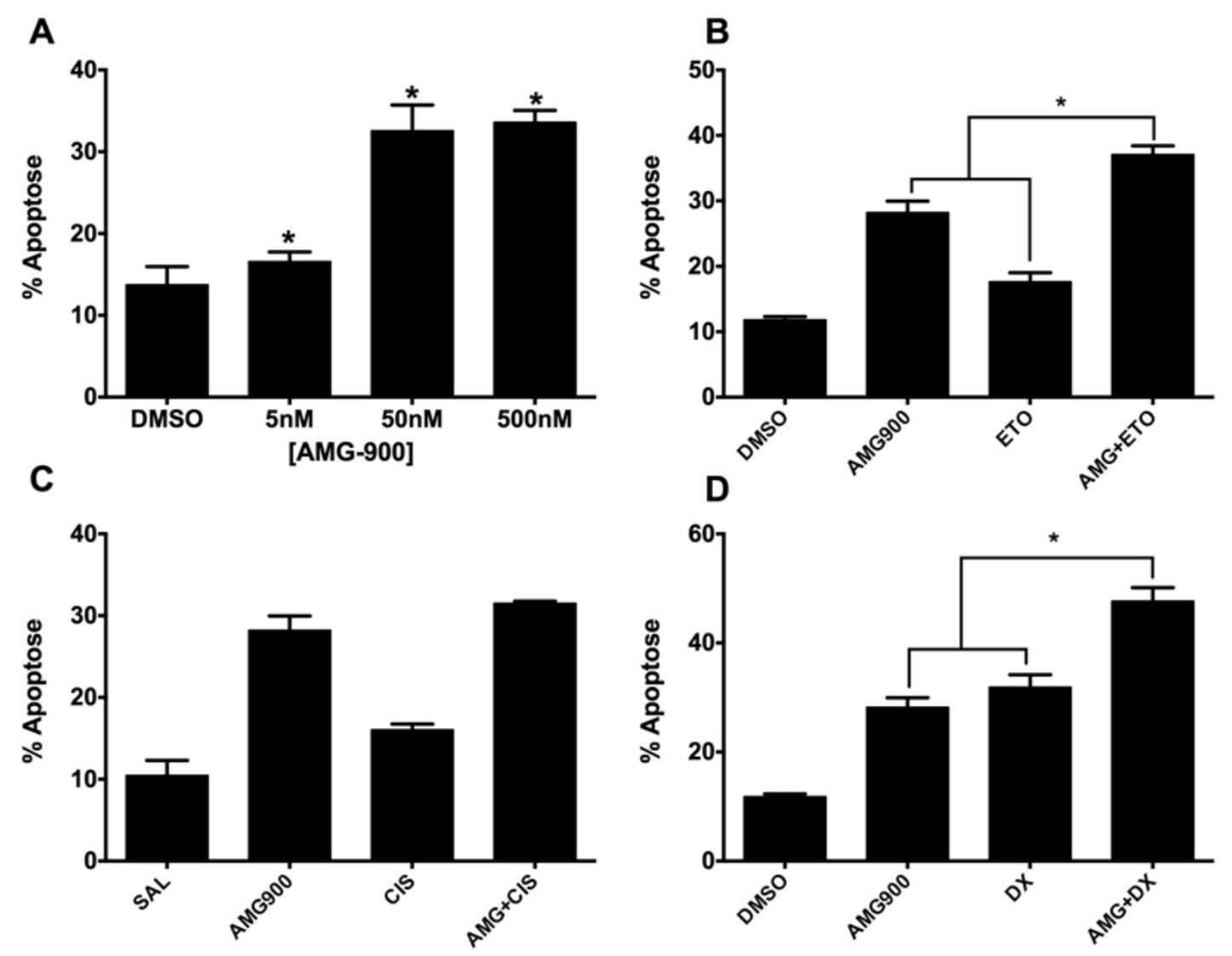

Figura 13 - Efeitos do AMG900 isolado (A) ou combinado com etoposídeo (B), cisplatina (C) ou doxorrubicina (D) na indução de apoptose. SAL=salina. ${ }^{*} \mathrm{p}<0,05$. Teste One-way ANOVA com pós-teste de Bonferroni.

\subsection{Efeito do AMG 900 na síntese de hormônios sintetizados pela linhagem H295A}

Para determinar se a inibição das aurora-quinases causada pelo AMG 900 poderia afetar a síntese de hormônios da linhagem H295A, foi realizada a dosagem dos hormônios: o sulfato de Dehidroepiandrosterona (DHEA-S), o 4-androstenediona (D4), a testosterona e o cortisol. 
Baseando-se no artigo que descreveu os efeitos do AMG-900 (Payton et al., 2010), dois tempos foram analisados neste experimento. No tempo 1, as células foram expostas à droga por 48h. No tempo 2, as células foram expostas ao AMG-900 às mesmas 48h, entretanto, após este tempo, as células foram lavadas e meio de cultura sem droga foi adicionado para a incubação por mais $48 \mathrm{~h}$. Em ambos os tempos a dose de 50nM foi testada na linhagem.

Conforme o resultado mostrado na Figura 14, o tratamento com o AMG900 diminuiu a síntese dos quatro hormônios estudados quando comparado com as células que foram tratadas com o veículo (DMSO). Em todos os casos ficou claro que no tempo 2 a inibição da síntese de hormônios foi mais intensa, causando uma diminuição da quantidade de hormônios no meio de cultura de aproximadamente 4 vezes para o DHEA-S e o D4 e de aproximadamente 6 vezes e 15 vezes para a testosterona e para o cortisol, respectivamente.
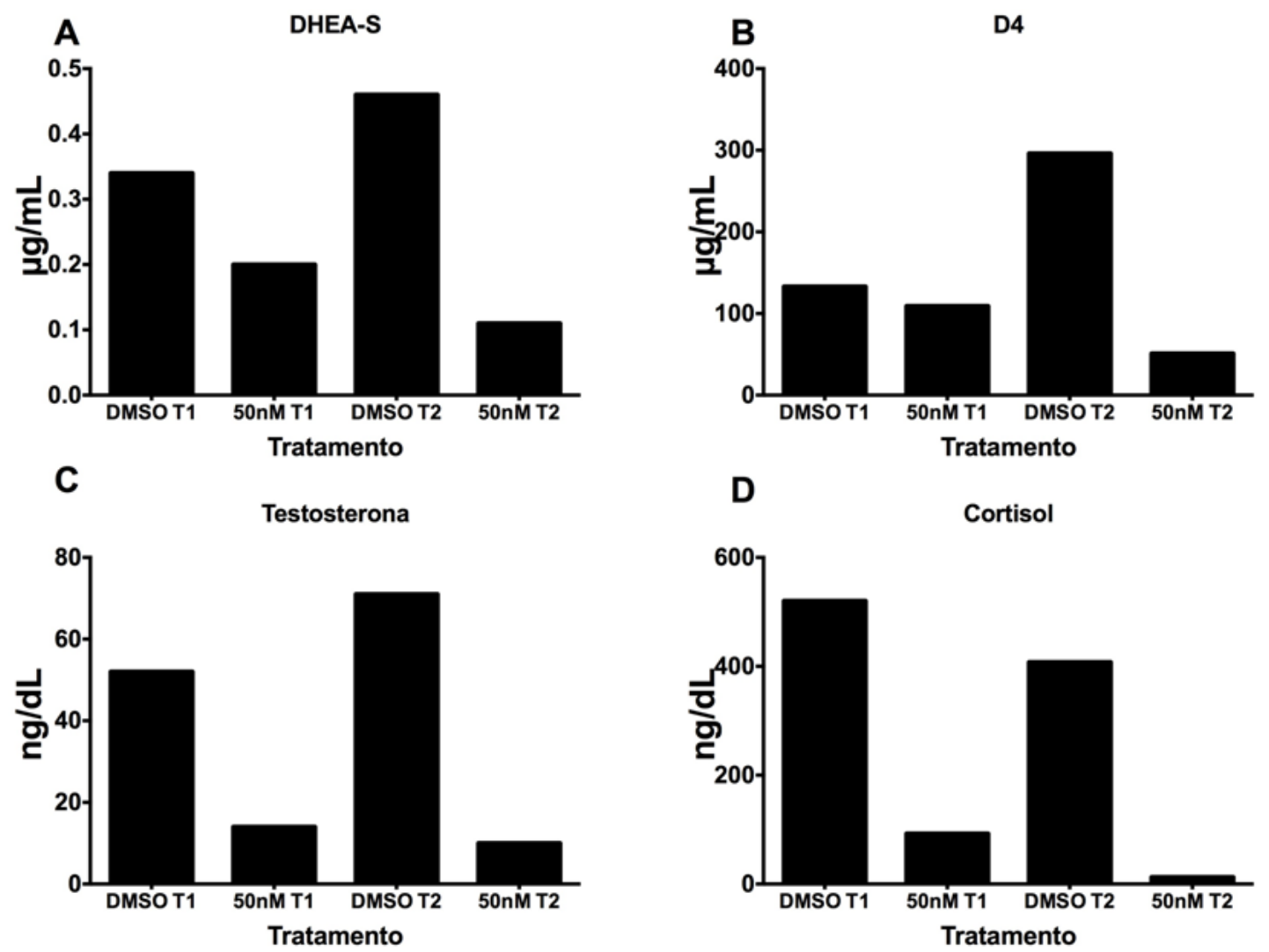

Figura 14 - Efeitos do AMG900 na síntese de hormônios sintetizados pala H295A. (A) Sulfato de dehidroepiandrosterona (DHEA-S), (B) 4-androstenediona (D4), (C) testosterona (D) cortisol. T1: 48h de exposição. T2: $48 \mathrm{~h}$ de exposição mais $48 \mathrm{~h}$ de incubação com meio de cultura livre de droga. 


\subsection{Efeitos do AMG 900 na expressão dos genes TP53, p21 e GDF15}

Com objetivo de investigar mecanismos moleculares desencadeados pela atividade do inibidor de aurora-quinases na linhagem H295A, foi estudada a expressão gênica do TP53, do p21 e do GDF15 após o tratamento com o AMG 900. Além de explorar os efeitos desta droga, este ensaio foi importante para padronizar o tempo de exposição e a dose do AMG 900 para as posteriores análises de microarray. O aumento da expressão destes genes está associado à resposta aos inibidores de aurora-quinases (Gizatullin et al., 2006; Li et al., 2009; Bosotti et al., 2012).

O esquema de tratamento foi o mesmo utilizado para a dosagem de hormônios, entretanto com as doses de 5, 50 e 500nM. Os genes TP53 e GDF 15 foram testados nos dois tempos e o gene $p 21$ foi testado somente no tempo 2 .

No tempo 1 não foi observada alteração na expressão do TP53 na linhagem estudada (Figura 15A). Por outro lado, um aumento acentuado da expressão deste gene de aproximadamente 6 vezes foi observado no tempo 2 e se manteve igual em todas as doses.

No caso do gene $G D F 15$, a expressão do gene manteve-se inalterada após o tratamento do tempo 1 (Figura 15B). No tempo 2 observou-se que a expressão deste gene aumentou aproximadamente 6 vezes na dose de $50 \mathrm{nM}$ e depois caiu para 3 vezes na dose de $500 \mathrm{nM}$.

A análise da expressão do $p 21$ no tempo 2 foi semelhante aos dados descritos acima. A linhagem apresentou um aumento da expressão de 6 vezes para este gene na dose de $50 \mathrm{nM}$, mas apresentou uma queda na expressão na dose de 500nM comparada com a dose de $50 \mathrm{nM}$ (Figura 15C).

Baseado nestes dados a dose de 50nM e o tempo foram selecionados para o estudo expressão gênica por microarranjos de cDNA. 

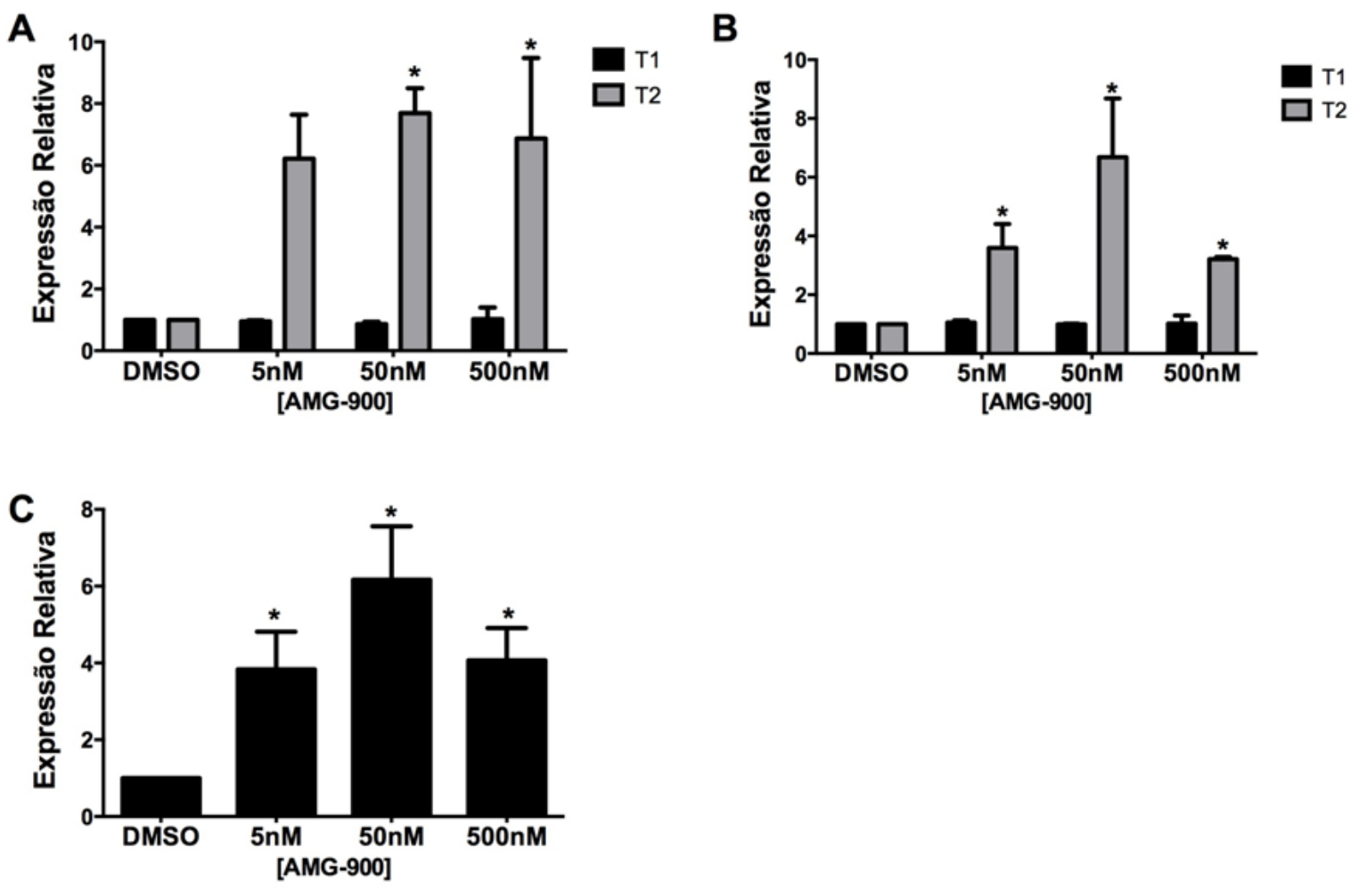

Figura 15 - Expressão relativa dos genes TP53 (A), GDF15 (B) e p21 (C) na linhagem H295A após o tratamento com o AMG-900. Tempo 1: 48h de exposição. Tempo 2: 48h de exposição mais 48h de incubação com meio de cultura livre de droga.

\subsection{Perfis de expressão gênica por microarranjos de cDNA}

Para a análise de microarray, foram utilizados RNAs provenientes da linhagem H295A tratada com DMSO (controle) ou com o AMG900 (50nM, tempo 2) em duplicata, totalizando um total de 4 hibridações.

Devido ao pequeno número de réplicas experimentais, os níveis de expressão e o (foldchange) em relação à amostra controle (DMSO) foram definidos como critério para categorizar os genes diferencialmente expressos. Para isso, foram selecionados todos os genes com FC $>2.0$ (induzidos) e todos com FC $<0.5$ (reprimidos) a partir do output da análise SAM. Esta análise revelou 697 genes induzidos e 503 reprimidos nas células tratadas com o AMG900 em relação ao controle.

Para a avaliação do efeito global do tratamento com o AMG900 nos diferentes processos bioloógicos, os genes diferencialmente expressos foram agrupados de acordo com suas funções biológicas utilizando-se a programa DAVID (Huang et al., 2009). A análise de vias de sinalização celular foi realizada a partir da lista de genes modulados com o intuito de complementar os resultados já obtidos. Essa análise auxiliou na visualização geral dos genes 
diferencialmente expressos considerando suas interrelações biológicas. Como resultado, oito processos biológicos associados aos genes foram escolhidos (Tabela III) por apresentarem importante relação com a biologia do carcinoma adrenocortical.

Dentre os processos biológicos identificados o de metabolismo de hormônios apresentou o maior número de grupos, seguido pelos processos envolvidos com as vias do AMP cíclico, a via Notch e a via do TGF $\beta$. Genes envolvidos com a regulação da proliferação celular também foram significativamente agrupados nesta análise.

Vale ressaltar que o GDF15, um dos genes selecionado previamente para padronizar o tempo e a dose do experimento de microarray, foi identificado na análise como induzido (Tabela III).

Os genes Aurora-A e Aurora-B não apresentaram variação na expressão após o tratamento com o AMG 900. 
Tabela 3 - Lista de processos biológicos selecionados e seus genes correspondentes

\begin{tabular}{|c|c|c|c|c|}
\hline Category & Term & Count & PValue & Genes \\
\hline GOTERM_BP_FAT & $\begin{array}{l}\text { GO:0048545 response to } \\
\text { steroid hormone stimulus }\end{array}$ & 22 & 0.002 & 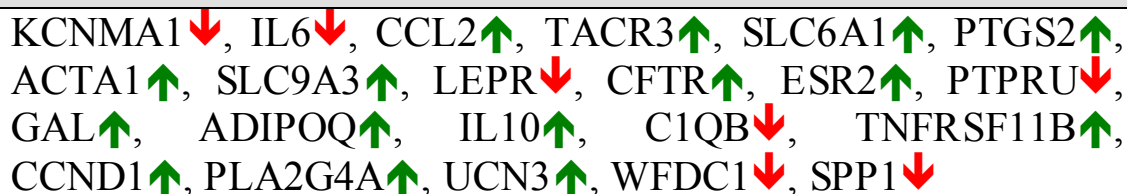 \\
\hline GOTERM_BP_FAT & $\begin{array}{l}\text { GO:0042127 regulation of cell } \\
\text { proliferation }\end{array}$ & 61 & 0.009 & 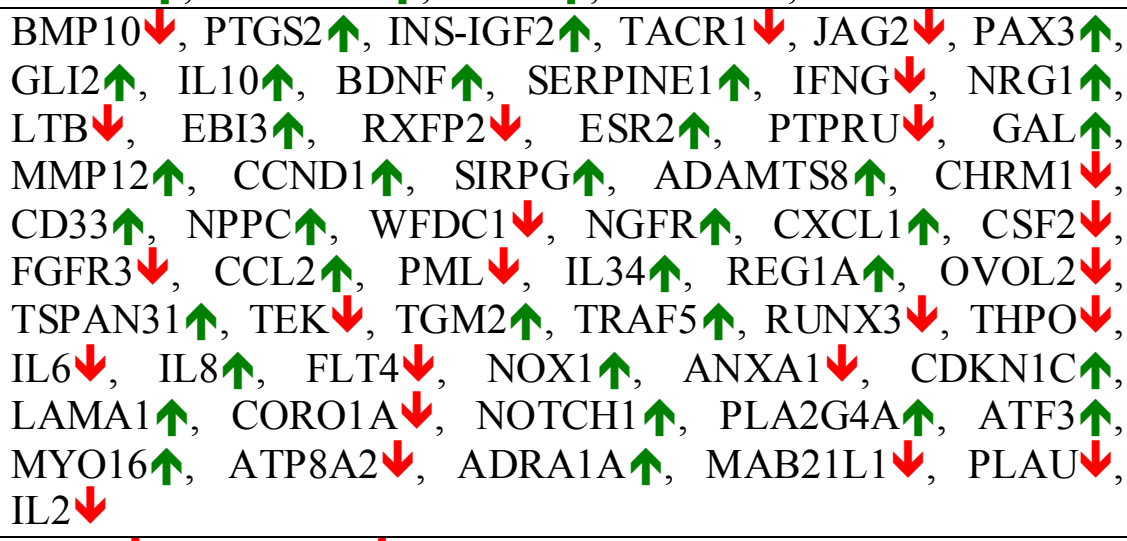 \\
\hline GOTERM_BP_FAT & $\begin{array}{l}\text { GO:0042445 hormone } \\
\text { metabolic process }\end{array}$ & 13 & 0.01 & 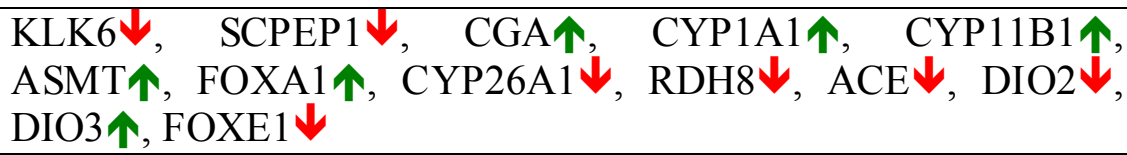 \\
\hline GOTERM_BP_FAT & $\begin{array}{c}\text { GO:0019933 cAMP-mediated } \\
\text { signaling }\end{array}$ & 12 & 0.01 & 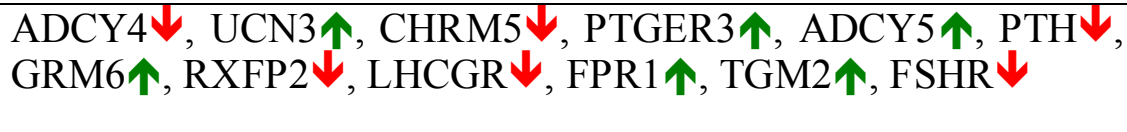 \\
\hline GOTERM_BP_FAT & $\begin{array}{l}\text { GO:0007179 transforming } \\
\text { growth factor beta receptor } \\
\text { signaling pathway }\end{array}$ & 9 & 0.01 & 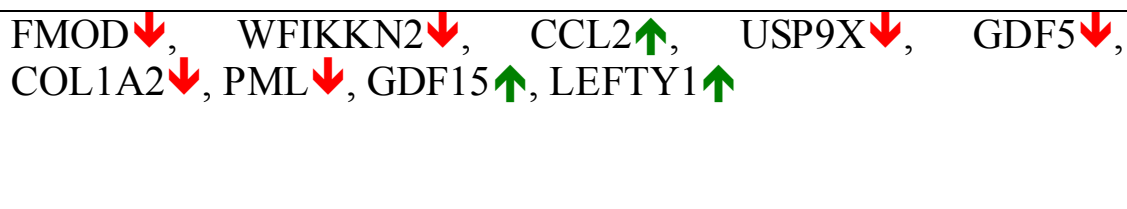 \\
\hline GOTERM_BP_FAT & $\begin{array}{l}\text { GO:0007219 Notch signaling } \\
\text { pathway }\end{array}$ & 8 & 0.02 & 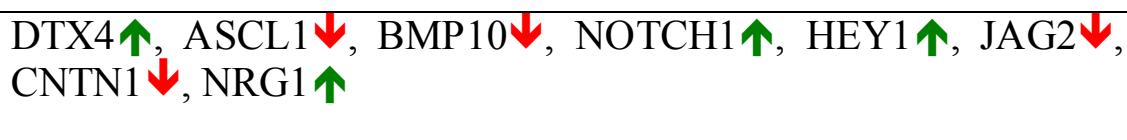 \\
\hline
\end{tabular}




\begin{tabular}{|c|c|c|c|c|}
\hline Category & Term & Count & PValue & Genes \\
\hline GOTERM_BP_FAT & $\begin{array}{l}\text { GO:0046883 regulation of } \\
\text { hormone secretion }\end{array}$ & 9 & 0.03 & 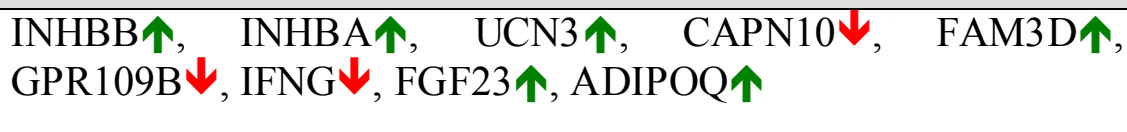 \\
\hline KEGG_PATHWAY & $\begin{array}{l}\text { hsa00140: Steroid hormone } \\
\text { biosynthesis }\end{array}$ & 7 & 0.05 & 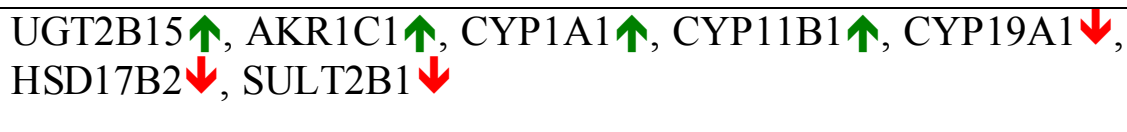 \\
\hline
\end{tabular}

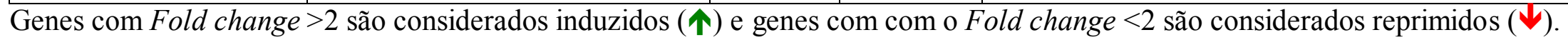




\section{DISCUSSÃO}

\subsection{A expressão dos genes Aurora-A e Aurora-B está associada com características clínicas desfavoráveis em TAC pediátricos}

Os tumores adrenocorticais (TAC) pediátricos são raros, entretanto sua incidência no Brasil é elevada devido à ocorrência da mutação germinativa TP53 p.R337H (Latronico et al., 2001; Ribeiro RC et al., 2001). Estes tumores são agressivos e exibem características clínicas, histológicas e biológicas diferentes dos tumores de adultos, sugerindo a presença de mecanismos moleculares distintos entres estes dois grupos (Faria \& Almeida 2012). A cirurgia é o tratamento mais efetivo para os TAC, no entanto os recursos terapêuticos para os pacientes de alto risco ou com doença avançada são ineficientes (Ribeiro et al, 2012). Portanto, novas terapias e/ou alvos terapêuticos são necessárias para o tratamento deste tumor.

Dentre os diversos alvos terapêuticos estudados atualmente, os membros da família das aurora-quinases (Aurora-A, B e C) têm se destacado. Estas proteínas atuam na manutenção da estabilidade do genoma e alterações no padrão de expressão de dois integrantes deste grupo, a Aurora-A e a B, foram descritas em diversos tumores. Além disso, a inibição farmacológica destas proteínas têm apresentado resultados relevantes para o tratamento do câncer (Kollareddy et al., 2012). No presente estudo, através da análise de uma grande coorte de TAC pediátricos e por meio de ensaios in vitro, apresentamos evidências de que as aurora-quinases podem ser interessantes alvos terapêuticos para o tratamento dos TAC pediátricos.

As características clínicas e patológicas dos pacientes pediátricos avaliados neste estudo, tais como idade, sexo, estadio tumoral, sintomas clínicos, dados de sobrevida e fatores prognósticos, assemelham-se ao perfil descrito pelo Registro Internacional de Tumor Adrenocortical Pediátrico (International Pediatric Adrenocortical Tumor Registry IPACTR), (Michalkiewicz et al. 2004). Da mesma forma, a frequência da mutação TP53 p.R337H observada em nossa casuística é semelhante à prevalência observada em outros estudos com amostras tumorais de crianças brasileiras (Latronico et al. 2001; Ribeiro et al. 2001; Sandrini et al. 2005).

A expressão dos genes Aurora-A e Aurora-B já foram avaliadas em TAC de adultos. de Reyniès et al. (2009) descreveram que a expressão elevada dos Aurora-A e Aurora-B foi associada com pior prognóstico e Giordano et al. (2003) observaram que o Aurora-A apresentou expressão elevada nos carcinomas em relação aos adenomas adenocorticais. Neste 
trabalho, foi descrito pela primeira vez que a expressão dos genes Aurora- $A$ e $B$ está associada com pior prognóstico e com uma baixa sobrevida em TAC pediátricos (esses dados foram recentemente publicados pelo grupo - Borges KS et al., 2013, Anexo IV).

A expressão e a associação destes genes com fatores prognósticos desfavoráveis já foi relatada em vários tumores como glioblastoma, câncer de pulmão, esôfago, fígado, ovário e mama (Gautschi et al., 2008). Entretanto, os mecanismos associados com o aumento da expressão desses genes ainda não estão totalmente elucidados. Como as aurora-quinases estão implicadas na manutenção da estabilidade do genoma, já está claro que as variações na expressão destas proteínas podem causar alterações na segregação dos cromossomos durante a divisão celular que consequentemente acarretaram em um aumento da instabilidade cromossômica (CIN) (Carter et al., 2006), uma característica marcante do câncer e já observada em tumores adrenocorticais (Doha et al., 2000; Stephan et al., 2008). É interessante destacar que níveis elevados de CIN estão associados com a progressão do tumor e com a sobrevida geral em TAC pediátricos (Figueiredo et al., 1999; Loncarevic et al., 2008). Estas informações sugerem então que a expressão elevada dos Aurora- $A$ e $B$ descritas neste trabalho pode estar envolvida com o aumento da CIN dos TAC pediátricos e consequentemente com a malignidade destes tumores.

Outros genes também contribuem para a manutenção da estabilidade do genoma humano. Entre estes está o TP53, considerado o mais importante gene supressor de tumor (Efeyan \& Serrano 2007). Nas regiões sul e sudeste do Brasil, uma mutação no domínio Cterminal da p53 está associada com uma incidência significativamente alta de TAC pediátricos. Esta mutação, caracterizada pela substituição de uma arginina por uma histidina no códon $337(\mathrm{R} 337 \mathrm{H})$, é responsável pela desestabilização da proteína em $\mathrm{pH}$ alcalino $(\mathrm{pH}$ 8.0) (Latronico et al., 2001; Ribeiro et al., 2001; DiGiammarino et al., 2002).

Neste trabalho, pacientes com a mutação do TP53 p.R337H apresentaram uma elevada expressão do gene Aurora-A. Embora neste caso não esteja claro o motivo desta associação, a interação da Aurora-A com a p53 já está bem estabelecida. A Aurora-A e a p53 se regulam negativamente. A Aurora-A promove a degradação e reduz a atividade de transativação da p53 através da sua fosforilação na serina 215 e na serina 315, respectivamente (Katayama et al., 2004; Liu et al., 2004). Além disso, a Aurora-A pode mediar a fosforilação da p53, o que impede a interação desta com a proteína MDM2 aumentando a sua estabilidade (Hsueh et al., 2012). Por outro lado, a p53 inibe a Aurora-A através da sua regulação pós-transcricional e pós-traducional (Wu et al., 2012). 
É importante destacar que a Aurora-A liga-se ao domínio C-terminal da p53 (resíduos 291-393), e mutações nessa região interferem com esta interação (Katayama et al., 2004; Gully et al., 2012). Além disso, foi relatado também que mutações que induzem alterações conformacionais neste domínio C-terminal também interferem com a ligação da p53 com a Aurora-A (Katayama et al., 2004). Estas informações trazem implicações para os dados encontrados neste trabalho, uma vez que a mutação TP53 p.R337H encontra-se na região Cterminal da proteína e em $\mathrm{pH}$ alcalino desencadeia alterações conformacionais na estrutura da p53 (DiGiammarino et al., 2002). Desta forma, estes dados sugerem que esta mutação do TP53 pode comprometer a regulação da Aurora-A pela p53 e vice-versa e isto resultaria em um processo de aumento e manutenção da instabilidade do genoma. Entretanto, a investigação dos possíveis efeitos do $\mathrm{pH}$ na atividade da p53 (R337H) e na sua interação com as Aurora-A ainda necessitam ser realizadas para esclarecer o processo de carcinogênese desencadeado pela mutação TP53 p.R337H.

\subsection{Efeitos do inibidor de aurora quinases AMG 900 na linhagem H295A}

Os dados discutidos até aqui sugerem que a expressão das aurora-quinases A e B nos TAC pediátricos desempenham um papel importante na manutenção de processos envolvidos com a biologia tumoral. Desta forma, é possível supor que a inibição da atividade destas proteínas poderia afetar a viabilidade destes processos e induzir diferentes efeitos antineoplásicos como a inibição da proliferação e a morte celular. Com esse intuito, neste trabalho foram realizadas análises de proliferação, apoptose, combinação de drogas e expressão gênica para investigar os efeitos da inibição das aurora-quinases pelo AMG 900 na linhagem de carcinoma de adrenal H295A.

Nesta investigação, o AMG 900 inibiu significativamente a proliferação e induziu apoptose na linhagem de carcinoma de adrenal H295A. Os dados observados neste trabalho estão de acordo com os publicados recentemente sobre os efeitos do AMG 900. Kalous et al. (2013) relataram que o AMG 900 inibiu a proliferação e causou apoptose em um painel de linhagens celulares de carcinoma de mama. Bush et al. (2013) mostraram que o AMG 900 foi capaz de bloquear a proliferação e induzir apoptose em linhagens de carcinoma de mama resistentes aos quimioterápicos paclitaxel e decetaxel.

Payton et al. (2006), considerando a diminuição da fosforilação da histona 3 fosforilada encontraram valores de IC50 de 8,2nM para o AMG 900. Por outro lado, Kalous et al. (2013) considerando a porcentagem de células apoptóticas, com tratamento de 5 dias 
obtiveram valores de IC50 abaixo da concentração de 10nM. É interessante notar que os efeitos observados na proliferação da linhagem de carcinoma de adrenal H295A foram menos intensos do que os relatados por Payton et al. (2006) e Kalous et al. (2013). Isto pode ter acontecido devido às diferentes metodologias utilizadas pelos estudos para avaliar a inibição da proliferação causada pelo AMG 900.

Os efeitos causados pelos diversos inibidores das aurora-quinases na divisão celular in vitro são semelhantes. O resultado predominante da exposição a estes agentes não é a inibição da progressão do ciclo celular. Porém, após a replicação do genoma, células tratadas com estas drogas sofrem um bloqueio transitório na mitose, que em seguida é revertido (mitotic slippage ou adaptação) e as células progridem pelo ciclo celular sem, entretanto, executar a citocinese, resultando assim em células poliplóides. Esse mecanismo é conhecido como endorreduplicação e pode ocorrer por diversas vezes após a inibição das aurora-quinases. Adicionalmente, células com o genoma poliplóide, fruto deste processo, podem sofrer uma parada na fase G1 seguinte do ciclo (G1 pós-mitótica) mediada pela expressão das proteínas p53 e p21, e acabar então sofrendo apoptose. A duração e a extensão destes efeitos podem variar dependendo da linhagem celular e das doses utilizadas da droga (Gizatullin et al., 2006; Benten et al., 2009; Nair et al., 2009; Marxer et al., 2013) (Fig 16).

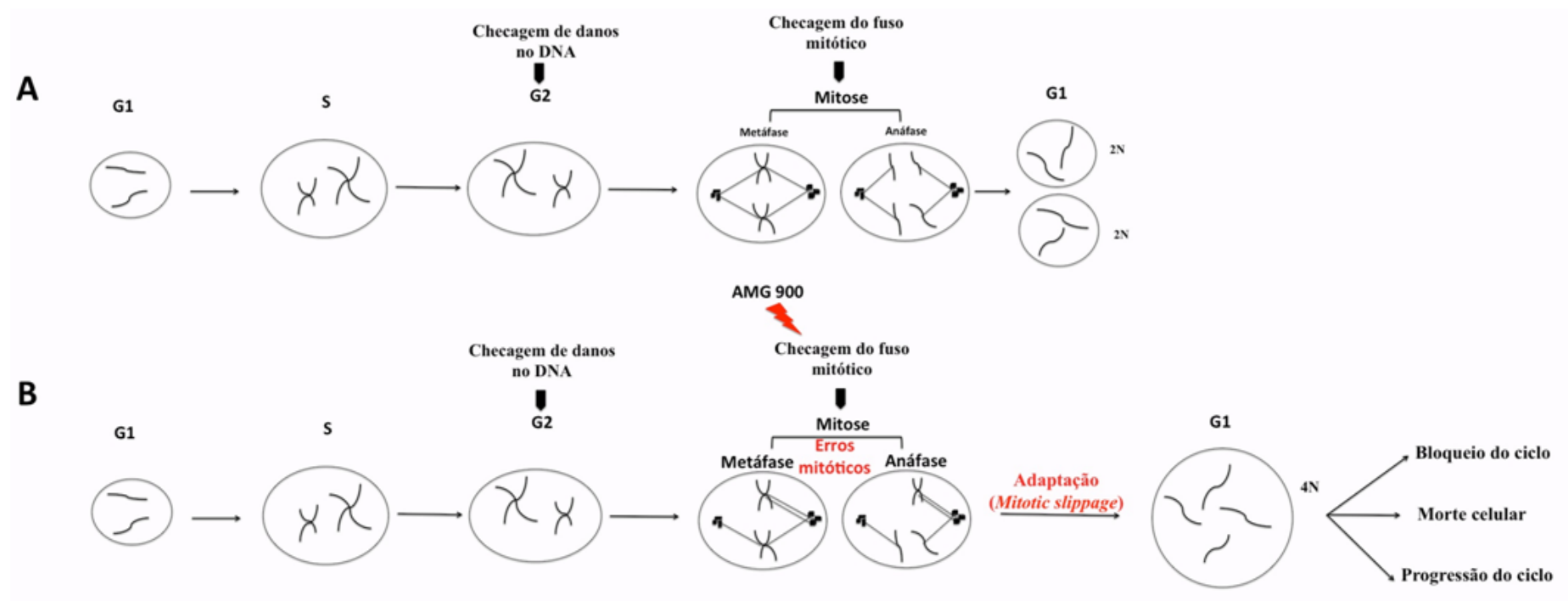

Figura 16 - Possível efeito do AMG 900 no ciclo celular da linhagem H295A. (A) Ciclo celular normal. Uma célula normal origina duas células filhas com o mesmo número de cromossomos da célula inicial. (B) Célula tratada com o AMG 900. Uma célula com os mecanismos de checagem do fuso mitótico inibidos progride pelo ciclo através de uma mitose defeituosa, completando-o sem executar a citocinese. Adaptado de Gizatullin et al., 2006 
Em linhagens tratadas pelo AMG 900 já foi descrita a ativação dos mecanismos de checagem pós-mitóticos na fase G1 através da indução das proteínas p53 e p21 (Payton et al, 2012; Kalous et al, 2013). No presente trabalho, embora não tenham sido realizados ensaios estudando o ciclo celular, o padrão de expressão dos genes observados após tratamento com o AMG 900 sugere um bloqueio na fase G1. Uma vez que, além do aumento da expressão dos genes TP53 e p21, foi observada também a modulação de diversos genes envolvidos com a proliferação celular que apresentam atividade na regulação da fase $\mathrm{G} 1$ do ciclo como o CDKN1C (p57) (Lee et al., 1995), CCND1 (ciclina D1) (Baldin et al., 1993), GLI2 (Regl et al. 2004), PAX3 (Fang et al., 2014), RUNX3 (Lin et al., 2012), PML (Mu et al., 1997), NOX1 (Wang et al., 2011), FLT4 (Kurenova et al., 2013), REG1A (Yu et al., 2012) e IFNG (Hobeika et al., 1998), entre outros. O perfil transcricional exibido acima em conjunto com os dados observados na literatura sugere que o tratamento da linhagem H295A com o AMG 900 está induzindo poliploidia e ativando os mecanismos de checagem pós-mitóticos da fase G1. Este processo pode estar associado com a inibição da proliferação e com a indução de apoptose observada neste trabalho.

\subsection{Efeitos do AMG 900 combinado com diferentes quimioterápicos na linhagem H295A}

A associação de quimioterápicos é uma abordagem comum no tratamento de diversos tumores. Recentemente, um estudo colaborativo constatou uma resposta de pacientes adultos com TAC em estadio avançado tratados com DOX-ETO-CIS seguido pelo mitotane, mas nenhuma diferença foi observada na sobrevida geral (Fassnacht et al., 2012). Esta combinação também já foi testada em casos pediátricos, mas os resultados não foram animadores (Zancanella et al., 2006). Os inibidores de aurora-quinases têm mostrado um potencial promissor ao serem combinado com outros quimioterápicos. No caso deste estudo, o AMG 900 foi combinado com os quimioterápicos doxorrubicina (DX), etoposídeo (ETO) e cisplatina (CIS). Individualmente, o efeito dos quimioterápicos na linhagem H295A foi relativamente pequeno, sendo que nenhum destes alcançou um efeito de $50 \%$ de inibição da proliferação. Esses dados estão de acordo com o observado por Nilubol et al. (2012), onde a linhagem de carcinoma de adrenal H295R foi pouco responsiva para estas drogas.

A associação AMG 900-DX apresentou os melhores resultados de sinergismo. Tanto na proliferação quanto na apoptose a combinação destas drogas foi mais eficaz do que as drogas isoladas. No caso do ETO, entretanto, este feito foi observado apenas na apoptose. Diferentemente do que aconteceu com a combinação AMG 900/CIS, onde nenhum efeito de sinergia foi encontrado. Outros trabalhos já combinaram pan-inibidores de aurora-quinases 
com estes quimioterápicos. O VX-680 agiu sinergicamente com a DX (Lee et al., 2006) e o ETO (Huang et al., 2008) em linhagens de próstata e de leucemia mielóide aguda, respectivamente. Winter et al. (2011) observaram que a combinação do tozasertib com a DX e o ETO culminou em efeitos sinérgicos em linhagens de tumores de Wilms pediátrico. No caso da CIS, somente inibidores específicos da Aurora-A foram combinados com esta droga, com resultados promissores em linhagens celulares de adenocarcinoma de esôfago (Seldev et al., 2012) e de meduloblastoma (El-Sheikh et al., 2010).

A DX e o ETO são inibidores da topoisomerase II, uma enzima que atua sobre a topologia do DNA controlando o superenrolamento do material genético através da indução de quebras transitórias no DNA. Os efeitos da inibição da atividade dessa enzima acarreta no acúmulo de quebras simples e duplas no DNA e no bloqueio da replicação e transcrição com indução da apoptose (Nitiss 2009). Por outro lado, a topoisomerase II também possui importantes atividades durante a mitose (Chang et al., 2003; Carpenter et al, 2004; Coelho et al., 2008).

A topoisomease II desempenha papel central na promoção de alterações estruturais do DNA centromérico que são essenciais para o estabelecimento de conexões sintélicas nos cinetocoros e posterior individualização e separação dos cromossomos durante a transição metáfase-anáfase. Adicionalmente, a atividade desta enzima permite a função normal da Aurora-B e eventual ativação dos mecanismos que corrigem conexões inadequadas do fuso celular com os cinetocoros (Coelho et al., 2008). Vale ressaltar que a inibição da topoisomerase II leva a falhas na separação cromossômica e à inibição da atividade da Aurora-B (Chang et al., 2003; Carpenter et al, 2004; Coelho et al., 2008). Com base nestas informações, é possível sugerir que a inibição da topoisomease II pode estar agindo sinergicamente com o AMG 900 devido à intensificação dos efeitos previamente desencadeados pela inibição das aurora-quinases, ou seja, aumentando a instabilidade cromossômica e consequentemente a apoptose.

A CIS é um quimioterápico à base de platina com potentes efeitos antitumorais. A sua atividade é atribuída à ligação ao DNA, com formação de aductos, originando ligações intra e intercadeias que induzem alterações estruturais. O seu efeito citotóxico é causado pela inibição da transcrição e replicação, induzindo a apoptose (Sehdev et al., 2012). Embora existam relatos do efeito sinérgico da CIS combinadas com outros inibidores específicos de aurora quinases, neste trabalho foi encontrado um efeito antagônica nesta combinação. Recentemente foi relatado que o bloqueio pós-mitótico em G1, com células poliplóides, aumenta a resistência à CIS (Shen et al, 2013). Além disso, células em G1 também são menos responsivas a esta droga (Mueller et al., 2006). Interessantemente, estes são os possíveis 
efeitos desencadeados pelo AMG 900 e que poderiam estar dificultando a associação dessas drogas. É importante destacar que os efeitos sinérgicos da combinação da cisplatina com outros inibidores de aurora quinases partiram de células bloqueadas em G2/M (Zhang \& Zhang 2011; Sehdev et al., 2012).

\subsection{Efeitos do AMG 900 na síntese de hormônios da linhagem H295A}

Um dos sinais mais frequentes encontrados em pacientes com TAC é o aumento dos níveis hormonais. No entanto, a síntese dessas substâncias decorrente dos TAC é relativamente ineficiente, resultando em níveis elevados de precursores hormonais. Estes tumores podem secretar vários tipos de hormônios e a co-secreção de cortisol com andrógenos é uma combinação frequente e altamente sugestiva de malignidade (Abiven et al., 2006; Cavlan et al., 2010). O excesso de hormônios geralmente interfere na qualidade de vida dos pacientes e pode até levar a óbito (Veytsman et al., 2009).

Neste trabalho, o tratamento com o AMG 900 foi capaz de induzir uma profunda inibição da síntese dos hormônios DHEA-S (sulfato de dehidroepiandrosterona), D4 (4androstenediona), testosterona e cortisol. O DHEA-S e o seu precursor D4 são os mais abundantes esteróides presentes na corrente sanguínea. A via proveniente destes precursores origina além da testosterona e seu metabólito ativo, a dehidrotestosterona (DHT), o estrogênio e seus metabólitos. A D4 e a DHEA-S têm apenas atividade androgênica fraca, mas quando secretados em excesso a partir de um TAC podem produzir um fenótipo clínico marcante (hirsutismo, virilização) (Cavlan et al., 2010). O cortisol, conhecido mais formalmente como hidrocortisona, é um glicocorticoide que é liberado em resposta ao hormônio ACTH. Ele é catalisado à partir de um produto menos potente chamado cortisona. Suas principais funções são aumentar a concentração de açúcar no sangue através da gluconeogênese e suprimir o sistema imunológico (Miller \& Auchus, 2011). Níveis elevados de cortisol causa a Síndorme de Cushing (Veytsman et al., 2009).

Este é o primeiro relato dos efeitos da inibição de aurora-quinases na síntese de hormônios. Interessantemente, diversos processos biológicos associados com o metabolismo hormonal foram modulados pelo AMG 900, entre estes está o de biossíntese de hormônios. Neste grupo estão os genes $U G T 2 B 15, A K R 1 C 1, C Y P 1 A 1, C Y P 11 B 1$, que foram induzidos, e os genes CYP19A1, HSD17B2 e o $S U L T 2 B 1$, que foram reprimidos (Fig. 17).

Entre os genes modulados, cinco estão envolvidos com a conversão de andrógenos para metabólitos inativos, o HSD17B2, o UGT2B15, o AKR1C1, o SULT2B1 e o CYP1A1. Os 
metabólitos inativos são mais polares, menos tóxicos, e mais facilmente excretados do corpo do que a substância original (Miller WL, Auchus 2011).

A HSD17B2 executa a conversão catalítica da testosterona em androstenediona, do estradiol em estrona, e do $5 \alpha$-androstenediol em DHEA. Variações genéticas do gene HSD17B2 estão associadas com diferenças nos níveis de testosterona no plasma de pacientes diagnosticados com câncer de próstata (Sun et al., 2011). O AKCR1C1 catalisa a

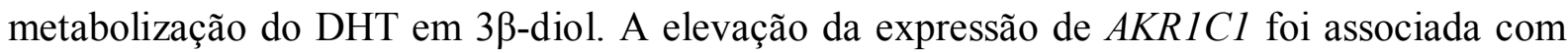
níveis reduzidos de DHT e inibição da proliferação em células de câncer de próstata (Ji et al., 2007). A UGT2B15 é uma glicosil transferase que age na inativação de andrógenos e células que expressam esta enzima são menos responsivas para o DHT (Barbier \& Bélanger 2008). O SULT2B1 codifica uma sulfotransferase hidroxiesteróide com um papel na eliminação do colesterol, do DHEA e dos estrogênios. Interessantemente, a inibição do SULT2B1 causa a diminuição da proliferação de células de carcinoma hepatocelular in vitro e in vivo (Steckelbroeck et al., 2004; Yang et al., 2013).

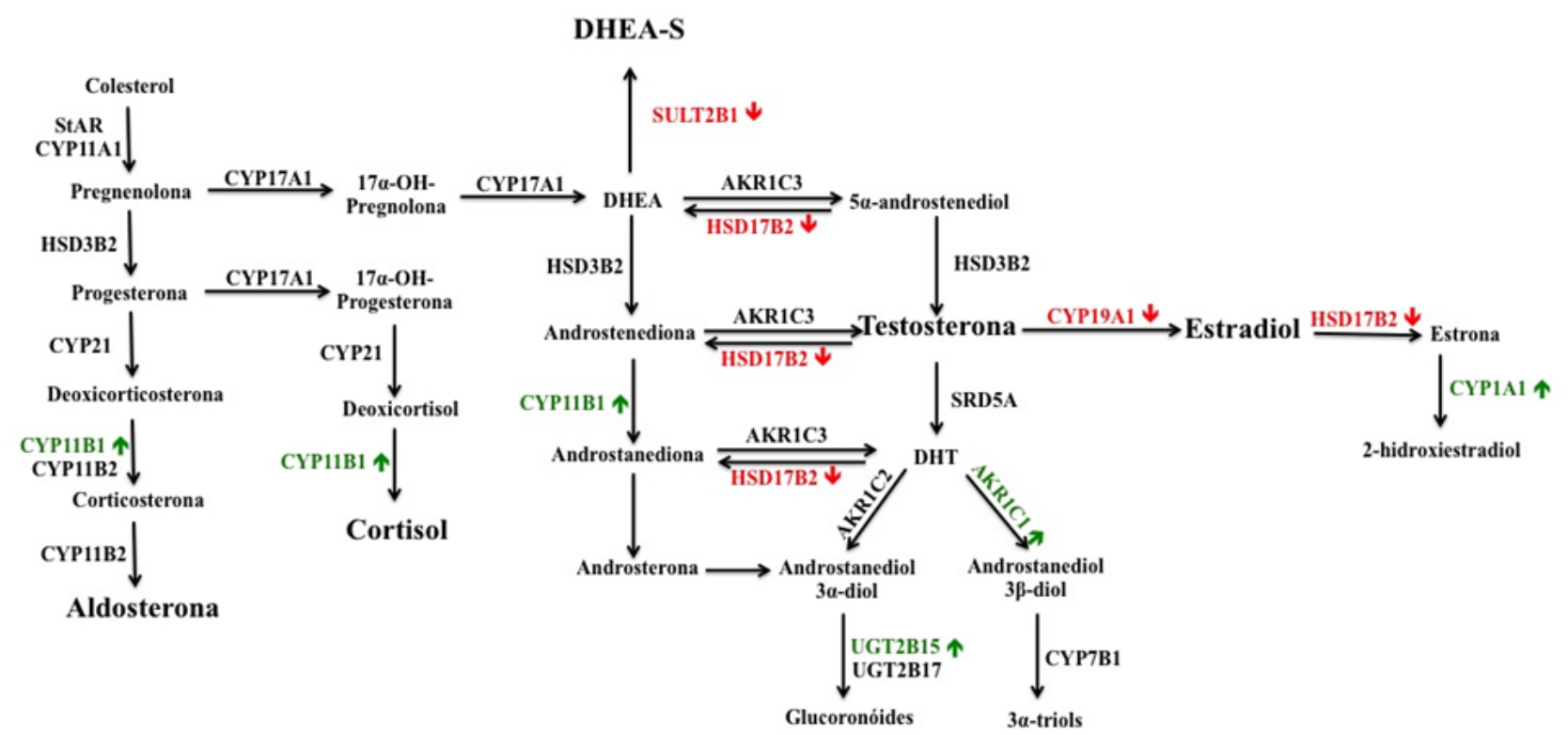

Figura 17 - Representação esquemática da via de síntese hormonal. Em destaque os genes modulados ( $\uparrow=$ induzido $\downarrow=$ reprimido) pelo tratamento com o inibidor de aurora quinases AMG 900. Adaptado de Zhu \& Conney 1998; Tsuchiya et al., 2004; Wang \& Rainey. 2012; Doherty et al., 2014.

Dois genes envolvidos com o metabolismo de estrógenos foram também modulados pelo AMG 900, o CYP1A1, responsável pelo primeiro passo na conversão de estrogênios para os seus metabólitos inativos (Tsuchiya et al., 2005), e o CYP19A1, que codifica para a enzima aromatase, responsável pela síntese de estrogênio usando andrógenos como substrato 
(Watanabe \& Nakajin 2004). A CYP19A1 é abundante em TAC de adultos (Barzon et al., 2008; Sirianni et al., 2012) e a inibição do estrogênio induz efeitos antiproliferativos na linhagem H295R, in vivo e in vitro (Sirianni et al., 2012). No presente trabalho este gene foi reprimido, o que indica uma favorável interferência na síntese de estrogênio da linhagem H295A.

O CYP11B1 participa de vários passos da síntese de hormônios, entre estes está a conversão do desoxicortisol em cortisol (Kempná \& Flück 2008). A expressão desta enzima foi inversamente proporcional à dosagem de cortisol neste trabalho, o que sugere que outros passos que precedem a atividade desta enzima na via podem estar sendo reprimidos pelo inibidor de aurora-quinases.

O metabolismo dos hormônios é orquestrado pelo padrão de expressão gênica apresentado em cada zona do córtex adrenal (Kempná \& Flück 2008; Wood et al., 2013). O estudo do perfil transcricional das zonas do córtex adrenal em Rattus norvegicus mostrou a expressão elevada do auror $a-b$ na zona glomerulosa. Este dado sugere que este gene pode estar envolvido no controle da produção hormonal zona-específica e na formação das zonas do córtex adrenal (Nishimoto et al., 2012), o que teoricamente poderia explicar o efeito do AMG 900 na síntese hormonal. Contudo, outros estudos serão importantes para elucidar este mecanismo.

Os resultados discutidos aqui mostraram que o AMG 900 causa alterações na expressão de enzimas envolvidas na síntese de hormônios bem como na expressão de enzimas associadas com o metabolismo de andrógenos, levando assim à redução dos níveis hormonais. Desta forma, é possível sugerir que o AMG 900, além de ser utilizado como um agente antitumoral poderia ser também utilizado como uma droga para o controle do excesso de hormônios. Vale ressaltar que os ensaios clínicos concluídos até o momento com diferentes inibidores de aurora quinases não evidenciaram efeitos adrenotóxicos, o que também vem sendo confirmado pelos ensaios in vivo com o AMG 900 (Payton et al., Bush et al., 2013; Kam et al., 2013).

\subsection{O AMG 900 afetou a via de sinalização Notch}

De acordo com a análise das vias de sinalização afetadas pelo tratamento com o AMG 900, a via Notch foi uma das mais significativamente afetada. A via Notch regula o metabolismo celular de acordo com o das células vizinhas e, consequentemente, controla a diferenciação, proliferação e eventos apoptóticos em vários tecidos, principalmente durante o 
desenvolvimento embrionário. Perturbações na atividade da via têm sido associadas com várias doenças genéticas humanas, inclusive o câncer (Guruharsha et al., 2012).

A sinalização da via Notch envolve a interação entre um ligante de membrana, geralmente proteínas da família Jagged (JAG1 e 2) ou Delta-like (DLL1, 3 e 4), e um receptor transmembranar, NOTCH1, 2, 3 ou 4, geralmente expresso em células adjacentes. Após a ligação do ligante ao receptor Notch, os complexos $\gamma$-secretase clivam o receptor Notch em dois locais liberando a molécula de sinalização ativa NICD (Notch clivada domínio intracelular). No citoplasma, o domínio intracelular de Notch (NICD) é translocado para o núcleo atuando como fator de transcrição ligando-se ao seu co-ativador CSL, ativando genes alvos tais como o HES1, o HERP1 e o HERP2. Além disso, outros co-reguladores, incluindo MASTERMIND, CBP/p300 e SMRT estão envolvidos no controle transcricional dependente da sinalização Notch (Andersson et al., 2011; Guruharsha et al., 2012).

Neste trabalho oito genes envolvidos com a via de sinalização Notch foram modulados pelo AMG 900, sendo que o NOTCH1, HEY1, NRG1 e o DTX4 foram induzidos e o ASCL1, BMP10, JAG2 e o CNTN1 reprimidos. Esse padrão de expressão sugere que a via NOTCH está sendo ativada pelo tratamento com o inibidor de aurora quinases. Essa constatação é baseada em relatos prévios onde a elevada expressão do NOTCH1 induz a expressão dos genes HEY1 (Sun et al., 2014) e NRG1 (Zhang et al., 2012) e inibiu a expressão do gene ASCL1 (Kunnimalaiyaa et al., 2006). O BMP10, o DTX4 e o CNTN1 também estão envolvidos com a via de sinalização Notch, entretanto os processos envolvidos com estes genes são pouco estudados (Yamamoto et al., 2001; Grego-Bessa et al., 2007; Zanotti \& Canalis 2009).

Poucos trabalhos investigaram a possível relação de membros da família das auroraquinases com a via de sinalização Notch. Regan et al. (2013) observaram que a Aurora-A controla a diferenciação de células mamárias epiteliais através da regulação da via Notch. Wang et al. (2006) estudando células progenitoras neurais de Drosophila, encontraram que células mutantes para o Aurora-A perdem a capacidade de inibir a via Notch, o que acarreta em aumento de proliferação. No nosso trabalho os dados também indicam que a atividade das aurora-quinases é importante para a inibição da via Notch, uma vez que esta inibição da atividade destas proteínas ativou a via.

A sinalização desregulada da via Notch tem sido associada a uma grande variedade de tumores tais como o neuroblastoma, câncer pulmão de células pequenas, de colo do útero e da próstata, mas isso foi pouco estudado em neoplasias adrenocorticais (Zhang et al., 2012; Sun et al., 2014). Ronchi et al. (2012) demonstraram que essa via está alterada em adenomas 
adrenocorticais secretores de cortisol. Simon et al. (2012) identificaram que o JAGl, um ativador da via, está aumentada em TAC de adultos e o silenciamento desde gene inibe a via de sinalização, causando diminuição da proliferação em uma linhagem de TAC. Tais dados sugerem que a inibição da via Notch em TAC poderia ser um alvo interessante para o tratamento deste tipo de tumor.

Finalmente, não está claro se os efeitos da ativação da via de sinalização Notch causados pelo AMG 900 está contribuindo ou interferindo com os efeitos antiproliferativos causados pelo inibidor, embora os dados indiquem na direção da segunda hipótese, uma vez que a inibição da via diminui a proliferação em linhagem de carcinoma de adrenal (Simon et al. 2012). Por outro lado, experimentos de combinação do AMG900 com inibidores da via Notch poderiam fornecer importantes informações sobre este processo.

Os dados mostrados neste trabalho confirmam que as aurora-quinases são potenciais alvos para o tratamento dos TAC, e que a utilização do inibidor AMG 900 poderá no futuro ser testado in vivo, inclusive associado com a doxorrubicina e o etoposídeo. 


\section{CONCLUSÕES}

- A expressão dos genes Aurora-A e Aurora-B está associada com fatores prognósticos desfavoráveis em TAC pediátricos;

- O tratamento com o AMG 900 inibiu a proliferação e induziu apoptose. Esses efeitos foram acompanhados pela modulação de genes característicos da fase G1 do ciclo celular;

- O AMG 900 agiu sinergicamente com a doxorrubicina e o estoposídeo na linhagem H295A, entretanto seus efeitos foram antagônicos com a cisplatina;

- A inibição das aurora-quinases causou uma diminuição da síntese de hormônios e esse efeito foi associado com a desregulação de genes envolvidos com a síntese e metabolismos dessas substâncias;

- A inibição das aurora-quinases induziu a ativação da via NOTCH;

- A inibição das aurora-quinases pelo AMG 900 pode ser uma possível abordagem para o tratamento dos TAC. 


\section{REFERÊNCIAS}

Abiven G, Coste J, Groussin L, Anract P, Tissier F, Legmann P, Dousset B, Bertagna X, Bertherat J. Clinical and biological features in the prognosis of adrenocortical cancer: poor outcome of cortisol-secreting tumors in a series of 202 consecutive patients. J Clin Endocrinol Metab. 2006;91(7):2650-5.

Achatz MI, Hainaut P, Ashton-Prolla P. Highly prevalent TP53 mutation predisposing to many cancers in the Brazilian population: a case for newborn screening? Lancet Oncol. 2009;10(9):920-5.

Adams RR, Carmena M, Earnshaw WC. ABCs of mitosis. Trends Cell Biol 2001;11(2):49-54.

Allolio B, Fassnacht M. Clinical Review: Adrenocortical Carcinoma: clinical update. Clin Endocrinol Metab 2006;91(6):2007-37.

Amgen. A Phase 1 First-in-Human Study Evaluating AMG 900 in Advanced Solid Tumors. Em: ClinicalTrials.gov [Internet]. Bethesda (MD): National Library of Medicine (US). 2000[citado 24/02/2014]. Disponível em: http://clinicaltrials.gov/ct2/show/NCT00858377 NLM Identifier: NCT00858377.

Amgen. Study Evaluating Orally Administered AMG 900 in Adult Subjects With Acute Myeloid Leukemia. Em: ClinicalTrials.gov [Internet]. Bethesda (MD): National Library of Medicine (US). 2000- [citado 24/02/2014]. Disponível em: http://clinicaltrials.gov/ct2/show/ NCT01380756 NLM Identifier: NCT01380756.

Anand S, Penrhyn-Lowe S, Venkitaraman AR. AURORA-A amplification overrides the mitotic spindle assembly checkpoint, inducing resistance to Taxol . Cancer Cell 2003;3(1):51-62.

Andersson ER, Sandberg R, Lendahl U. Notch signaling: simplicity in design, versatility in function. Development. 2011;138(17):3593-612.

Andrews PD. Aurora kinases: shining lights on the therapeutic horizon? Oncogene 2005:24;5005-5015.

Antonini SR, Colli LM, Ferro L, Mermejo L, Castro Md. Childhood adrenocortical tumors: from a clinical to a molecular approach. Arq Bras Endocrinol Metabol. 2011;55(8):599-606

Assumpção JG, Seidinger AL, Mastellaro MJ, Ribeiro RC, Zambetti GP, Ganti R, Srivastava K, Shurtleff S, Pei D, Zeferino LC, Dufloth RM, Brandalise SR, Yunes JA. Association of the germline TP53 R337H mutation with breast cancer in southern Brazil. BMC Cancer. 2008 Dec 1;8:357. 
Aubert S, Wacrenier A, Leroy X, Devos P, Carnaille B, Proye C, et al. Weiss system revisited: a clinicopathologic and immunohistochemical study of 49 adrenocortical tumors. Am J Surg Pathol. 2002;26:1612-9.

Baldin V, Lukas J, Marcote MJ, Pagano M, Draetta G. Cyclin D1 is a nuclear protein required for cell cycle progression in G1. Genes Dev. 1993 May;7(5):812-21.

Barbier O, Bélanger A. Inactivation of androgens by UDP-glucuronosyltransferases in the human prostate. Best Pract Res Clin Endocrinol Metab. 2008;22(2):259-70.

Barzon L, Masi G, Pacenti M, Trevisan M, Fallo F, Remo A, Martignoni G, Montanaro D, Pezzi V, Palù G. Expression of aromatase and estrogen receptors in human adrenocortical tumors. Virchows Arch. 2008;452(2):181-91.

Benten D, Keller G, Quaas A, Schrader J, Gontarewicz A, Balabanov S, Braig M, Wege H, Moll J, Lohse AW, Brummendorf TH. Aurora kinase inhibitor PHA-739358 suppresses growth of hepatocellular carcinoma in vitro and in a xenograft mouse model. Neoplasia. 2009;11(9):934-44.

Bischoff JR, Anderson L, Zhu Y, Mossie K, Ng L, Souza B, Schryver B, Flanagan P, Clairvoyant F, Ginther C, Chan CS, Novotny M, Slamon DJ, Plowman GD. A homologue of Drosophila aurora kinase is oncogenic and amplified in human colorectal cancers. EMBO J 1998, 17(11):3052-65.

Borges KS, Moreno DA, Martinelli CE Jr, Antonini SR, de Castro M, Tucci S Jr, Neder L, Ramalho LN, Seidinger AL, Cardinalli I, Mastellaro MJ, Yunes JA, Brandalise SR, Tone LG, Scrideli CA Spindle assembly checkpoint gene expression in childhood adrenocortical tumors (ACT): Overexpression of Aurora kinases $\mathrm{A}$ and $\mathrm{B}$ is associated with a poor prognosis. Pediatr Blood Cancer. 2013;60(11):1809-16.

Bosotti R, Carpinelli P, Healy S, Locatelli G, Cappella P, Lanfrancone L, Calogero R, Moll $\mathrm{J}$, Isacchi A. Transcriptional analysis of the Aurora inhibitor Danusertib leading to biomarker identification in TP53 wild type cells. Mol Cancer. 2012 21;11(1):42.

Boss DS, Beijnen JH, Schellens JH. Clinical experience with aurora kinase inhibitors: a review. Oncologist. 2009;14(8):780-93.

Boveri, T. Zur Frage der Entsehung Maligner Tumoren. Fischer, Jena, 1914.

Bush TL, Payton M, Heller S, Chung G, Hanestad K, Rottman JB, Loberg R, Friberg G, Kendall RL, Saffran D, Radinsky R. AMG 900, a small-molecule inhibitor of aurora kinases, potentiates the activity of microtubule-targeting agents in human metastatic breast cancer models. Mol Cancer Ther. 2013;12(11):2356-66. 
Carmena M, Earnshaw WC. The cellular geography of aurora kinases. Nat Rev Mol Cell Biol. 2003;4(11):842-54.

Carpenter AJ, Porter ACG. Construction, characterization, and complementation of a conditional-lethal DNA topoisomerase II \{alpha\} mutant human cell line. Mol Biol Cell. 2004;15:5700-5711.

Carter SL, Eklund AC, Kohane IS, et al. A signature of chromosomal instability inferred from gene expression profiles predicts clinical outcome in multiple human cancers. Nat Genet 2006; 38:1043-1048.

Castro-Gamero AM, Borges KS, da Silva Silveira V, Lira RC, de Paula Gomes Queiroz R, Valera FC, Scrideli CA, Umezawa K, Tone LG. Inhibition of nuclear factor- $\kappa B$ by dehydroxymethylepoxyquinomicin induces schedule-dependent chemosensitivity to anticancer drugs and enhances chemoinduced apoptosis in osteosarcoma cells. Anticancer Drugs. 2012;23(6):638-50.

Cavlan D, Bharwani N, Grossman A. Androgen- and estrogen-secreting adrenal cancers. Semin Oncol. 2010 Dec;37(6):638-48.

Chan CS, Botstein D. Isolation and characterization of chromosome-gain and increase-inploidy mutants in yeast. Genetics 1993;135(3):677-91.

Chang C-J, Goulding S, Earnshaw WC, Carmena M. RNAi analysis reveals an unexpected role for topoisomerase II in chromosome arm congression to a metaphase plate. J Cell Sci. 2003;116:4715-4726.

Chou TC. Theoretical basis, experimental design, and computerized simulation of synergism and antagonism in drug combination studies. Pharmacol Rev. 2006;58:621-681.

Coelho PA, Queiroz-Machado J, Carmo AM, Moutinho-Pereira S, Maiato H, Sunkel CE. Dual role of topoisomerase II in centromere resolution and aurora B activity. PLoS Biol. 2008 Aug 26;6(8):e207.

Courjal F, Cuny M, Rodriguez C, Louason G, Speiser P, Katsaros D, Tanner MM, Zeillinger $\mathrm{R}$, Theillet C. DNA amplifications at 20q13 and MDM2 define distinct subsets of evolved breast and ovarian tumours. Br J Cancer 1996,74(12):1984-9.

de Reyniès A, Assié G, Rickman DS, et al. Gene expression profiling reveals a new classification of adrenocortical tumors and identifies molecular predictors of malignancy and survival. J Clin Oncol 2009; 27:1108-1115. 
DiGiammarino EL, Lee AS, Cadwell C, Zhang W, Bothner B, Ribeiro RC, Zambetti G, Kriwacki RW. A novel mechanism of tumorigenesis involving $\mathrm{pH}$-dependent destabilization of a mutant p53 tetramer. Nat Struct Biol. 2002 Jan;9(1):12-6.

Doherty D, Dvorkin SA, Rodriguez EP, Thompson PD. Vitamin D receptor agonist EB1089 is a potent regulator of prostatic "intracrine" metabolism. Prostate. 2014;74(3):273-85.

Dohna M, Reincke M, Mincheva A, et al. Adrenocortical carcinoma is characterized by a high frequency of chromosomal gains and high-level amplifications. Genes Chromosomes Cancer $2000 ; 28: 145-152$.

Dreier MR, Grabovich AZ, Katusin JD, Taylor WR. Short and long-term tumor cell responses to Aurora kinase inhibitors. Exp Cell Res. 2009;315(7):1085-99.

Ducat, D, Zheng, Y. Aurora kinases in spindle assembly and chromosome segregation. Exp Cell Res. 2004 Nov 15;301(1):60-7.

Duensing S, Lee BH, Dal Cin P, Münger K.. Excessive centrosome abnormalities with-out ongoing numerical chromosomal instability in a Burkitt's lymphoma. Mol Cancer 2003,2(1):30.

Efeyan A, Serrano M. p53: guardian of the genome and policeman of the oncogenes. Cell Cycle. 2007;6(9):1006-10.

El-Sheikh A, Fan R, Birks D, Donson A, Foreman NK, Vibhakar R Inhibition of Aurora Kinase A enhances chemosensitivity of medulloblastoma cell lines. Pediatr Blood Cancer. 2010;55(1):35-41.

Else T, Kim A, Sabolch A, Raymond V, Kandathil A, Caoili E, Shruti J, Miller BS, Giordano TJ, Hammer GD. Adrenocortical carcinoma. Endocr Rev. 2013. Ahead of print

Fang WH, Wang Q, Li HM, Ahmed M, Kumar P, Kumar S. PAX3 in neuroblastoma: oncogenic potential, chemosensitivity and signalling pathways. $J$ Cell Mol Med. 2014;18(1):38-48.

Faria AM, Almeida MQ. Differences in the molecular mechanisms of adrenocortical tumorigenesis between children and adults. Mol Cell Endocrinol. 2012;31;351(1):52-7

Fassnacht M, Terzolo M, Allolio B et al. Combination chemotherapy in advanced adrenocortical carcinoma. N Engl J Med. 2012 Jun 7;366(23):2189-97. 
Figueiredo BC, Sandrini R, Zambetti GP, Pereira RM, Cheng C, Liu W, Lacerda L, Pianovski MA, Michalkiewicz E, Jenkins J, Rodriguez-Galindo C, Mastellaro MJ, Vianna S, Watanabe F, Sandrini F, Arram SB, Boffetta P, Ribeiro RC. Penetrance of adrenocortical tumours associated with the germline TP53 R337H mutation. J Med Genet. 2006;43(1):91-6.

Figueiredo BC, Stratakis CA, Sandrini R, et al. Comparative genomic hybridization analysis of adrenocortical tumors of childhood. J Clin Endocrinol Metab 1999; 84:1116-1121.

Fischer SJ, Benson LM, Fauq A, Naylor S, Windebank AJ. Cisplatin and dimethyl sulfoxide react to form an adducted compound with reduced cytotoxicity and neurotoxicity. Neurotoxicology. 2008;29:444-452.

Fu J, Bian M, Jiang Q, Zhang C. Roles of Aurora kinases in mitosis and tumorigenesis. Mol Cancer Res. 2007;5(1):1-10.

Gautschi O, Heighway J, Mack PC, Purnell PR, Lara PN Jr, Gandara DR. Aurora kinases as anticancer drug targets. Clin Cancer res 2008;14(6):1639-1648.

Gazdar AF, Oie HK, Shackleton CH, Chen TR, Triche TJ, Myers CE, Chrousos GP, Brennan MF, Stein CA, La Rocca RV. Establishment and characterization of a human adrenocortical carcinoma cell line that expresses multiple pathways of steroid biosynthesis. Cancer Res. 1990 Sep 1;50(17):5488-96.

Giordano TJ, Thomas DG, Kuick R, Lizyness M, Misek DE, Smith AL, Sanders D, Aljundi RT, Gauger PG, Thompson NW, Taylor JM, Hanash SM. Distinct transcriptional profiles of adrenocortical tumors uncovered by DNA microarray analysis. Am J Pathol. 2003;162(2):521-31.

Gisselsson D, Jonson T, Yu C, Martins C, Mandahl N, Wiegant J, Jin Y, Mertens F, Jin C. Centrosomal abnormalities, multipolar mitoses, and chromosomal instability in head and neck tumours with dysfunctional telomeres. Br J Cancer 2002,87(2):202-7.

Gizatullin F, Yao Y, Kung V, Harding MW, Loda M, Shapiro GI. The Aurora kinase inhibitor VX-680 induces endoreduplication and apoptosis preferentially in cells with compromised p53-dependent postmitotic checkpoint function. Cancer Res. 2006;66(15):7668-77.

Glover DM, Leibowitz MH, McLean DA, Parry H. Mutations in aurora prevent centrosome separation leading to the formation of monopolar spindles. Cell 1995;81(1):95-105.

Grego-Bessa J, Luna-Zurita L, del Monte G, Bolós V, Melgar P, Arandilla A, Garratt AN, Zang H, Mukouyama YS, Chen H, Shou W, Ballestar E, Esteller M, Rojas A, Pérez-Pomares JM, de la Pompa JL. Notch signaling is essential for ventricular chamber development. Dev Cell. 2007 Mar; 12(3):415-29. 
Gully CP, Velazquez-Torres G, Shin JH, Fuentes-Mattei E, Wang E, Carlock C, Chen J, Rothenberg D, Adams HP, Choi HH, Guma S, Phan L, Chou PC, Su CH, Zhang F, Chen JS, Yang TY, Yeung SC, Lee MH. Aurora B kinase phosphorylates and instigates degradation of p53. Proc Natl Acad Sci U S A. 2012 Jun 12;109(24):E1513-22.

Guruharsha KG, Kankel MW, Artavanis-Tsakonas S. The Notch signalling system: recent insights into the complexity of a conserved pathway. Nat Rev Genet. 2012;13(9):654-66.

Hobeika AC, Etienne W, Cruz PE, Subramaniam PS, Johnson HM. IFNgamma induction of p21WAF1 in prostate cancer cells: role in cell cycle, alteration of phenotype and invasive potential. Int J Cancer. 1998 3;77(1):138-45.

Hough AJ, Hollifield JW, Page DL, Hartmann WH. Prognostic factors in adrenal cortical tumors. A mathematical analysis of clinical and morphologic data. Am J Clin Pathol. 1979;72(3):390-9.

Hsueh KW, Fu SL, Chang $\mathrm{CB}$, Chang YL, Lin CH. A novel Aurora-A-mediated phosphorylation of p53 inhibits its interaction with MDM2. Biochim Biophys Acta. 2013 Feb;1834(2):508-15.

Huang DW, Sherman BT, Lempicki RA. Systematic and integrative analysis of large gene lists using DAVID Bioinformatics Resources. Nature Protoc. 2009;4(1):44-57.

Huang XF, Luo SK, Xu J, Li J, Xu DR, Wang LH, Yan M, Wang XR, Wan XB, Zheng FM, Zeng YX, Liu Q. Aurora kinase inhibitory VX-680 increases Bax/Bcl-2 ratio and induces apoptosis in Aurora-A-high acute myeloid leukemia. Blood. 2008 Mar 1;111(5):2854-65.

Ishimoto H, Jaffe RB. Development and function of the human fetal adrenal cortex: a key component in the feto-placental unit. Endocr Rev. 2011;32(3):317-55.

Jallepalli PV, Lengauer C. Chromosome segregation and cancer: cutting through the mystery. Nat Rev Cancer. 2001;1(2):109-17.

Jeng YM, Peng SY, Lin CY, Hsu HC. Overexpression and amplification of Aurora A in hepatocellular carcinoma. Clin Cancer Res 2004, 10(6):2065-71.

Kaestner P, Stolz A, Bastians H. Determinants for the efficiency of anticancer drugs targeting either Aurora-A or Aurora- B kinases in human colon carcinoma cells. Mol Cancer Ther. 2009 ;8(7):2046-56. 
Ji Q, Chang L, Stanczyk FZ, Ookhtens M, Sherrod A, Stolz A. Impaired dihydrotestosterone catabolism in human prostate cancer: critical role of $\mathrm{AKR} 1 \mathrm{C} 2$ as a pre-receptor regulator of androgen receptor signaling. Cancer Res. 2007;67(3):1361-9.

Kalous O, Conklin D, Desai AJ, Dering J, Goldstein J, Ginther C, Anderson L, Lu M, Kolarova T, Eckardt MA, Langerød A, Børresen-Dale AL, Slamon DJ, Finn RS. AMG 900, pan-Aurora kinase inhibitor, preferentially inhibits the proliferation of breast cancer cell lines with dysfunctional p53. Breast Cancer Res Treat. 2013;141(3):397-40.

Kam Cheung, Gloria Juan, William Wayne, et al. AMG 900, a Potent and Highly Selective Aurora Kinase Inhibitor Shows Promising Preclinical Activity Against Acute Myeloid Leukemia Cell Lines In Vitro and In Vivo. Blood 2013 122:3823

Katayama H, Sasai K, Kawai H, Yuan ZM, Bondaruk J, Suzuki F, Fujii S, Arlinghaus RB, Czerniak BA, Sen S. Phosphorylation by aurora kinase A induces Mdm2-mediated destabilization and inhibition of p53. Nat Genet. 2004 Jan;36(1):55-62.

Kempná P, Flück CE. Adrenal gland development and defects. Best Pract Res Clin Endocrinol Metab. 2008;22(1):77-93.

Kimura M, Kotani S, Hattori T, Sumi N, Yoshioka T, Todokoro K, Okano Y. Cell cycledependente expression and spindle pole localization of a novel human protein kinase, Aik, related to Aurora of Drosophila and yeast Ipl1. J Biol Chem 1997, 272(21):13766-71.

Kollareddy M, Zheleva D, Dzubak P, Brahmkshatriya PS, Lepsik M, Hajduch M. Aurora kinase inhibitors: Progress towards the clinic. Invest New Drugs. 2012 Feb 18. [Epub ahead of print].

Krämer A, Schweizer S, Neben K, Giesecke C, Kalla J, Katzenberger T, Benner A, MüllerHermelink HK, Ho AD, Ott G. Centrosomome aberrations as a possible mechanism for chromosomal instability in non-Hodgkin's lymphoma. Leukemia 2003,17(11):2207-13.

Kunnimalaiyaan M, Vaccaro AM, Ndiaye MA, Chen H. Overexpression of the NOTCH1 intracellular domain inhibits cell proliferation and alters the neuroendocrine phenotype of medullary thyroid cancer cells. J Biol Chem. 2006;281(52):39819-30.

Kurenova E, Liao J, He DH, Hunt D, Yemma M, Bshara W, Seshadri M, Cance WG. The FAK scaffold inhibitor C4 disrupts FAK-VEGFR-3 signaling and inhibits pancreatic cancer growth. Oncotarget. 2013;4(10):1632-46.

Latronico AC, Pinto EM, Domenice S, Fragoso MC, Martin RM, Zerbini MC, Lucon AM, Mendonca BB. An inherited mutation outside the highly conserved DNA-binding domain of the p53 tumor suppressor protein in children and adults with sporadic adrenocortical tumors. $\mathrm{J}$ Clin Endocrinol Metab. 2001;86(10):4970-3. 
Leal LF, Mermejo LM, Ramalho LZ, Martinelli CE Jr, Yunes JA, Seidinger AL, Mastellaro MJ, Cardinalli IA, Brandalise SR, Moreira AC, Tone LG, Scrideli CA, Castro M, Antonini SR. Wnt/beta-catenin pathway deregulation in childhood adrenocortical tumors. J Clin Endocrinol Metab. 2011;96(10):3106-14.

Lee EC, Frolov A, Li R, Ayala G, Greenberg NM. Targeting Aurora kinases for the treatment of prostate cancer. Cancer Res. 2006 15;66(10):4996-5002.

Lee MH1, Reynisdóttir I, Massagué J. Cloning of p57KIP2, a cyclin-dependent kinase inhibitor with unique domain structure and tissue distribution. Genes Dev. 1995 Mar $15 ; 9(6): 639-49$.

Lengauer C, Kinzler K W, Vogelstein B. Genetic instability in colorectal cancers. Nature 1997,386(6625):623-7.

Lerario AM, Moraitis A, Hammer GD. Genetics and epigenetics of adrenocortical tumors. Mol Cell Endocrinol. 2013 Nov 9. [Epub ahead of print]

Li J, Anderson MG, Tucker LA, Shen Y, Glaser KB, Shah OJ. Inhibition of Aurora B kinase sensitizes a subset of human glioma cells to TRAIL concomitant with induction of TRAILR2. Cell Death Differ. 2009;16(3):498-511.

Li X, Sakashita G, Matsuzaki H, Sugimoto K, Kimura K, Hanaoka F, Taniguchi H, Furukawa $\mathrm{K}$, Urano T. Direct association with inner centromere protein (INCENP) activates the novel chromosomal passenger protein, Aurora-C. J Biol Chem 2004,279(45):47201-11.

Libè R, Fratticci, A Bertherat, J. Adrenocortical cancer: pathophysiology and clinical management. Endocrine-Related Cancer 2007;14:13-28.

Lin FC, Liu YP, Lai CH, Shan YS, Cheng HC, Hsu PI, Lee CH, Lee YC, Wang HY, Wang CH, Cheng JQ, Hsiao M, Lu PJ. RUNX3-mediated transcriptional inhibition of Akt suppresses tumorigenesis of human gastric cancer cells. Oncogene. 2012 Sep 27;31(39):4302-16.

Liu Q, Kaneko S, Yang L, Feldman RI, Nicosia SV, Chen J, Cheng JQ. Aurora-A abrogation of p53 DNA binding and transactivation activity by phosphorylation of serine 215 . J Biol Chem. 2004;279(50):52175-82.

Livak KJ, Schmittgen TD. Analysis of relative gene expression data using real-time quantitative PCR and the 2(-Delta Delta C(T)) Method. Methods. 2001 Dec;25(4):402-8

Lok W, Klein RQ, Saif MW. Aurora kinase inhibitors as anti-cancer therapy. Anticancer Drugs. 2010;21(4):339-50. 
Loncarevic IF, Hering A, Posorski N, et al. Number of genomic imbalances correlates with the overall survival for adrenocortical cancer in childhood. Pediatr Blood Cancer 2008; $51: 356-362$.

Lopes CS, Sunkel CE. The spindle checkpoint: From Normal cell Division to Tumorgenesis. Archives of Medical Research 2003;34:155-165.

Lorea CF, Moreno DA, Borges KS, Martinelli CE Jr, Antonini SR, de Castro M, Tucci S Jr, Neder L, Ramalho LN, Cardinalli I, Seidinger AL, Mastellaro MJ, Yunes JA, Brandalise SR, Tone LG, Scrideli CA. Expression profile of apoptosis-related genes in childhood adrenocortical tumors: low level of expression of BCL2 and TNF genes suggests a poor prognosis. Eur J Endocrinol. 2012;167(2):199-208.

Marumoto T1, Zhang D, Saya H. Aurora-A - a guardian of poles. Nat Rev Cancer. 2005 Jan;5(1):42-50.

Marxer M, Ma HT, Man WY, Poon RY. p53 deficiency enhances mitotic arrest and slippage induced by pharmacological inhibition of Aurora kinases. Oncogene. 2013 Aug 19. doi: 10.1038/onc.2013.325. [Epub ahead of print]

Matthews N, Visintin C, Hartzoulakis B, Jarvis A, Selwood DL. Aurora A and B kinases as targets for cancer: will they be selective for tumors? Exp Rev Anticancer Ther 2006;6(1):109-120.

Mendonca BB, Lucon AM, Menezes CA, et al. Clinical, hormonal and pathological findings in a comparative study of adrenocortical neoplasms in childhood and adulthood. J Urol. 1995; 154:2004-9.

Meraldi, P, Honda, R, Nigg, EA. Aurora kinases link chromosome segregation and cell division to cancer susceptibility. Curr Op in Gen \& Develo 2004;14(1):29-36.

Michalkiewicz E, Sandrini R, Figueiredo B, Miranda EC, Caran E, Oliveira-Filho AG, Marques R, Pianovski MA, Lacerda L, Cristofani LM, Jenkins J, Rodriguez-Galindo C, Ribeiro RC. Clinical and outcome characteristics of children with adrenocortical tumors: a report from the International Pediatric Adrenocortical Tumor Registry. J Clin Oncol. 2004;22(5):838-45.

Miller WL, Auchus RJ. The molecular biology, biochemistry, and physiology of human steroidogenesis and its disorders. Endocr Rev. 2011;32(1):81-151.

Montembault, E., Prigent, C. Aurora kinase: therapeutic potential. Drugs and future 2005;30(1):1-9.

Mountzios G, Terpos E, Dimopoulos MA. Aurora kinases as targets for cancer therapy. Cancer treatment Reviews 2008;34:175-182. 
Mu ZM, Le XF, Vallian S, Glassman AB, Chang KS. Carcinogenesis. Stable overexpression of PML alters regulation of cell cycle progression in HeLa cells. 1997;18(11):2063-9.

Mueller S, Schittenhelm M, Honecker F, Malenke E, Lauber K, Wesselborg S, Hartmann JT, Bokemeyer C, Mayer F. Cell-cycle progression and response of germ cell tumors to cisplatin in vitro. Int J Oncol. 2006;29(2):471-9.

Nair JS, Ho AL, Tse AN, Coward J, Cheema H, Ambrosini G, Keen N, Schwartz GK. Aurora $\mathrm{B}$ kinase regulates the postmitotic endoreduplication checkpoint via phosphorylation of the retinoblastoma protein at serine 780. Mol Biol Cell. 2009;20(8):2218-28.

Neben, K, Korshunov, A, Benner, A. Microarray-Based Screening for Molecular Markers in Medulloblastoma Revealed STK15 as Independent Predictor for Survival. Cancer Res. 2004 1;64(9):3103-11.

Nilubol N, Zhang L, Shen M, Zhang YQ, He M, Austin CP, Kebebew E. Four clinically utilized drugs were identified and validated for treatment of adrenocortical cancer using quantitative high-throughput screening. J Transl Med. 2012 21;10:198.

Nishimoto K, Rigsby CS, Wang T, Mukai K, Gomez-Sanchez CE, Rainey WE, Seki T. Transcriptome analysis reveals differentially expressed transcripts in rat adrenal zona glomerulosa and zona fasciculata. Endocrinology. 2012;153(4):1755-63.

Nitiss JL. Targeting DNA topoisomerase II in cancer chemotherapy. Nat Rev Cancer. 2009;9(5):338-50.

Opocher, G, Schiavi, F, Cicala, MV. Genetics of adrenal tumors. Minerva Endocrinol 2009;34(2):107-21.

Ota T, Suto S, Katayama H, Han ZB, Suzuki F, Maeda M, Tanino M, Terada Y, Tatsuka M. Increase mitotic phosphorylation of histone $\mathrm{H} 3$ attributable to AIM/Aurora-B overexpression contributes to chromosome number instability. Cancer Res 2002,62(18):5168-77.

Ota T, Suto S, Katayama H, Han ZB, Suzuki F, Maeda M, Tanino M, Terada Y, Tatsuka M. Increased mitotic phosphorylation of histone $\mathrm{H} 3$ attributable to AIM-1/Aurora-B overexpression contributes to chromosome number instability. Cancer Res. 2002 15;62(18):5168-77.

Palmero EI, Schüler-Faccini L, Caleffi M, Achatz MI, Olivier M, Martel-Planche G, Marcel V, Aguiar E, Giacomazzi J, Ewald IP, Giugliani R, Hainaut P, Ashton-Prolla P.Detection of $\mathrm{R} 337 \mathrm{H}$, a germline TP53 mutation predisposing to multiple cancers, in asymptomatic women participating in a breast cancer screening program in Southern Brazil. Cancer Lett. 2008;261(1):21-5. 
Payton M, Bush TL, Chung G, Ziegler B, Eden P, et al. Preclinical evaluation of AMG 900, a novel potent and highly selective pan-aurora kinase inhibitor with activity in taxane-resistant tumor cell lines. Cancer Res. 2010:1;70(23):9846-54.

Pérez Fidalgo JA, Roda D, Roselló S, Rodríguez-Braun E, Cervantes A. Aurora kinase inhibitors: a new class of drugs targeting the regulatory mitotic system. Clin Transl Oncol. 2009;11(12):787-98.

Pihan GA, Wallace J, Zhou Y, Doxsey SJ. Centrosome abnormalities and chromosomal instability occur together in pre- invasive carcinomas. Cancer Res 2003, 63(6):1398-404.

Pinto EM, Billerbeck AE, Villares MC, Domenice S, Mendonça BB, Latronico AC. Founder effect for the highly prevalent $\mathrm{R} 337 \mathrm{H}$ mutation of tumor suppressor p53 in Brazilian patients with adrenocortical tumors. Arq Bras Endocrinol Metabol. 2004;48(5):647-50.

Reg G, Kasper M, Schnidar H, Eichberger T, Neill GW, Ikram MS, Quinn AG, Philpott MP, Frischauf AM, Aberger F. The zinc-finger transcription factor GLI2 antagonizes contact inhibition and differentiation of human epidermal cells. Oncogene. 2004 12;23(6):1263-74.

Regan JL, Sourisseau T, Soady K, Kendrick H, McCarthy A, Tang C, Brennan K, Linardopoulos S, White DE, Smalley MJ. Aurora A kinase regulates mammary epithelial cell fate by determining mitotic spindle orientation in a Notch-dependent manner. Cell Rep. 2013 $11 ; 4(1): 110-23$.

Reznikoff CA, Belair CD, Yeager TR, Savelieva E, Blelloch RH, Puthenveettil JA, Cuthill S. A molecular genetic model of human bladder pathogenesis. Semin Oncol 1996,23(5):571-84.

Ribeiro RC, Figueiredo B. Childhood adrenocortical tumours. Eur J Câncer 2004;40:11171126.

Ribeiro RC, Pinto EM, Zambetti GP, Rodriguez-Galindo C. The International Pediatric Adrenocortical Tumor Registry initiative: contributions to clinical, biological, and treatment advances in pediatric adrenocortical tumors. Mol Cell Endocrinol. 2012;351(1):37-43.

Ribeiro RC, Sandrini F, Figueiredo B, Zambetti GP, Michalkiewicz E, Lafferty AR, DeLacerda L, Rabin M, Cadwell C, Sampaio G, Cat I, Stratakis CA, Sandrini R. An inherited p53 mutation that contributes in a tissue-specific manner to pediatric adrenal cortical carcinoma. Proc Natl Acad Sci U S A. 2001 Jul 31;98(16):9330-5.

Rodriguez H, Hum DW, Staels B, Miller WL. Transcription of the human genes for cytochrome P450scc and P450c17 is regulated differently in human adrenal NCI-H295 cells than in mouse adrenal Y1 cells. J Clin Endocrinol Metab. 1997;82(2):365-71. 
Rodriguez-Galindo C, Figueiredo BC, Zambetti GP, Ribeiro RC 2005 Biology, clinical characteristics, and management of adrenocortical tumors in children. Pediatr Blood Cancer 45:265-273.

Ronchi CL, Leich E, Sbiera S, Weismann D, Rosenwald A, Allolio B, Fassnacht M. Single nucleotide polymorphism microarray analysis in cortisol-secreting adrenocortical adenomas identifies new candidate genes and pathways. Neoplasia. 2012;14(3):206-18.

Sandrini R, Ribeiro RC, DeLacerda L. Childhood adrenocortical tumors. J Clin Endocrinol Metab. 1997;82(7):2027- 31.

Sasai K, Katayama H, Stenoien DL, Fujii S, Honda R, Kimura M, Okano Y, Tatsuka M, Suzuki F, Nigg EA, Earnshaw WC, Brinkley WR, Sen S. Aurora-C kinase is a novel chromosomal passenger protein that can complement Aurora-B kinase function in mitotic cells. Cell motil Cytoskeleton 2004,59(4):249-63.

Sato N, Mizumoto K, Nakamura M, Maehara N, Minamishima YA, Nishio S, Nagai E, Tanaka M. Correlation between centrosome abnormalities and chromosomal instability in human pancreatic cancer cells. Cancer Genetic Cytogenetic 2001,126(1):13-9.

Saunders WS, Shuster M, Huang X, Gharaibeh B, Enyenihi AH, Petersen I, Gollin SM. Chromosomal instability and cytoskeletal defects in oral cancer cells. Proc Natl acad Sci USA 2000,97(1)303-8.

Sbragia L, Oliveira-Filho AG, Vassallo J, Pinto GA, Guerra-Junior G, Bustorff-Silva J. Adrenocortical tumors in Brazilian children: immunohistochemical markers and prognostic factors. Arch Pathol Lab Med. 2005 ;129(9):1127-31.

Schmidt M, Bastians H. Mitotic drug targets and the developed of novel anti-mitotic anticancer drugs. Drug Resistance Updates 2007;10:162-181.

Scrideli CA, Carlotti CG Jr, Okamoto OK, Andrade VS, Cortez MA, Motta FJ, LucioEterovic AK, Neder L, Rosemberg S, Oba-Shinjo SM, Marie SK, Tone LG. Gene expression profile analysis of primary glioblastomas and non-neoplastic brain tissue: identification of potential target genes by oligonucleotide microarray and real-time quantitative PCR. J Neurooncol. 2008;88(3):281-91.

Sehdev V, Peng D, Soutto M, Washington MK, Revetta F, Ecsedy J, Zaika A, Rau TT, Schneider-Stock R, Belkhiri A, El-Rifai W. The aurora kinase A inhibitor MLN8237 enhances cisplatin-induced cell death in esophageal adenocarcinoma cells. Mol Cancer Ther. 2012;11(3):763-74. 
Seidinger AL, Mastellaro MJ, Paschoal Fortes F, Godoy Assumpção J, Aparecida Cardinalli I, Aparecida Ganazza M, Correa Ribeiro R, Brandalise SR, Dos Santos Aguiar S, Yunes JA. Association of the highly prevalent TP53 R337H mutation with pediatric choroid plexus carcinoma and osteosarcoma in southeast Brazil. Cancer. 2011;117(10):2228-35.

Shen H, Perez RE, Davaadelger B, Maki CG. Two 4N cell-cycle arrests contribute to cisplatin-resistance. PLoS One. 2013;8(4):e59848.

Simon DP, Giordano TJ, Hammer GD. Upregulated JAG1 enhances cell proliferation in adrenocortical carcinoma. Clin Cancer Res. 2012;18(9):2452-64.

Sirianni R, Zolea F, Chimento A, Ruggiero C, Cerquetti L, Fallo F, Pilon C, Arnaldi G, Carpinelli G, Stigliano A, Pezzi V. Targeting estrogen receptor- $\alpha$ reduces adrenocortical cancer (ACC) cell growth in vitro and in vivo: potential therapeutic role of selective estrogen receptor modulators (SERMs) for ACC treatment. J Clin Endocrinol Metab. 2012 Dec;97(12):E2238-50.

Steckelbroeck, S., Nassen, A., Ugele, B., Ludwig, M., Watzka, M., Reissinger, A., Clusmann, H., Lütjohann, D., Siekmann, L., Klingmüller, D. and Hans, V. H. (2004), Steroid sulfatase (STS) expression in the human temporal lobe: enzyme activity, mRNA expression and immunohistochemistry study. Journal of Neurochemistry 89: 403-417.

Stephan EA, Chung TH, Grant CS, et al. Adrenocortical carcinoma survival rates correlated to genomic copy number variants. Mol Cancer Ther 2008; 7:425-431.

Sun T, Oh WK, Jacobus S, Regan M, Pomerantz M, Freedman ML, Lee GS, Kantoff PW. The impact of common genetic variations in genes of the sex hormone metabolic pathways on steroid hormone levels and prostate cancer aggressiveness. Cancer Prev Res (Phila). 2011;4(12):2044-50.

Sun W, Gaykalova DA, Ochs MF et al. Activation of the NOTCH Pathway in Head and Neck Cancer. Cancer Res. 2014;74(4):1091-104.

Sutter JA, Grimberg A. Adrenocortical tumors and hyperplasias in childhood--etiology, genetics, clinical presentation and therapy. Pediatr Endocrinol Rev. 2006 Sep;4(1):32-9.

Tanaka T, Kimura M, Matsunaga K, Fukada D, Mori H, Okano Y. Centrosomal kinase AIK1 is overexpressed in invasive ductal carcinoma of the breast. Cancer Res. 1999 May 1;59(9):2041-4.

Tanner MM, Grenman S, Koul A, Johannsson O, Meltzer P, Pejovic T, Borg A, Isola JJ. Frequent amplification of chromosomal region 20q12-q13 in ovarian cancer. Clinical Cancer Res 2000,6(5):1833-9. 
Tatsuka M, Katayama H, Ota T, Tanaka T, Odashima S, Suzuki F, Terada Y. Multinuclearity and increased ploidy caused by overexpression of the aurora- and Ipll-like midbodyassociated protein mitotic kinase in human cancer cells. Cancer Res. 1998 Nov 1;58(21):4811-6.

Tsuchiya Y, Nakajima M, Yokoi T. Cytochrome P450-mediated metabolism of estrogens and its regulation in human. Cancer Lett. 2005 28;227(2):115-24

Tucci S Jr, Martins AC, Suaid HJ, Cologna AJ, Reis RB. The impact of tumor stage on prognosis in children with adrenocortical carcinoma. J Urol. 2005;174(6):2338-42, discussion 2342 .

van Slooten H, Schaberg A, Smeenk D, Moolenaar AJ. Morphologic characteristics of benign and malignant adrenocortical tumors. Cancer 1985;55:766-73.

Veytsman I, Nieman L, Fojo T. Management of endocrine manifestations and the use of mitotane as a chemotherapeutic agent for adrenocortical carcinoma. J Clin Oncol. 2009;27(27):4619-29

Wajchenberg BL, Albergaria Pereira MA, Medonca BB, et al. Adrenocortical carcinoma: clinical and laboratory observations. Cancer. 2000; 88:711-36.

Wang H, Somers GW, Bashirullah A, Heberlein U, Yu F, Chia W. Aurora-A acts as a tumor suppressor and regulates self-renewal of Drosophila neuroblasts. Genes Dev. 2006 Dec 15;20(24):3453-63.

Wang R, Dashwood WM, Nian H, Löhr CV, Fischer KA, Tsuchiya N, Nakagama H, Ashktorab H, Dashwood RH. NADPH oxidase overexpression in human colon cancers and rat colon tumors induced by 2-amino-1-methyl-6-phenylimidazo[4,5-b]pyridine (PhIP). Int J Cancer. 2011 Jun 1;128(11):2581-90.

Wang T, Rainey WE. Human adrenocortical carcinoma cell lines. Mol Cell Endocrinol. 2012; 351(1): 58-65.

Watanabe M, Nakajin S. Forskolin up-regulates aromatase (CYP19) activity and gene transcripts in the human adrenocortical carcinoma cell line H295R. J Endocrinol. 2004;180(1):125-33.

Wieneke JA, Thompson LD, Heffess CS. Adrenal cortical neoplasms in the pediatric population: a clinicopathologic and immunophenotypic analysis of 83 patients. Am J Surg Pathol. 2003; 27:867-81. 
Weiss LM. Comparative histologic study of 43 metastasizing and non metastasizing adrenal cortical tumors. Am J Surg Pathol v. 8, p. 163-169, 1984.

Winter GE, Rix U, Lissat A, Stukalov A, Müllner MK, Bennett KL, Colinge J, Nijman SM, Kubicek S, Kovar H, Kontny U, Superti-Furga G. An integrated chemical biology approach identifies specific vulnerability of Ewing's sarcoma to combined inhibition of Aurora kinases A and B. Mol Cancer Ther. 2011;10(10):1846-56.

Wu CC, Yang TY, Yu CT, Phan L, Ivan C, Sood AK, Hsu SL, Lee MH. p53 negatively regulates Aurora A via both transcriptional and posttranslational regulation. Cell Cycle. 2012;11(18):3433-42.

Yamamoto N, Yamamoto S, Inagaki F, Kawaichi M, Fukamizu A, Kishi N, Matsuno K, Nakamura K, Weinmaster G, Okano H, Nakafuku M. Role of Deltex-1 as a transcriptional regulator downstream of the Notch receptor. J Biol Chem. 2001 30;276(48):45031-40.

Yang X1, Xu Y, Guo F, Ning Y, Zhi X, Yin L, Li X. Hydroxysteroid sulfotransferase SUL T2B1b promotes hepatocellular carcinoma cells proliferation in vitro and in vivo. PLoS One. $2013 ; 8(4): \mathrm{e} 60853$

Zancanella P, Pianovski MA, Oliveira BH, Ferman S, Piovezan GC, Lichtvan LL, Voss SZ, Stinghen ST, Callefe LG, Parise GA, Santana MH, Figueiredo BC. Mitotane associated with cisplatin, etoposide, and doxorubicin in advanced childhood adrenocortical carcinoma: mitotane monitoring and tumor regression. J Pediatr Hematol Oncol. 2006 Aug;28(8):513-24.

Zanotti S, Canalis E. Notch and the skeleton. Mol Cell Biol. 2010;30(4):886-96.

Zhang D, Hirota T, Marumoto T, Shimizu M, Kunitoku N, Sasayama T, Arima Y, Feng L, Suzuki M, Takeya M, Saya H. Cre-loxP-controled periodic Aurora-A overexpression induces mitotic abnormalities and hyperplasia in mammary glands of mouse models. Oncogene 2004,23(54):8720-30.

Zhang K, Wong P, Zhang L, Jacobs B, Borden EC, Aster JC, Bedogni B. A Notch1neuregulin1 autocrine signaling loop contributes to melanoma growth. Oncogene. 2012 25;31(43):4609-18.

Zhang L, Zhang S. ZM447439, the Aurora kinase B inhibitor, suppresses the growth of cervical cancer SiHa cells and enhances the chemosensitivity to cisplatin. J Obstet Gynaecol Res. 2011;37(6):591-600.

Zhou H, Kuang J, Zhong L, Kuo WL, Gray JW, Sahin A, Brinkley BR, Sen S. Tumour amplified kinase STK15/BTAK induces centrosome amplification, aneuploidy and transformation. Nat Gentec 1998,20(2):189-93. 
Zhu BT, Conney AH. Functional role of estrogen metabolism in target cells: review and perspectives. Carcinogenesis. 1998;19(1):1-27

Zhun YU, Jiang GENG, Jun-hua ZHENG, Bin YANG, Qi-ruo GAO, Guang-chun WANG, Bo PENG. Small interfering RNA targeting REG1A gene inhibits the proliferation of human bladder cancer cell line T24 in vitro. Tumor 2012;32(3):159-163. 


\section{ANEXOS}




\subsection{Anexo I}

(Tabela dos parâmetros clínicos e patológicos dos pacientes pediátricos com tumor adrenocortical)

Parâmetros avaliados: Sexo; Idade; Diagnóstico patológico (Adenoma ou Carcinoma); Apresentação clínica (hormonal); Tamanho tumoral em gramas e $\mathrm{cm}^{3}$; Estadio tumoral de acordo com a classificação de Sandrini modificada (Rodriguez-Galindo et al. (2005); Presença da mutação TP53-R337H; Evento (remissão ou óbito-recidiva); Sobrevida livre de eventos; Óbito; e Sobrevida geral (seguimento em meses).

\begin{tabular}{|c|c|c|c|c|c|c|c|c|c|c|c|c|}
\hline Paciente & Sexo & \begin{tabular}{|c|}
$\begin{array}{c}\text { Idade ao diagóstico } \\
\text { (meses) }\end{array}$ \\
\end{tabular} & Patologia & $\begin{array}{c}\text { Clínica } \\
\text { (Hormonal) }\end{array}$ & $\begin{array}{l}\text { Tamanho } \\
\text { tumor }(g)\end{array}$ & $\begin{array}{l}\text { Tamanho } \\
\text { tumor }\left(\mathrm{cm}^{3}\right)\end{array}$ & $\begin{array}{c}\text { Estadio } \\
\text { (Sandrini) }\end{array}$ & TP53-R337H & $\begin{array}{c}\text { Evento } \\
\text { (remissão / óbito-recidiva) } \\
\end{array}$ & $\begin{array}{c}\text { SLE } \\
\text { (meses) }\end{array}$ & Óbito & $\begin{array}{c}\begin{array}{c}\text { Sobrevida Geral } \\
\text { (meses) }\end{array} \\
\end{array}$ \\
\hline 7 & Feminino & 22 & Adenoma & Virilização & 39 & 12 & I & Sim & Não & 55.5 & Não & 55.5 \\
\hline 54 & Feminino & 96 & Carcinoma & Misto & 580 & 1008 & IV & Sim & Sim & 23.3 & Sim & 23.3 \\
\hline 57 & Feminino & 13 & Carcinoma & Virilização & 40 & 38 & I & Sim & Não & 54.2 & Não & 54.2 \\
\hline 58 & Masculino & 27 & Adenoma & Misto & 80 & 150 & II & Sim & Não & 162.2 & Não & 162.2 \\
\hline 59 & Masculino & 12 & Carcinoma & Virilização & 102 & 91 & II & Sim & Não & 16 & Não & 16 \\
\hline 82 & Feminino & 29 & Carcinoma & Virilização & 80 & 47 & I & Sim & Sim & 15.7 & $\operatorname{Sim}$ & 15.7 \\
\hline 96 & Feminino & 17 & Adenoma & Virilização & 20 & 25 & I & Sim & Não & 116.2 & Não & 116.2 \\
\hline 105 & Masculino & 11 & Carcinoma & Virilização & 25.9 & 63 & I & Sim & Não & 157.8 & Não & 157.8 \\
\hline 146 & Feminino & 17 & Carcinoma & Virilização & 50 & 56 & I & Sim & Não & 116.2 & Não & 37.5 \\
\hline 150 & Feminino & 137 & Carcinoma & NS & 2350 & 3300 & II & Não & Sim & 53 & Não & 130 \\
\hline 164 & Feminino & 84 & Carcinoma & Virilização & 230 & 365 & IV & Sim & Sim & 16 & $\mathrm{LS}$ & 16.8 \\
\hline 170 & Masculino & 20 & Carcinoma & Misto & 60 & 69 & I & Sim & Sim & 8 & Não & 155.9 \\
\hline 171 & Feminino & 94 & Carcinoma & Misto & 380 & 544 & IV & Sim & Sim & 2.8 & $\operatorname{Sim}$ & 19.9 \\
\hline 179 & Masculino & 21 & Carcinoma & NS & 75 & 196 & IV & Não & Não & 75.8 & Não & 75.8 \\
\hline 189 & Feminino & 19 & Carcinoma & Virilização & ND & 4 & I & Sim & Não & 76 & Não & 76 \\
\hline
\end{tabular}




\begin{tabular}{|c|c|c|c|c|c|c|c|c|c|c|c|c|}
\hline Paciente & Sexo & \begin{tabular}{|c|}
$\begin{array}{c}\text { Idade ao diagóstico } \\
\text { (meses) }\end{array}$ \\
\end{tabular} & Patologia & $\begin{array}{c}\text { Clínica } \\
(\text { Hormonal })\end{array}$ & $\begin{array}{l}\text { Tamanho } \\
\text { tumor }(\mathrm{g})\end{array}$ & $\begin{array}{l}\text { Tamanho } \\
\text { tumor }\left(\mathrm{cm}^{3}\right)\end{array}$ & $\begin{array}{c}\text { Estadio } \\
\text { (Sandrini) }\end{array}$ & TP53-R337H & $\begin{array}{c}\text { Evento } \\
\text { (remissão / óbito-recidiva) }\end{array}$ & $\begin{array}{c}\text { SLE } \\
\text { (meses) }\end{array}$ & Óbito & \begin{tabular}{|c|}
$\begin{array}{c}\text { Sobrevida Geral } \\
\text { (meses) }\end{array}$ \\
\end{tabular} \\
\hline 195 & Masculino & 11 & Adenoma & Misto & 40 & 53 & I & Não & Não & 148.9 & Não & 148.9 \\
\hline 209 & Feminino & 73 & Adenoma & Misto & 3.3 & 1.8 & I & Não & Não & 137.3 & Não & 137.3 \\
\hline 234 & Feminino & 12 & Carcinoma & Virilização & 38 & 17 & I & Sim & Não & 29.3 & Não & 29.3 \\
\hline 235 & Feminino & 29 & Carcinoma & Virilização & 377 & 810 & III & Sim & Não & 134.8 & Não & 134.8 \\
\hline 264 & Feminino & 92 & Indeterminado & Virilização & 102 & 73 & II & Sim & Não & 35.7 & Não & 35.7 \\
\hline 290 & Masculino & 13 & Carcinoma & Virilização & 7 & 214 & IV & Sim & Não & 164.8 & Não & 168.4 \\
\hline 328 & Feminino & 10 & Carcinoma & Virilização & 38 & 23 & I & Sim & Não & 57.3 & Não & 57.3 \\
\hline 351 & Feminino & 29 & Carcinoma & Virilização & 40 & 23 & I & Sim & Não & 51.4 & Não & 51.4 \\
\hline 361 & Feminino & 36 & Carcinoma & Misto & 16 & 26 & I & Sim & Não & 92.4 & Não & 92.4 \\
\hline 383 & Feminino & 16 & Adenoma & Misto & 35 & 75 & I & Sim & Não & 120.9 & Não & 120.9 \\
\hline 387 & Feminino & 16 & Carcinoma & Virilização & 185 & 174 & II & Sim & Sim & 0.4 & Sim & 0.4 \\
\hline 387 & Masculino & 185 & Carcinoma & Cushing & 703 & 1120 & IV & Sim & Sim & 1 & Sim & 9 \\
\hline 393 & Masculino & 36 & Carcinoma & Misto & 44 & 13 & I & Sim & Sim & 38 & Não & 66.5 \\
\hline 394 & Feminino & 108 & Carcinoma & Misto & 520 & 472 & II & Sim & Sim & 9.9 & Sim & 9.9 \\
\hline 397 & Feminino & 23 & Adenoma & Misto & 39 & 51 & I & Sim & Não & 51.6 & Não & 51.6 \\
\hline 400 & Feminino & 15 & Carcinoma & NS & 70 & 12 & I & Sim & Não & 19.4 & Não & 19.4 \\
\hline 410 & Masculino & 129 & Carcinoma & Virilização & 155 & 164 & II & Sim & Sim & 21 & Sim & 21 \\
\hline 412 & Feminino & 187 & Carcinoma & Virilização & 570 & 619 & II & Não & Não & 75.8 & Não & 75.8 \\
\hline 415 & Feminino & 17 & Carcinoma & Virilização & 385 & 400 & II & Sim & Não & 69.8 & Não & 69.8 \\
\hline 430 & Feminino & 20 & Carcinoma & Misto & 113 & 295 & III & Sim & Sim & 4.5 & LS & 4.5 \\
\hline 446 & Feminino & 22 & Carcinoma & Misto & 84 & 30 & I & Sim & No & 7.7 & No & 7.7 \\
\hline 470 & Feminino & 16 & Carcinoma & Virilização & 68 & 70 & III & Sim & No & 17 & No & 17 \\
\hline 487rp & Feminino & 19 & Carcinoma & Virilização & 228 & 28 & III & Sim & No & 13 & No & 13 \\
\hline 487camp & Feminino & 13 & Carcinoma & Virilização & 20 & 697 & III & Sim & No & 49.6 & No & 49.6 \\
\hline 525 & Masculino & 33 & Carcinoma & Cushing & 828 & 2025 & IV & Sim & Sim & 8 & Sim & 8 \\
\hline
\end{tabular}




\begin{tabular}{|c|c|c|c|c|c|c|c|c|c|c|c|c|}
\hline Paciente & Sexo & $\begin{array}{c}\text { Idade ao diagóstico } \\
\text { (meses) }\end{array}$ & Patologia & $\begin{array}{c}\text { Clínica } \\
\text { (Hormonal) }\end{array}$ & $\begin{array}{l}\text { Tamanho } \\
\text { tumor (g) }\end{array}$ & $\begin{array}{l}\text { Tamanho } \\
\text { tumor }\left(\mathrm{cm}^{3}\right)\end{array}$ & $\begin{array}{l}\text { Estadio } \\
\text { (Sandrini) }\end{array}$ & TP53-R337H & $\begin{array}{c}\text { Evento } \\
\text { (remissão / óbito-recidiva) }\end{array}$ & $\begin{array}{c}\text { SLE } \\
\text { (meses) }\end{array}$ & Óbito & $\begin{array}{c}\text { Sobrevida Geral } \\
\text { (meses) }\end{array}$ \\
\hline 532 & Feminino & 18 & Carcinoma & Virilização & 15 & 7 & I & Sim & Sim & . & No & 97 \\
\hline 545 & Masculino & 34 & Adenoma & Misto & 28.5 & 50 & I & Sim & No & 101 & No & 101 \\
\hline 596 & Feminino & 12 & Carcinoma & Virilização & 30 & 13 & I & Sim & No & 66.9 & No & 66.9 \\
\hline 613 & Feminino & 13 & Carcinoma & Virilização & 160 & 114 & II & No & No & 86.5 & No & 86.5 \\
\hline 632 & Feminino & 19 & Carcinoma & Virilização & 340 & 411 & III & Sim & Sim & 7.6 & Sim & 7.6 \\
\hline 686 & Feminino & 22 & Carcinoma & Misto & 20 & 31 & I & Sim & Sim & 15.8 & LS & 15.8 \\
\hline 687 & Feminino & 25 & Carcinoma & Virilização & 65 & 39 & I & Sim & No & 42.6 & No & 42.6 \\
\hline 698 & Feminino & 145 & Adenoma & Misto & 53 & 157 & I & No & No & 80.6 & No & 80.6 \\
\hline 702 & Feminino & 10 & Carcinoma & Virilização & 35 & 10 & I & Sim & No & 51.7 & No & 51.7 \\
\hline 740 & Feminino & 44 & Adenoma & Virilização & 20 & 22 & I & Sim & No & 110.4 & No & 110.4 \\
\hline 748 & Masculino & 52 & Carcinoma & Virilização & 810 & 621 & III & Sim & No & 57.6 & No & 57.6 \\
\hline 762 & Masculino & 5 & Carcinoma & Virilização & 20 & 16 & I & Sim & No & 76.9 & No & 76.9 \\
\hline 799 & Feminino & 66 & Carcinoma & Misto & 351 & 720 & III & Sim & Sim & 1 & Sim & 15.5 \\
\hline 811 & Feminino & 38 & Carcinoma & Misto & 6 & 5 & I & Sim & No & 9.8 & No & 9.8 \\
\hline 840 & Feminino & 64 & Adenoma & Virilização & 55 & 34 & I & Sim & Sim & . & No & 88 \\
\hline 922 & Feminino & 23 & Adenoma & Virilização & 39 & 51 & I & Sim & No & 82 & No & 82 \\
\hline 950 & Feminino & 5 & Carcinoma & Virilização & 53 & 175 & I & Sim & No & 62 & No & 62 \\
\hline 1116 & Feminino & 28 & Adenoma & Virilização & 15 & 36 & I & No & No & 39.8 & No & 39.8 \\
\hline
\end{tabular}

NA - Dados não disponíveis; LS - Perda de seguimento; SLE - Sobrevida Livre de Evento 


\subsection{Anexo II}

Sobrevida livre de eventos em 5 anos e Sobrevida Geral de acordo com as características clínicas e com a classficção de Sandrini.

\begin{tabular}{|c|c|c|c|c|}
\hline & SLE-5 anos & $\mathbf{P}$ & $\begin{array}{l}\text { Sobrevida geral } \\
\qquad 5 \text { anos }\end{array}$ & $\mathbf{P}$ \\
\hline \multicolumn{5}{|l|}{ Idade } \\
\hline$<4$ anos $(n: 46)$ & $81.2 \pm 6.0$ & $0.002^{*}$ & $90.6 \pm 4.5$ & $0.004^{*}$ \\
\hline$\geq 4 \operatorname{anos}(n: 14)$ & $36.9 \pm 13.8$ & & $53.8 \pm 13.8$ & \\
\hline \multicolumn{5}{|l|}{ Tamanho do tumor } \\
\hline$<\operatorname{logg}(n: 40)$ & $88.3 \pm 5.5$ & $<0.001 *$ & $97.2 \pm 2.7$ & $<0.001 *$ \\
\hline$\geq \operatorname{logg}(n: 20)$ & $36.7 \pm 11.6$ & & $48.5 \pm 12.1$ & \\
\hline$<200 \mathrm{~cm}^{3}(\mathrm{n}: 44)$ & $84.4 \pm 5.9$ & $<0.001 *$ & $92.5 \pm 4.2$ & $<0.001 *$ \\
\hline$\geq 200 \mathrm{~cm}^{3}(\mathrm{n}: 16)$ & $35.2 \pm 12.4$ & & $47.6 \pm 13.8$ & \\
\hline \multicolumn{5}{|l|}{ Patologia $^{I}$} \\
\hline Weiss criteria $<3$ (n:13) & $100.0 \pm 0.0$ & $0.01 *$ & $100.0 \pm 0.0$ & $0.05^{*}$ \\
\hline Weiss criteria $\geq 3$ (n:46) & $60.7 \pm 7.9$ & & $74.8 \pm 7.0$ & \\
\hline \multicolumn{5}{|l|}{ TP53 R337H } \\
\hline Negativo (n:8) & $85.7 \pm 13.2$ & 0.24 & $100.0 \pm 0.0$ & 0.16 \\
\hline Positivo (n:52) & $68.0 \pm 6.9$ & & $78.1 \pm 6.1$ & \\
\hline \multicolumn{5}{|l|}{ Classificação (Sandrini) } \\
\hline Estadio 1 (n:35) & $86.8 \pm 6.2$ & $0.003^{*}$ & $96.9 \pm 3.1$ & $0.001 *$ \\
\hline Estadio II (n:10) & $54.9 \pm 17.2$ & & $68.6 \pm 15.1$ & \\
\hline Estadio III (n:8) & $62.5 \pm 17.1$ & & $68.6 \pm 18.6$ & \\
\hline Estadio IV (n:7) & $28.6 \pm 17.1$ & & $33.3 \pm 19.2$ & \\
\hline
\end{tabular}

${ }^{1}$ - 1 paciente com escore indeterminado

* - Estatisticamente significativo $(\mathrm{P} \leq 0.05)$ 


\subsection{Anexo III}

Aprovação do projeto pelo Comitê de Ética em Pesquisa HCRP e FMRP-USP; Processo HCRP n $\left.{ }^{\circ} 8380 / 2010\right)$

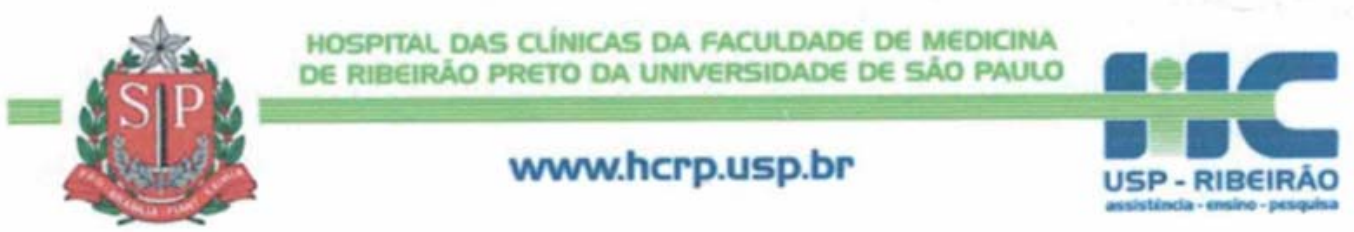

Ribeirão Preto, 23 de julho de 2010

Oficio $\mathrm{n}^{\circ} 2436 / 2010$

$\mathrm{CEP} / \mathrm{MGV}$

Prezado Professor,

O trabalho intitulado "ESTUDOS MOLECULARES EM NEOPLASIAS DA CRIANÇA E DO ADOLESCENTE: ASSINATURA DE MICRORNAS E ESTUDOS FUNCIONAIS DE GENES CANDIDATOS A TERAPIA ALVO" foi analisado "AD REFERENDUM" pelo Comitê de Ética em Pesquisa e enquadrado na categoria: APROVADO, bem como o Termo de Consentimento Livre e Esclarecido, de acordo com o Processo HCRP $\mathrm{n}^{\circ} 8380 / 2010$.

Este Comitê segue integralmente a Conferência Internacional de Harmonizaçāo de Boas Práticas Clínicas (IGH-GCP), bem como a Resoluçâo nº 196/96 CNS/MS.

Lembramos que devem ser apresentados a este CEP, O Relatório Parcial e o Relatório Final da pesquisa.

Atenciosamente.

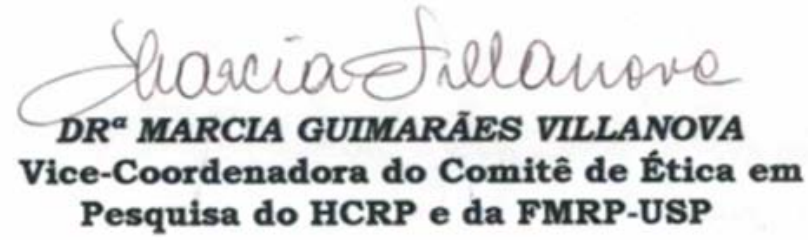

Ilustríssimo Senhor

PROF. DR. CARLOS ALBERTO SCRIDELI

Depto. de Puericultura e Pediatria

Comitê de Ética em Pesquisa HCRP e FMRP-USP - Campus Universitário

FWA - 0000 2733; IRB - 00002186 e Registro SISNEP/CONEP nº 4

Fone (16) 3602-2228 - E-mail : cep $a$ herp.usp.br

Monte Alegre 14048-900 Ribeiråo Preto SP 


\title{
8.4 Anexo IV
}

\section{Spindle Assembly Checkpoint Gene Expression in Childhood Adrenocortical Tumors (ACT): Overexpression of Aurora Kinases A and B Is Associated With a Poor Prognosis}

\author{
Kleiton Silva Borges, MSc, ${ }^{1}$ Daniel Antunes Moreno, PhD, ${ }^{1}$ Carlos Eduardo Martinelli Jr., MD, PhD, ${ }^{2}$ \\ Sonir Roberto Rauber Antonini, MD, PhD, ${ }^{2}$ Margaret de Castro, MD, PhD, ${ }^{3}$ Silvio Tucci Jr., MD, PhD, ${ }^{4}$ \\ Luciano Neder, MD, PhD, ${ }^{5}$ Leandra Naira Zambelli Ramalho, MD, PhD, ${ }^{5}$ Ana Luiza Seidinger, PhD, ${ }^{6}$ \\ Izilda Cardinalli, MD, PhD, ${ }^{6}$ Maria José Mastellaro, MD, PhD, ${ }^{6}$ José Andres Yunes, PhD, ${ }^{6}$ Silvia Regina Brandalise, $\mathrm{MD}, \mathrm{PhD},{ }^{6}$ \\ Luiz Gonzaga Tone, MD, PhD, ${ }^{1,2}$ and Carlos Alberto Scrideli, MD, PhD ${ }^{2 *}$ \\ Background. Pediatric adrenocortical tumors (ACT) are rare \\ malignancies and treatment has a small impact on survival in \\ dvanced disease and the di \\ mportant in new therapeutic approaches. Methods. The mRNA \\ expression levels of spindle checkpoint genes $A \cup R K A, A \cup R K B, B \cup B$, \\ and $B \cup B R 1$ were analyzed in 60 children with $A C T$ by quantitative \\ real time PCR. The anticancer effect of ZM447439, an experimental \\ AURK inhibitor, was analyzed in a primary childhood ACT culture \\ carrying the TP53 P.R337H mutation. Results. A significant \\ P.R337H mution. Results. A significant \\ association was \\ core $\geq 3$ and higher $A U R K A$ (2.0-fold, $P=0.01$ ), $A U R K B$ (7.0-fold, \\ $P=0.007$ ), and $B \cup B R 1$ (5.8-fold, $P=0.007$ ) gene expression, and \\ between unfavorable event (death or relapse) and higher expression \\ Key words: adrenocortical tumor; AURK; childhood; prognosis; spindle assembly checkpoint genes \\ of AURKA (6.0-fold, $P=0.034)$ and $A U R K B(17$-fold, $P=0.013)$. \\ Overexpression of $A \cup R K A$ and $A \cup R K B$ was associated with lower \\ event-free survival in uni- $(P<0.001$ and $P=0.006$, respectively) and \\ multivariate $(P=0.002$ and $P=0.03$, respectively) analysis. Signifi- \\ cant lower Event free survival (EFS) was also observed in patients with \\ moderate/strong immunostaining to AURKA $(P=0.012)$ and AURKB \\ $(P=0.045)$. ZM447439 was able to induce inhibition of proliferation \\ and colony formation in a primary childhood $A C T$ culture carrying \\ Conclusion. Our results suggest that \\ $A U R K A$ and $A U R K B$ overexpression in pediatric $A C T$ may be related \\ to more aggressive disease and the inhibition of these proteins could \\ be an interesting approach for the treatment of these tumors. Pediatr \\ Blood Cancer 2013;60:1809-1816. 2013 Wiley Periodicals, Inc.
}

\section{INTRODUCTION}

Pediatric adrenocortical tumors (ACT) are very rare malignancies corresponding to only $0.2 \%$ of pediatric cancers [1-3] However, in Southern Brazil an inherited germline TP53 mutation (p.R337H) greatly increases the predisposition to the development of childhood ACT, whose incidence is $10-15$ higher than the worldwide rate. This heterozygous germline mutation has been found in over $80 \%$ of Brazilian patients with childhood ACT [4-6]

Current therapy for pediatric ACT primarily relies on surgical resection of the tumor. Mitotane (a DDT-related compound), with or without DNA-damaging agents, has been used in advanced disease, although with small impact on survival [3]. The overall 5 year disease-free survival is estimated at $50 \%$; however, patients with stage IV disease have less than a $20 \%$ chance of long-term survival $[5,6]$. Thus, new therapeutic approaches are needed to improve the survival of these patients.

Chromosomal instability (CIN) is a hallmark of cancer [7] Several studies have shown high levels of CIN in adrenocortical carcinoma $[8,9]$, inclusive in childhood patients where chromosomal imbalances were associated with overall survival and tumor progression $[10,11]$. Several genes are related with development of CIN, among them are the spindle checkpoint genes [12]

Spindle checkpoint genes are important for chromosome segregation during mitosis. A faithful segregation of the duplicate chromosomes is required to preserve the genome stability and one of the main mechanisms of cell division control is the spindle assembly checkpoint (SAC) [12]. SAC is a cell cycle surveillance system that ensures proper kinetochore-microtubule attachment, being essential to avoid chromosome missegregation [13]. The SAC is composed of several signaling proteins including the Aurora kinase family, budding uninhibited by benzimidazoles 1 (BUB1), BUB2, BUB3, and BUB1 homologue beta (BUB1B, also known as BUBR1), mitotic arrest

(C) 2013 Wiley Periodicals, Inc.

DOI $10.1002 / \mathrm{pbc} .24653$

Published online 20 June 2013 in Wiley Online Library

(wileyonlinelibrary.com). deficient protein 1 (MAD1), MAD2, and monopolar spindle 1 (MPS1). Dysfunction of these genes could result in aneuploidy, which is implicated in the development of many human cancers [12,13]. Among the SAC components, BUBI, BUBR1, and Aurora kinases A and $B$ are those most frequently involved in human cancer $[14,15]$.

Although some of these genes have been described as overexpressed in adult ACT in microarray studies [16,17], the expression profile of SAC-related genés in pediatric ACT and their clinical impact remain undetermined. The aim of the present study was to analyze the expression profile of the genes AURKA, AURKB, BUB1,

${ }^{1}$ Department of Genetics, Ribeirão Preto Medical School, University of São Paulo, Ribeirão Preto, São Paulo, Brazil; ${ }^{2}$ Department of Pediatrics, Ribeirão Preto Medical School, University of São Paulo, Ribeirão Preto, São Paulo, Brazil; ${ }^{3}$ Department of Internal Medicine, Ribeirão Preto Medical School, University of São Paulo, Ribeirão Preto, São Paulo, Brazil; ${ }^{4}$ Department of Surgery, Ribeirão Preto Medical School, University of São Paulo, Ribeirão Preto, São Paulo, Brazil: 'Department of Pathology, Ribeirão Preto Medical School, University of São Paulo, Ribeirão Preto, São Paulo, Brazil; ${ }^{6}$ Department of Oncology Pediatric, Centro Infantil Boldrini and State University of Campinas, Campinas, São Paulo, Brazil

Grant sponsor: Fundação de Amparo a Pesquisa do Estado de São Paulo (FAPESP); Grant numbers: 2010/7020-9; 2010/08699-5

Additional Supporting Information may be found in the online version of this article at the publisher's web-site.

Conflict of interest: Nothing to declare.

"Correspondence to: Carlos Alberto Scrideli, Pediatrics Department, Ribeirão Preto Medical School, University of São Paulo, Avenida Bandeirantes 3900, Ribeirão Preto, SP 14049-900, Brazil.

E-mail: scrideli@fmrp.usp.br

Received 11 April 2013; Accepted 24 May 2013 
and $B U B R I$ in consecutive pediatric $\mathrm{ACT}$ and its association with clinical and biological features, as well as the anticancer effect of ZM447439, an experimental AURK inhibitor, on a primary childhood ACT culture carrying the TP53 p.R337H mutation.

\section{SUBJECTS AND METHODS}

\section{Subjects}

Sixty consecutive pediatric patients with ACT diagnosed between October 1991 and July 2009 were enrolled in the study. Disease stage was classified according to the modified Sandrini classification proposed for childhood ACT [3] and the histological diagnosis was based on the criteria described by Weiss et al. [18]. Eleven non-neoplastic adrenal cortex samples were used as control tissues and were obtained from children who had undergone nephrectomy due to Wilms' tumor without adrenal invasion. The study was approved by the local Ethics Committees (protocol numbers $9374 / 2003$ and $8380 / 2010$ ) and a signed statement of informed consent was obtained from the parents of pediatric patients and control subjects.

We evaluated 46 females and 14 males with a mean age at diagnosis of 40.5 months (range 5-187 months). Fifty-seven patients presented hormone-secreting tumors. Thirty-five patients were classified as stage $I, 10$ as stage $I I, 8$ as stage III, and 7 as stage IV. The TP53 p.R337H mutation was evaluated by direct DNA sequencing and was detected in $52 / 60(86.6 \%)$ patients with ACT. Forty-six tumors $(76.6 \%)$ presented Weiss classification scores $\geq 3,13$ scores $<3$, and 1 had an undetermined score. After surgery, patients were examined monthly during the first year, at least twice a year for 5 years, and thereafter annually. Follow-up ranged from 8 to 168 months (median: 68.3 months). Prognostic clinical and pathological features are described in Table I.

\section{RNA Isolation and cDNA Synthesis}

Frozen tumor tissues and control adrenal cortex samples were microdissected. Total RNA of tumor and control tissue samples was extracted using TRIzol Reagent (Invitrogen, Karlsruche, Germany) according to the manufacturer's protocol. cDNA synthesis was performed with the High Capacity cDNA Reverse Transcription kit (Applied Biosystems, Inc., Foster City, CA) and MultiScribe enzyme using $500 \mathrm{ng}$ RNA in a $25 \mu$ l reaction.

\section{mRNA Quantification by Real-Time PCR (RQ-PCR)}

The relative mRNA expression levels of the genes analyzed were quantified using real-time PCR analysis with the ABI PRISM 7700 Sequence Detection System (Applied Biosystems, Inc.). Amplification of the specific sequences was performed using on demand TaqMan probes: AURKA (Hs00269212_m1), AURKB (Hs00177782_ml), BUBl (Hs01557701_ml), BUBRI (Hs00176169_ml), and GAPDH (4326317-E 0905031) (Applied Biosystems, Inc.). All samples were analyzed in triplicate using $G A P D H$ as the reference gene. The $2^{-\Delta \Delta C_{\mathrm{T}}}$ equation was applied to calculate the relative expression of ACT samples [19]. The median gene expression values of all non-neoplastic adrenal tissues were used as reference and defined as 1 .

\section{Immunohistochemistry (IHC) Analysis}

Immunohistochemistry studies were performed in a subset of 48 tumor tissue samples from the 60 patients. The sections were incubated with a monoclonal primary antibody specific for AURKA and AURKB (Millipore, Temecula, CA, 1:100 dilution) according to the manufacturer's instructions, followed by signal detection with the avidin-biotin system (Vectastain Elite ABC Kit, Universal; Vector Laboratories, Inc., Burlingame, CA). Immunohistochemical results were evaluated for intensity and staining frequency of nuclear and cytoplasmic components. The intensity of staining was graded 0 (negative), 1 (weak), 2 (moderate), and 3 (strong). The percentage of positive cells was rated as follows: 0 points, $0 \% ; 1$ point, $1-10 \% ; 2$ points, $11-25 \% ; .3$ points, $25-50 \% ; 4$ points, $>51 \%$. Points for expression and percentage of positive cells were added (total score of $0-7$ ), and classified as negative (score 0 ), weak (total 1-2), moderate (total 3-4), or strong (total 5-7).

TABLE I. Five-Year Event-Free Survival (EFS) and Overall Survival (OS) According to Clinical Features and Sandrini's Classification

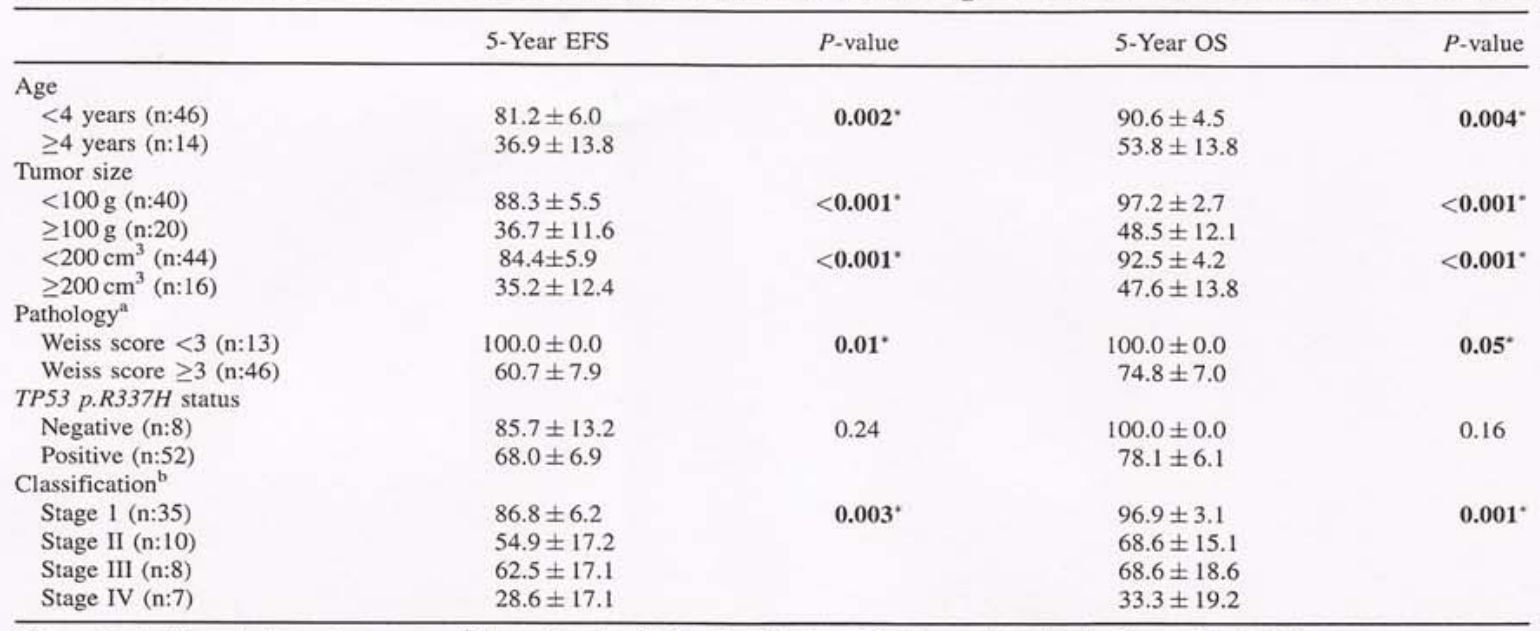

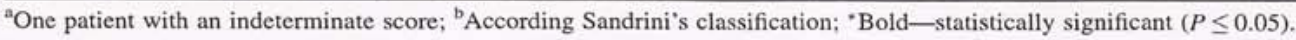

Pediatr Blood Cancer DOI 10.1002/pbc 


\section{Cell Primary Culture}

A primary culture was obtained from a functioning adrenocortical carcinoma (stage IV with p.R337H TP53 mutation) diagnosed in a 1.1-year-old girl. Cells were culture in HAMF10 (Gibco BRL, Life Technologies, Carlsbad, CA) supplemented with $10 \%$ fetal bovine serum, penicillin $(100 \mathrm{U} / \mathrm{ml})$ and streptomycin $(100 \mu \mathrm{g} / \mathrm{ml})$ at $37^{\circ} \mathrm{C}$ in a humidified $5 \% \mathrm{CO}_{2}$ incubator.

Cultures were grown for 4 weeks and frozen. To experiments the cultures were frozen in SFB containing 10\% DMSO and preserved in liquid nitrogen. To experiments the cultures were thawed and expanded for one additional passage. All the in vitro experiments were performed between the third and fifth passage. This culture overexpressed both AURKA (2.6-fold) and AURKB (14.9-fold) when compared to the median values of the nonneoplastic samples.

\section{Aurora Kinase Inhibitor}

The ZM447439 (ZM) inhibitor is an experimental selective ATP-competitive inhibitor of Aurora-A, $-\mathrm{B}$, and $-\mathrm{C}$ in vitro $[20]$ and was obtained from Tocris Cookson, Inc. (Ellisville, MO). The compound was diluted to $10 \mathrm{mmol} / \mathrm{L}$ using $99 \% \mathrm{DMSO}$ and stored at $-20^{\circ} \mathrm{C}$.

\section{Proliferation Assay}

For the proliferation assay, cells were seeded on 96-well plates ( $3 \times 10^{3} /$ well). After 24 hours, the medium was replaced with fresh medium containing the treatment and then cultured for 24,48 , and 72 hours. After treatment, the culture medium was removed and replaced with medium containing $10 \mu \mathrm{l}$ XTT dye $(3 \mathrm{mg} / \mathrm{ml})$ (XTT II; Roche Molecular Biochemicals, Indianapolis, IN) in each well. The plates were incubated for 2 hours at $37^{\circ} \mathrm{C}$ and the formazan product were measured at $450 \mathrm{~nm}$ using an iMarkmicroplate reader (Bio-Rad Laboratories, Hercules, CA). The experiments were performed twice in triplicate at different times. Data were analyzed by the median-effect method (Calcusyn software; Biosoft, Ferguson, MO) to calculate the dose with $50 \%$ inhibition of proliferation (Dm or IC50 values).

\section{Clonogenic Assay}

The effect of ZM447439 on clonogenic capacity was evaluated by the clonogenic assay. After trypsinization, single cell suspensions of 300 cells were seeded in 6-well plates and treated with ZM447439 at concentrations of $200 \mathrm{nM}, 800 \mathrm{nM}$, and $1 \mu \mathrm{M}$ for 48 hours. After treatment, the culture medium was removed and replaced with drug-free medium. The cell cultures were incubated for 15 days and the colonies were then rinsed with PBS, fixed with methanol and stained with Giemsa. The colonies with $>50$ cells were counted. Assays were performed in triplicate.

\section{Statistical Analysis}

The association between the following variables: age $(<4$ years vs. $\geq 4$ years), tumor weight $(<100 \mathrm{~g}$ vs. $\geq 100 \mathrm{~g})$, tumor size $\left(<200 \mathrm{~cm}^{3}\right.$ vs. $\left.\geq 200 \mathrm{~cm}^{3}\right)$, TP53 p.R377H mutation (positive vs. negative), pathology (Weiss score $<3$ vs. $\geq 3$ ), disease stage, eventfree survival (death/relapse vs. complete remission), overall survival (death vs. alive), and the expression levels of each gene Pediatr Blood Cancer DOI 10.1002/pbc
AURK and Prognosis in Pediatric ACT

analyzed was determined by the Mann-Whitney test. Event free survival (EFS) analysis (with relapse and/or death due to any cause being considered as unfavorable events) was carried out based on Kaplan-Meier curves, using the twofold higher median values of gene expression by non-neoplastic adrenal samples as the cut-off point. Curves for different groups were compared by the log-rank test. The Cox proportional regression model was used for multivariate analysis of prognostic factors. The correlation between the expression values of the analyzed genes was determined by the Spearman correlation coefficient. Cell-line data were analyzed by ANOVA followed by the Bonferroni test, as appropriate. Data were analyzed using the SPSS Graduate Pack 20.0 software (SPSS, Inc., Chicago, IL) and GraphPad Prism 5.0 (GraphPad Software, San Diego, CA). The level of significance was set at $P \leq 0.05$ in all analyses.

\section{RESULTS}

\section{Expression of SAC-Related Genes in ACT and Non- Neoplastic Controls}

Compared to non-neoplastic adrenal samples, ACT presented significantly higher expression levels of the BUBI (6.0-fold, $P<0.0001)$ and $B U B R I(6.5$-fold, $P=0.001)$ genes. No significant differences were observed regarding the expression of $A U R K A$ $(P=0.090)$ and $A U R K B(P=0.437$; Fig. 1).

\section{Expression of SAC-Related Genes and Clinical and Biological Characteristics}

It is interesting to point out that a positive correlation was observed between $A U R K A$ and $A U R K B(\mathrm{r}=0.496, P<0.001)$ and also between $B U B I(\mathrm{r}=0.288, P=0.022)$ and $B U B R I(\mathrm{r}=0.418$, $P=0.001$ ).

Higher expression levéls of AURKA (2.0-fold, $P=0.01)$, $A U R K B$ (7.0-fold, $P=0,01$ ), and $B U B R I$ (5.8-fold, $P=0.007$ ) were associated with $A C T$ with a Weiss score $\geq 3$. Patients with unfavorable events presented higher expression levels of AURKA (6.0-fold, $P=0.034)$ and $A U R K B$ (17-fold, $P=0.013)$. Death was associated with higher expression levels of AURKA (4.8-fold, $P=0.050)$ and $A U R K B$ (11.2-fold, $P=0.040)$. Patients with p.R337H TP53 mutation presented significantly higher expression values of $A U R K A$ (8.5-fold, $P=0.014$ ) and BUBRI (7.5-fold, $P=0.009$ ). These data are shown in Figure 2.

In order to analyze a possible correlation between the expression levels of these genes and 5-year EFS, the patients were divided into two groups using the twofold higher than median value of the expression of the respective genes observed in non-neoplastic adrenal controls as a cut-off between low and high expression.

High expression of the AURKA gene was associated with a significantly lower 5 -year EFS $(34.3 \pm 13.1 \%$ vs. $82.6 \pm 6.6 \%$, $P<0.0001$ ), with a higher risk of an unfavorable event (HR: 6.822 , 95\% CI: $2.400-19.394, P<0.0001)$. The same was true for AURKB $(40.0 \pm 15.5 \%$ vs. $77.5 \pm 6.8 \%, P=0.006)$, with a higher risk of an unfavorable event (HR: $3.799,95 \%$ CI: $1.350-10.687, P=0.01$ ) (Fig. 3). Multivariate analysis showed that high expression of the AURKA gene was an independent unfavorable prognostic factor $(P=0.002)$ when analyzed in combination with stage IV, age $>4$ years, weight $\geq 100 \mathrm{~g}$ and tumor size $\geq 200 \mathrm{~cm}^{3}$. Excluding $A U R K A$ from the model, the $A U R K B$ gene $(P=0.026$; HR: 3.624 , 

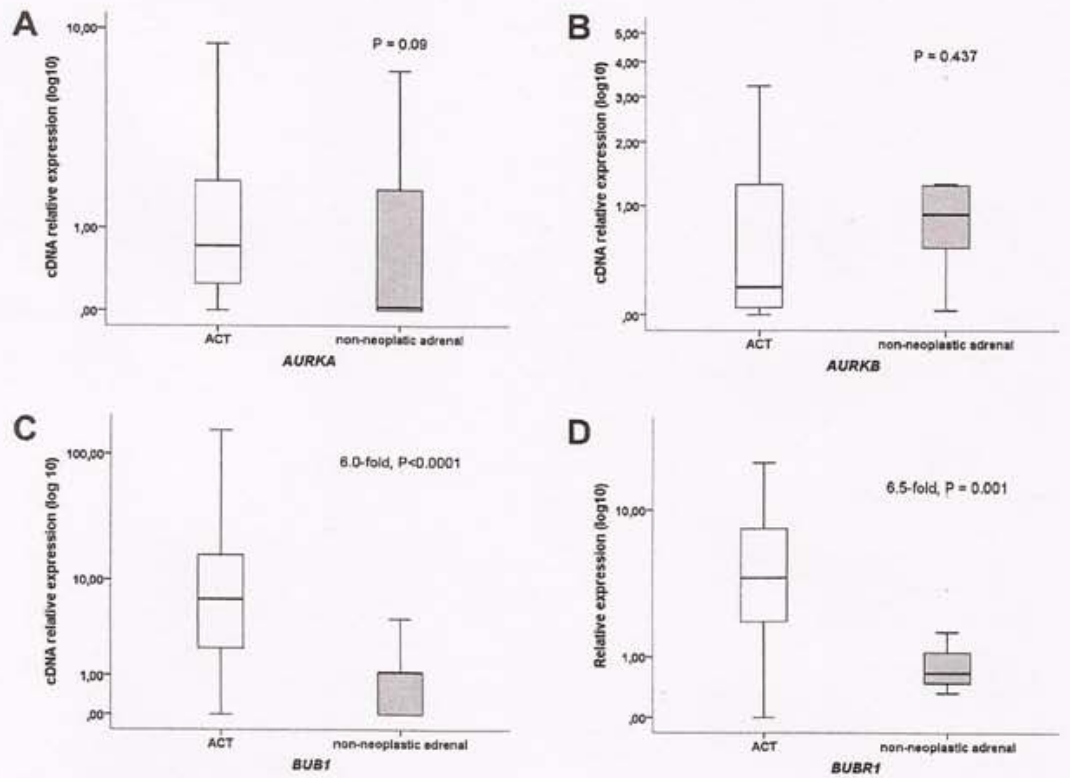

Fig. 1. Relative mRNA expression of the genes $A U R K A(\mathbf{A}), A U K B(\mathbf{B}), B U B(\mathbf{C})$ and $B U B R I(\mathrm{D})$ in childhood ACT and childhood non-neoplastic adrenal cortex. The lines correspond to the median value of expression. Results are presented as $\log 10$ scale and as fold-change. "Significant by the Mann-Whitney test.

95\% CI: 1.160-11.382) was also an prognostic factor when analyzed in combination with weight $\geq 100 \mathrm{~g}(P=0.030$, HR: $6.211,95 \%$ CI: $1.195-32.280)$, age $>4$ years $(P=0.574)$, stage IV $(P=0.294)$ and tumor size $\geq 200 \mathrm{~cm}^{3}(P=0.898)$. No significant differences in 5-year EFS were observed for BUBI $(P=0.12)$ or BUBRI $(P=0.32)$.

When only the patients with Weiss score $\geq 3$ were analyzed, higher expression levels of AURKA (5.3-fold, $P=0.044$ ) and AURKB (9.3-fold, $P=0.016)$ were observed in patients presenting an unfavorable event. In this group, high expression of the AURKA gene were associated with a lower 5-year EFS $(34.3 \pm 13.1 \%$ vs. $73.4 \pm 9.6 \%, P=0.002)$ and a higher risk of an unfavorable event (HR: $4.476,95 \%$ CI: $1.580-12.678, P=0.005$ ). High expression of $A U R K B$ were also associated with a lower 5-year EFS (33.3 $\pm 15.7 \%$ vs. $68.8 \pm 9.0 \%, P=0.020)$ and with a higher risk of an unfavorable event (HR: 3.184, 95\% CI: $1.132-8.958, P=0.028$; Fig. 3). Multivariate analysis showed that high expression of the AURKA gene unfavorable prognostic factor $(P=0.004, \mathrm{HR}: 5.454$, 95\% CI: $1.734-17.152)$ and $A U R K B$ gene $(P=0.036$; HR: 3.338 , 95\% CI: $1.080-10.276$ ) were also an independent when analyzed in combination with age, stage IV, weight $\geq 100 \mathrm{~g}$ and tumor size $\geq 200$. No significant differences in 5-year EFS were observed for BUBl $(P=0.26)$ or BUBRI $(P=0.84)$.

\section{Expression of AURKA and AURKB Determined by IHC}

The AURKA and AURKB protein expression was evaluated by IHC and the results were similar to those observed when using RQ-

Pediatr Blood Cancer DOI 10.1002/pbc
PCR. Forty-one out of $48(85.4 \%)$ ACT samples analyzed showed immunoreactivity for AURKA. In 12 cases (25\%) immunoreactivity was classified as strong, in 17 cases $(35.4 \%)$ as moderate, in 12 $(25 \%)$ as weak and in $7(14.6 \%)$ it was negative. Regarding AURKB, immunoreactivity was positive in 37 out of $48(77.8 \%)$ ACT samples. Six $(12.5 \%)$ tumors presented immunoreactivity classified as strong, $16(35.5 \%)$ as moderate, $15(31.2 \%)$ as weak and 8 $(16.6 \%)$ showed negative or weak immunoreactivity; in three cases $(6.2 \%)$ the result was inconclusive due to intense background staining and they were excluded from analysis. The cases were interpreted as AURKA or AURKB positive if the neoplastic cells showed moderate or strong staining. In the group with positivity for the AURKA protein the median relative mRNA expression detected by RQ-PCR was 1.17 (mean: 2.71 , range: $0.00-16.94$ ) and in the group with weak/negative AURKA expression the median mRNA expression was 0.50 (mean: 0.97 , range: $0.00-8.67)(P=0.040)$. In the group with positivity for AURKB protein the median relative mRNA expression detected by RQ-PCR was 0.24 (mean: 2.44 , range: $0.00-25.75$ ) and in the group with weak/negative expression the median mRNA expression was 0.06 (mean: 0.67 , range: 0.00 8.41) $(P=0.010)$. A representative AURKA and AURKB IHC staining is shown in Figure 4.

The 5-year EFS was lower in the patients with strong/moderate AURKA immunoreactivity $(55.2 \pm 10.5 \%$ vs. $94.4 \pm 5.4 \%, P=$ 0.012 ) with a higher risk of an unfavorable event (HR: $8.717,95 \%$ CI: $1.123-67.692, P=0.038)$. Patients with strong/moderate AUKB immunoreactivity had a lower 5 -year EFS $(53.2 \pm 11.9 \%$ vs. $84.8 \pm$ $8.1 \%, P=0.045)$ and a higher risk of an unfavorable event (HR: $3.487,95 \%$ CI: $0.942-12.909, P=0.061$ ). 
AURK and Prognosis in Pediatric ACT

E
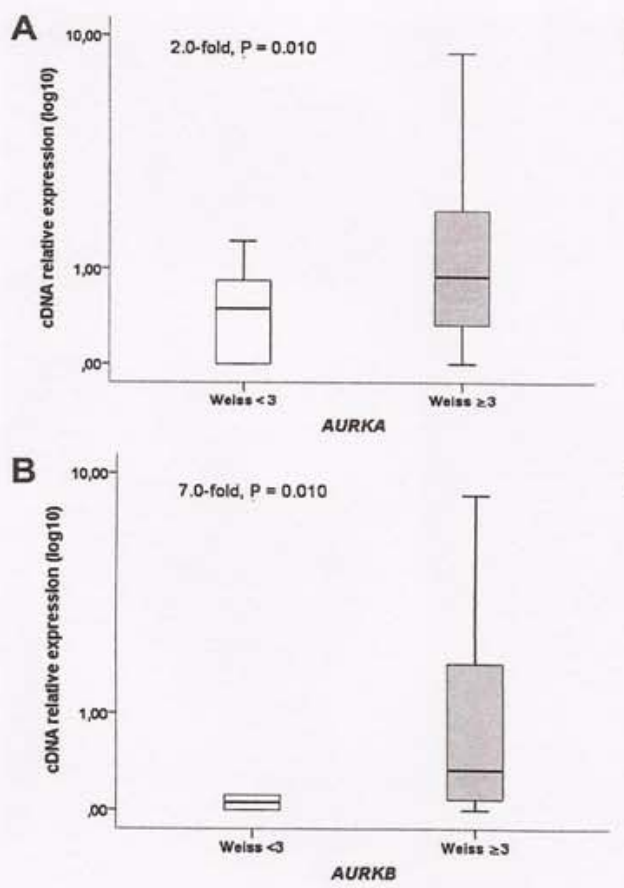

C
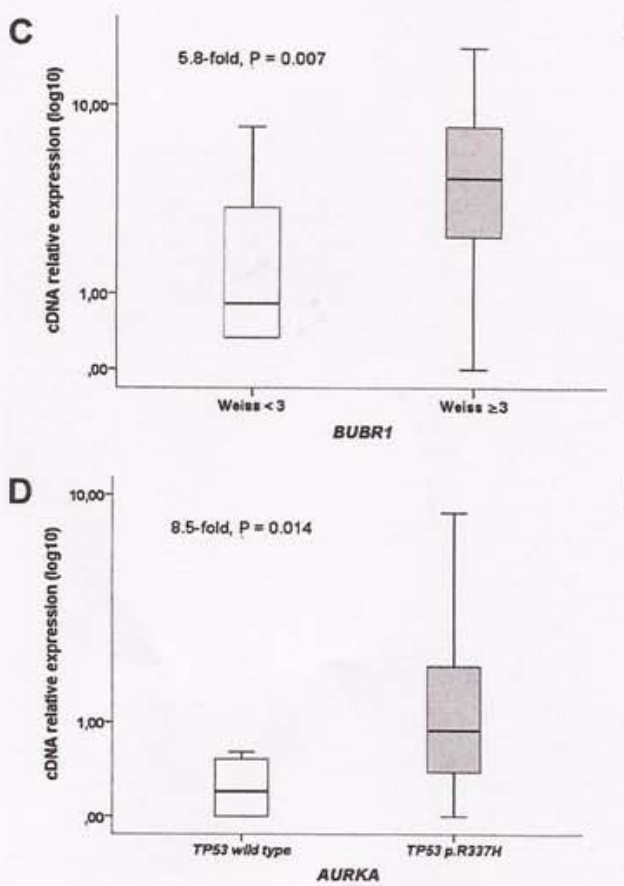
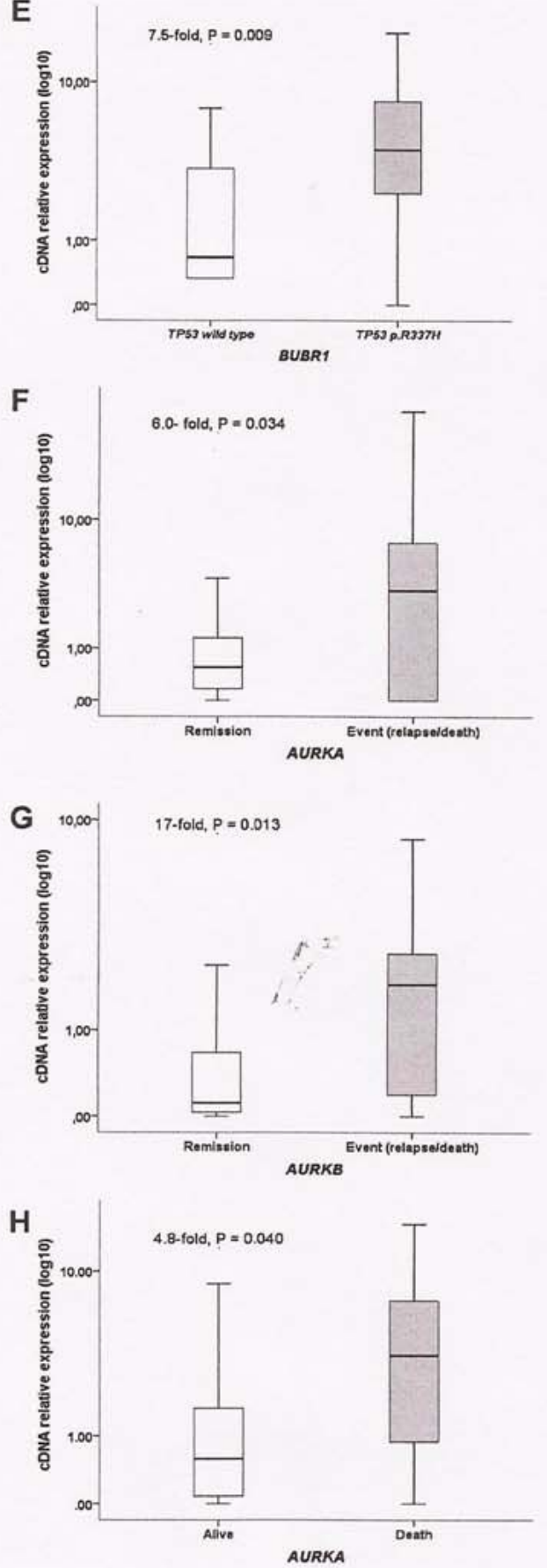

Fig. 2. Relative mRNA expression of the genes AURKA (A), AURKB (B) and BUBRI (C) according to Weiss score; AURKA (D) and BUBRI (E) according to $p . R 337 H$ TP53 mutation; AURKA (F) and $A U R K B(\mathbf{G})$ according to event; and $A U R K A(\mathbf{H})$ according to survival. The lines correspond to the median value of expression. Results are presented as $\log 10$ scale and as fold-change. "Significant by the Mann-Whitney test.

Pediatr Blood Cancer DOI 10.1002/pbc 
A

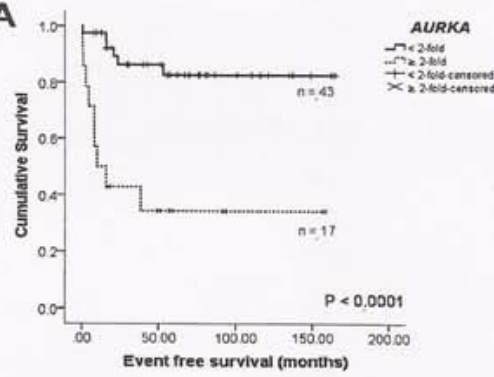

B

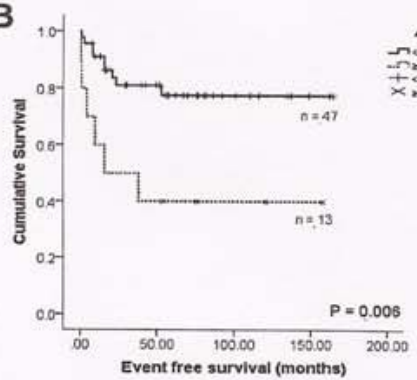

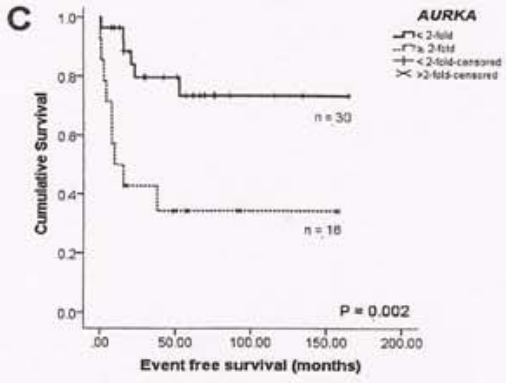

D

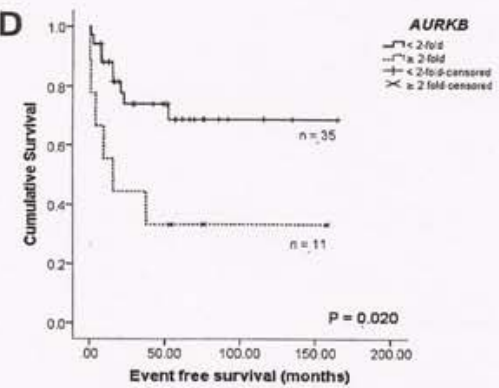

Fig. 3. Kaplan-Meier plots of event-free survival (EFS) according to the relative gene expression, below or above the twofold median value observed in non-neoplastic adrenal samples for AURKA (A) and AURKB (B) in the overall group of patients and AURKA (C) and AURKB (D) in the group of $\mathrm{ACT}$ patients with Weiss criteria $\geq 3$

\section{Functional Studies}

Primary culture of ACT was sensitive to $\mathrm{ZM}$, showing a dose- and time-dependent inhibition of proliferation after treatment $(P<0.05)$ (Fig. 5), with an IC value of $14.9 \pm 0.2 \mu \mathrm{M}$. ZM also inhibited colony formation in primary culture in a dose-dependent manner, reaching a maximum effect at the dose of $1 \mu \mathrm{M}(P<0.05)$ (Fig. 5$)$.
A

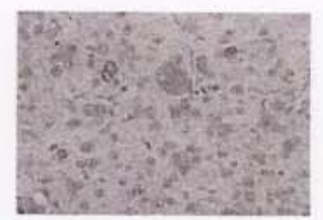

B

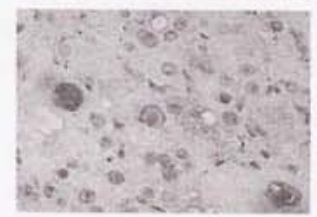

\section{C}

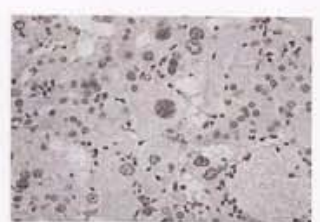

D

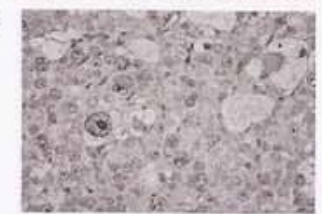

Fig. 4. AURK IHC staining features. Samples of childhood ACT with positive nuclear and cytoplasmic expression of AURKA (A and B) and AURKB (C and D) (original magnification 400x).

Pediatr Blood Cancer DOI 10.1002/pbc

\section{DISCUSSION}

The current treatment stfategies for advanced pediatric ACT or a high risk of disease recurrence have a small impact on survival [3]. Inhibition of the Aurora' and SAC kinases has been suggested as a potential target to treat human cancers but its therapeutic potential for childhood ACT has not been considered before. In this study we demonstrate the overexpression of $B U B I$ and $B U B R I$ in $A C T$ compared to non-neoplastic adrenal as well as the association of overexpression of Aurora kinases A and B with a poor outcome in these tumors. Moreover, we present the first in vitro evidence that Aurora inhibitors may be effective for the treatment of these patients.

Adrenocortical carcinomas are characterized by high levels of CIN [9]. In childhood adrenal tumors chromosomal imbalances were associated with overall survival and tumor progression $[10,11]$. .Among the genes associated in maintaining chromosomal integrity are the SAC kinases such as BUB 1 and BUBR1. They play a central role in preventing aneuploidy by missegregation of sister chromatids during mitosis $[14,21]$. BUB1 and BUBR1 have been found expressed at high levels in many human cancers and it has been suggested that they can be responsible for neoplastic transformation $[22,23]$.

In the present study we found a highly significant overexpression of $B U B I$ and $B U B R I$ in $A C T$ compared to nonneoplastic adrenal tissue and also of $B U B R I$ in tumors with a Weiss score $\geq 3$. These results are similar to those reported for other human cancers when compared to their normal counterparts, such as clear cell kidney carcinomas [22] and gastric cancer [23]. 

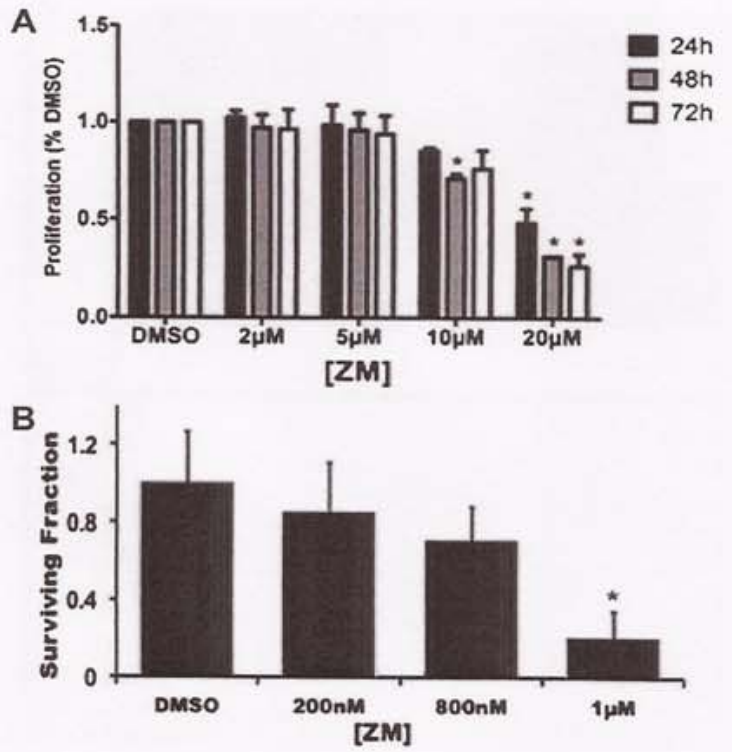

Fig. 5. Effects of Aurora kinase inhibition by ZM447439 (ZM) on adrenocortical carcinoma cells. $\mathrm{ZM}$ inhibited the proliferation $(\mathbf{A})$ and reduced the clonogenic capacity (B) of the childhood ACT primary culture. Results represent the mean of two independent experiments performed in triplicate. ${ }^{\circ} P<0.05$.

suggesting that $B U B I$ and $B U B R I$ could be involved in the development of childhood ACT. The present data also agrees with previous microarray study on adult ACT where BUBRI has been reported to be overexpressed in carcinomas when compared to adenomas and non-neoplastic adrenals [17]. Moreover, combined expression of $B U B R I$ with the $P I N K I$ gene has been described as a predictor of survival in adult ACT [16]. In our study, no significant association between the expression of $B U B I$ and $B U B R I$ and survival was found in childhood ACT. This result is in agreement with a study showing no association of $B U B I$ expression with overall survival in childhood ACT [24].

The Aurora kinase family comprises three structurally related serine/threonine kinases (Aurora $\mathrm{A}-\mathrm{C}$ ) that ensure proper spindle assembly and accurate chromosome segregation in mitosis [25]. Studies have shown that the ectopic expression of AURKA in mouse NIH3T3 cells and Rat-1 fibroblasts causes centrosome amplification and transformation in vitro as well as tumorigenesis in vivo [26], but the same was not true for AURKB [15]. However, both $A U R K A$ and $A U R K B$ can induce tetraploidy and enhance chromosome instability and tumor invasiveness [15].

The present study showed that AURKA and AURKB overexpression was significantly associated with more advanced as well as lower tumor stages. Microrarray studies of adult ACT also demonstrated that $A U R K A$ and $A U R K B$ expression was increased and associated with a poor prognosis [16]. A correlation between $A U R K A$ and $A U R K B$ up-regulation and clinical aggressiveness has been described for several human cancers including acute myelogenous leukemia [27], head and neck squamous Pediatr Blood Cancer DOI 10.1002/pbc cell carcinoma [28], squamous cell cervical cancer [29], nonsmall cell lung carcinoma [30], glioblastoma [31], ovarian carcinoma [32]. bladder carcinoma [33], and hepatocellular carcinoma [34]. These finding suggest that AURKA and AURKB may be involved in the molecular pathways of childhood ACT and their inhibition could be a new approach to its treatment.

It has been described that TP53 is a negative regulator of AURKA and its deficiency leads to overexpression of AURKA [35]. This observation is inagreementwith our data which showed significant overexpression of AURKA in patients carrying p.R337H TP53 mutation, suggesting that this mutation could be associated with AURKA overexpression in ACT. The role of AURKs in ACT without or with TP53 mutation other than p.R337H needs further investigation.

Preclinical studies have demonstrated potent effects of the specific inhibitory activity of the Aurora kinases [36-38] including preclinical models of pediatric cancer [39]. Results of clinical phase I studies using different Aurora kinase inhibitors have demonstrated that in general these drugs are well-tolerated and have limited nonhematological toxicity $[36,37]$. Several phase II clinical trials are currently being conducted in different human cancers (http:// clinicaltrials.org).

ZM447439 is an experimental Aurora kinase inhibitor with effects very related to others Aurora kinase inhibitors currently in clinical trial such as VX-680, PF-03814735 and AT9283 [15,20]. In the present study we showed that ZM447439 reduced the colony formation of a childhood ACT primary culture specimen presenting the p.R337H TP53 mutation. Moreover, ZM447439 effectively inhibited the proliferation of this ACT culture. These results were similar to those observed in other studies targeting Aurora kinases in different cancer cells and in xenograft models [38-40], suggesting a potential therapeutic effect also on childhood ACT.

The IC50 value of $\mathrm{ZM}$ in ACT primary culture was similar to that previously reported in studies that also treated primary cultures with Aurora kinase inhibitors such as ZM and R763/ AS703569 $[38,40]$. Primary tumor cultures are believed to be more similar to in vivo tumors than cancer cell lines [38], thereby, it is interesting that $\mathrm{ZM}$ caused a growth-inhibiting activity on primary culture of ACT and diminished effectively its survival after long term exposure as showed through clonogenic assay. Although all these functional findings have been interesting, others should be conduced using human cell model of ACT and xenograft model to validate the potential effects of Aurora kinase inhibition in ACT.

In summary, we have shown that $A U R K A$ and $A U R K B$ overexpression was significantly associated with more aggressive disease and risk of relapse and death in childhood ACT, especially in those with Weiss criteria $\geq 3$. In addition, we demonstrated that Aurora kinase inhibition suppressed growth of a childhood ACT primary culture specimen presenting the p.R337H TP53 mutation. On this basis, controlled preclinical and clinical studies are necessary to evaluate the therapeutic potential of Aurora kinase inhibitors in childhood ACT.

\section{ACKNOWLEDGMENTS}

This study was supported by public grants from Fundação de Amparo a Pesquisa do Estado de São Paulo (FAPESP) (grant 2010/ 7020-9). FAPESP fellowship to KSB (2010/08699-5). 


\section{REFERENCES}

1. Sandriti R, Ribeiro RC, DeLacerda L. Chillhood adrenocortical tumors. 1 Clin Endocrinol Metat
$1997.822027-2203$ 1997:82:2027-2203.

Sondrin R. Figueiredo B, et at. Clinical and outcome characteristier of childrea with drenocortical tumors: A report from the International Pediatric Adrenocortical Tumor Registry. J Clia

3. Rodriguez-Gatindo C, Figueiredo BC, Zambenti GP, et at. Biology, clinical characteristics, and
managernemt of adrenocortical tumors in childer. Pediatr Blood Cancer 2005:45:265-273.

4. Latronico AC, Pinto EM, Dornenice S, et at An interited mutatioa outside the highly conserved DNA binding domain of the p 53 tumor suppressor protein in children and adults with sporadic athenocorticat

5. Sadrini F. Villani DP, Tucci S, et al. Inberitance of R337H p53 gene mutation in childrea with sporadie

-

adrenoconticat

7. Carter SL, Ektund AC, Kotane is, et at A signature of ch-3ite.

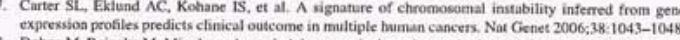

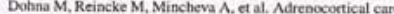
of chrounowomal gains and high-level amplifications, Genex Chromosomes Cancer $2000: 28: 145-152$. Stephan EA, Chung TH, Orant CS, et al. Adrenocortical carcinoma survival rates correlated to genomic copy number variants. Mol Cancer Ther 2008:74:425-43.

12. Figueiredo BC, Stratakis CA, Sandrini $R$, et al. Coapparative genomic bybridization analysis of

sarvivel for adrening A, Posorski N, et at. Number of genomic imbalances correlates with the overall

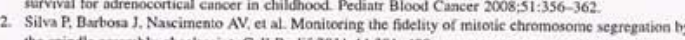
the spindile assembly checkpoint. Cell Probif 2011;44:391-400.

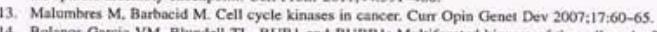

Multifaceted kinases of the cell cycle. Trend

Biochem Sci 2010:36:141-150.

15. Green MR, Woolery JE, Mahadevan D. Update on aurora kinase targeted therapeutic in oncology, Expert Opin Drus Discov 2011:6:291-307.

. de Reynies $\lambda$, Assie G, Rickman DS, et al. Geve expression profling reveals a new classification of alrenocortical tumors and ideng

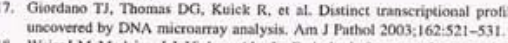

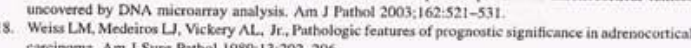

Carcinomiz. Am J Surg Pathol 1989:13:202-206.

Livak KJ.Schnittgen TD. Analysis of relative gene expression data using real-time quantitative PCR and the 2(-Delta Deta CT) method. Methods 2001:25:402-408.

targeting BubR1, Mad2, and Cenp.E to kinetoctores. I Cell Biol 2003:161:267-280.

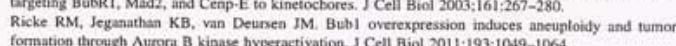
formation through Aurora B kinase hyperactivation. J Cell Biol 2011:193:1049-1064.

Pinto M, Vieira), Ribterio FR, et al. Overexpeession of the mitotic checkpoint genes BUB1 and BUBR1 is
23. Grabsch H. Takeno S, Pursons WJ, et al Overexpersion of the mitotic checkpoint genes BUB1, BUBRI.

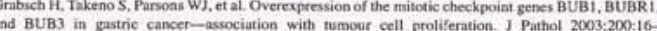

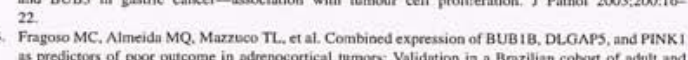
as predictors of pyor outcome in adrenocortical tumoss: Validation in a Brazilian cobort of adult and

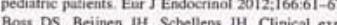

. Zhou H. Kuang 1, Zhoag 1 , a

et al. Tumour amplifed kinuse STK15/BTAK induces centrosome Lucena-Araujo AR, de Oliveira FM. Leite-Cueva SD. et al. High expressioa of AURKA ma AURKB is essociand with unfavorable cylogeneteic sboormalities and hight white blood cell count in patients wit Reiter R. Gais P.

progression and thortened survival in bead and neck squamows cell cercinoma. Clis Cancer Res 2006:12:5136-5141.

. Twu NF, Yuan CC, Yen MS. Expression of Aurnora kinase $\Lambda$ and $B$ in normat and malignant cervical tissue

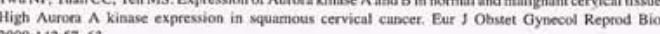

(i) DC, et at. Overexpression of aurona B kinase (AURKB) in primary nooBenetic instability. Br I Cascer 2005:93:719-729.

1. Scrideli CA. Carloti CG. Jf. Okamoto OK, et al. Gene expeession profile analysis of primary flioblastomas and noo-neophastic brain tissue: Identification of potential turget genes by oligonuelecotide

32 Yang $F$, Ouo $\mathrm{X}$, Yang $\mathrm{G}$, et al. AURKA und BRC 2 expression highty correlate with prognonis of endometriod ovarian cartinoma. Mod Pathol 2011:24:836-845,

Bufo P, Sanguedolce F, Tortorellin S, et al. Expression of mitotic kinases phospbo-aurora A and aurora B
correlates with clinical and patbological parameters in bladder neoplasmis. Histod Histopathol 2010,25:1371-1377.

in Z2, Jeng YM, Hu FC. et al. Significance of Aurora B overexperssion in Depanocellutur carcinoma. Wu CC, Yang TY, Yu CT, et al p 53 negatively, regulen.

A vis botb transcriptional and Sostransslational tegulation. Cell Cycle 2012:11:3433-3442. Nurora kimase inthibitor danusertib in patients with advanced or metastatic solid tumbers. I Clis Oncol

7. Diamond IR, Bastos BR. Hansen RU, et at. Phase I safery, pharnacokinetic, and pharmacodynamic study tovel angiogenenic and Aurora kinase inhibitor, in putients wir

38. Borges KS, Cantro-Gamero AM. Moreso DA, et at. Inthibition of Aurora kinases enthances chemosensitivity to temozolonide and cuuses radiosensitization in glioblastoma cells. I Cancer Res Clin Oncol 2012;138:405-14.

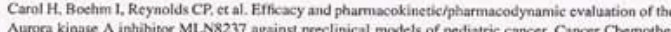

Pharmacol 2011:68:1291-1304. As703569 identihed through an image-based phenotypic screen. I Cancer Res Cin Oncol 2010;136:99- 